\title{
DEVELOPMENT AND CONSTRUCTION OF A MOLYBDENUM TEST STAND
}

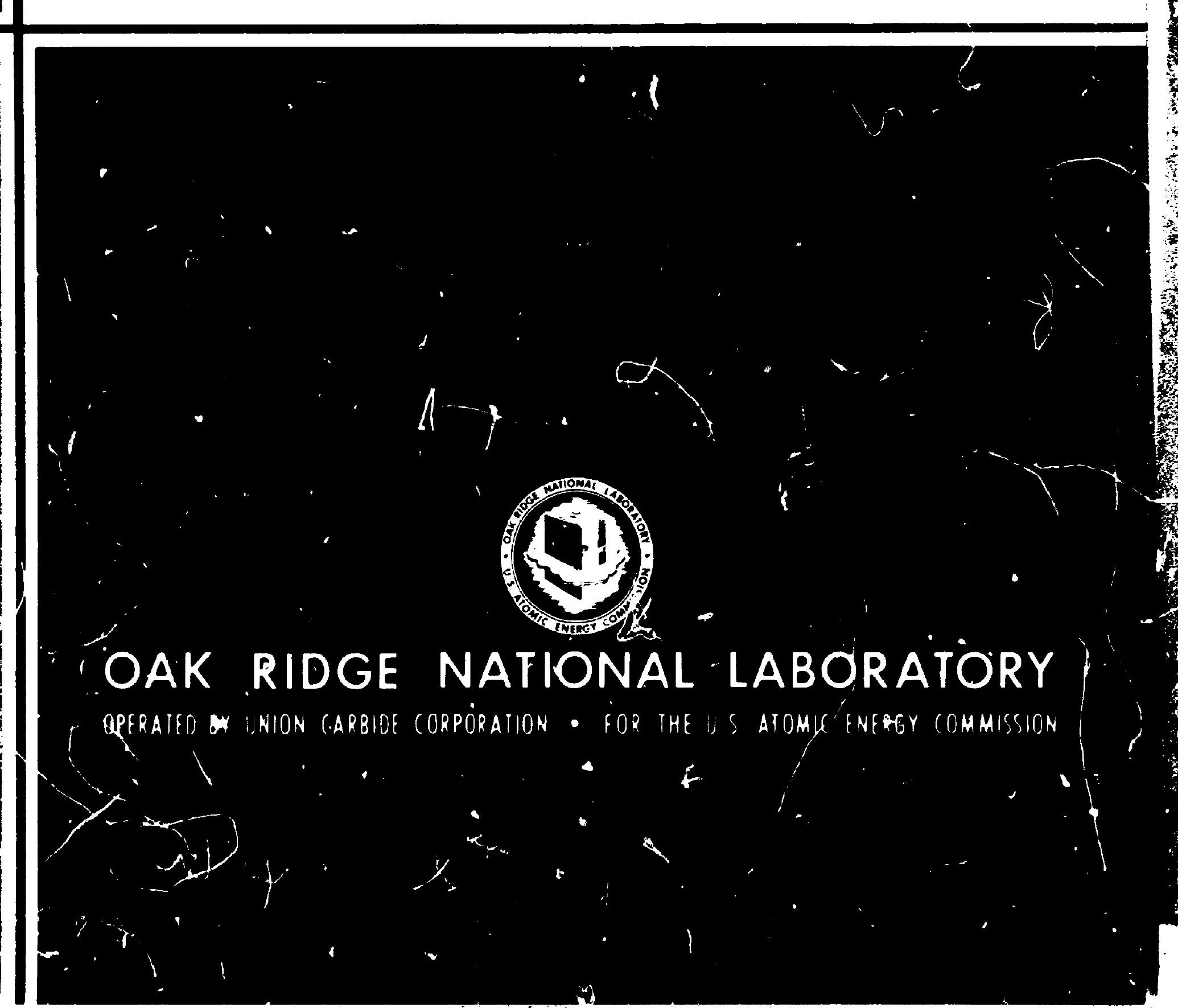




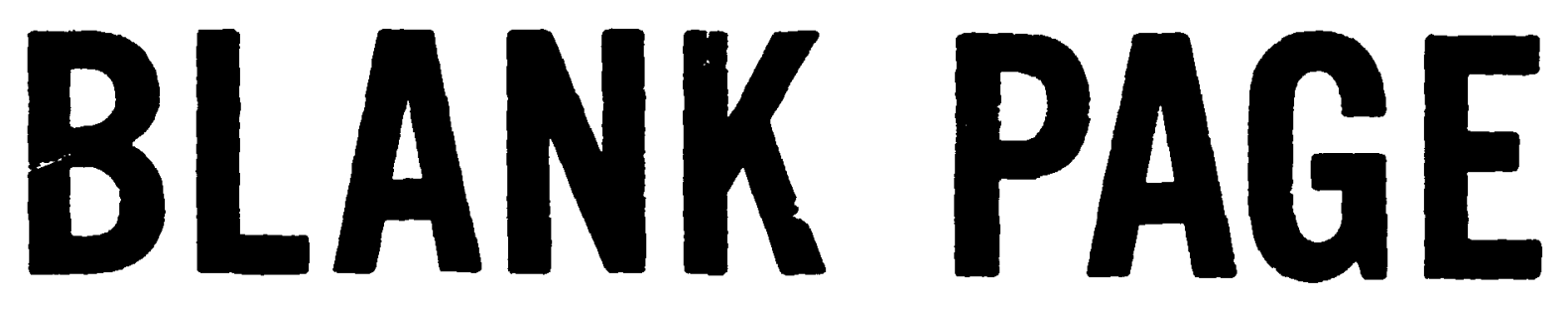


Printed in the United Statzs of America. Available from National Technical Information Service

U.S. Des sartment of Commerce

5285 Part Royal Road, Springfield, Virginia 221:i1

Price: Printud Copy \$b.45; Microfiche $\$ 0.95$

This report was prepared as an axcount of work sponsored by the United

States Government. Neither $t^{\prime}$ ie United States nor the United States Atomic Energy Commission, nor any c': their employees, nor any of their contractors, subcontractcrs, or their employees, makes any warranty, express on implied, or assumes any legal liability or responsibility for the accuracy. completeness or usefuiness of any information, apperatus, product or process disclosed, or represents the: its use sould not infringe privately owned rights. 
Principal Contributors

N. C. Cole

R. E. PicDcnalci

J. R. DiStefano

A. J. Moorhead 


\section{CONTENTS}

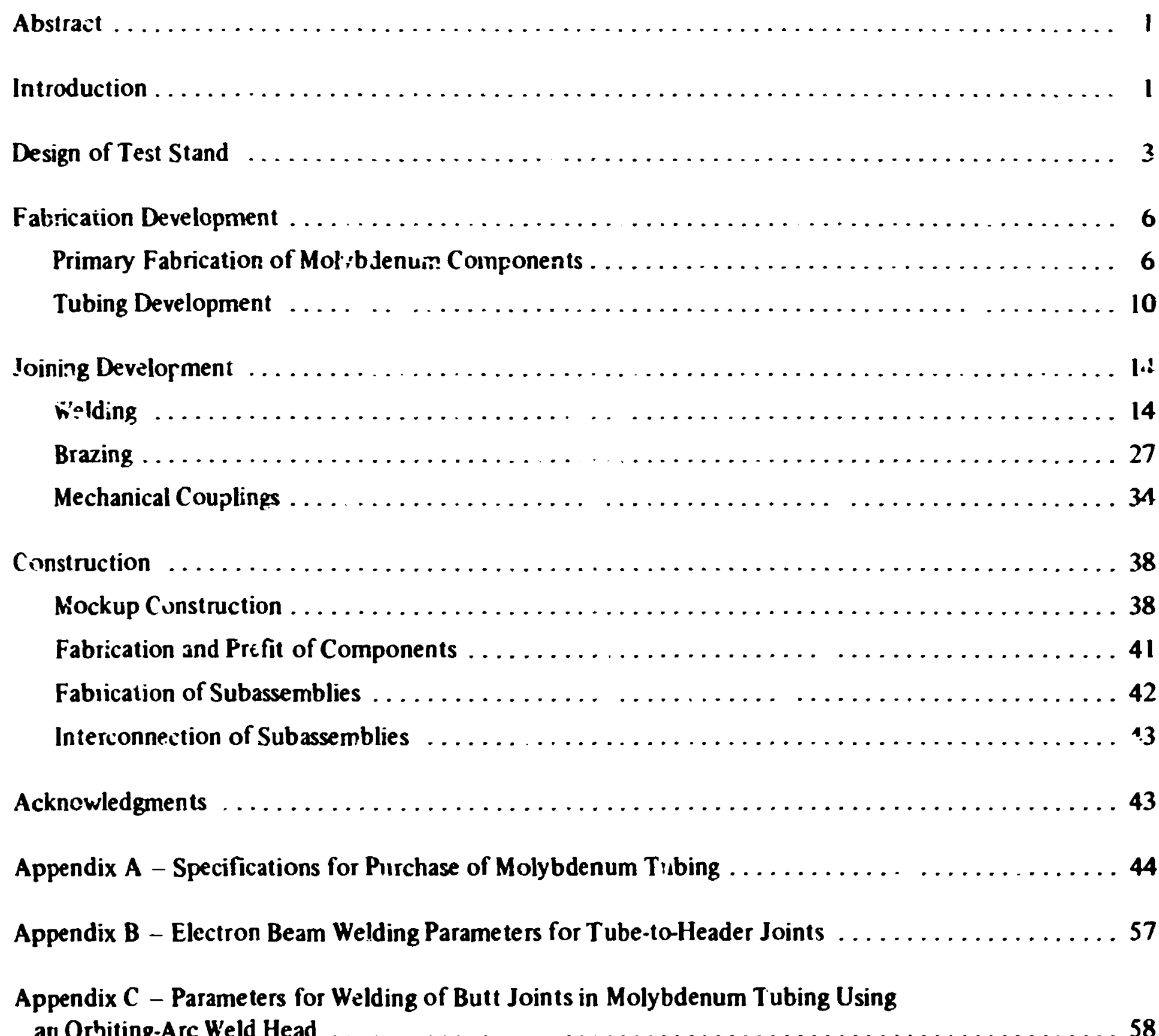




\title{
DEVELOPMENT AND CONSTR!JCTION UF A MOL YBDENUM TEST STAND
}

Compiled by

\author{
I. R DiStefino A. J. Mourhead \\ Principal Contrihutors \\ V. C. Cole R. F. MacDonild \\ J. R. Disiteiano A. I. Mlowrhead
}

\begin{abstract}
The discunery si a woci-ss that uses liquid bismuth at 500 to $700^{\circ} \mathrm{C}$ to remove protactinium and fissiun pr iJucis from th: molten salt fuel of a breeder react or ted to a search for suitable containment materials. Although several other efractory reisls or grapivice may be suitable, moiybdenum appears

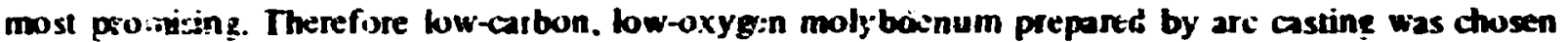
as the structusal material for a reaucti extraction test sand that would be representative of typical equipment. He re ugnized that the use of wrolybdenum as a structural material would require unorthowox a sembly procolures and inr...se stringent limitations on the system design. However, this material appa: ently possesses the best combination of properties such as fabricability, and oxidation ano corrusion resistance. Fina! desgn was ietermined after the development of appropriate fabrication and joining te:hniques.

Procedure; vere develoued fer the production of closet-end molytedenum balf sections by bact extrusion. Parts that were generalky free from cracks and inad hiell-chuality sarfaces were pnoduced by the use of $\mathrm{ZrO}_{2}$-coated plunger: and dies and extr:sion bbank prehes: temperatures of 1600 is $1700^{\prime} \mathrm{C}$. In croperation with a ocmmercial verdor, we forsd that molybdemum tubing with innorovai ductility could be produced by careful removal of contamination introduced during tubine fabrication.

Complex components were fabricaled by weldine, uing either the gas tungsten-arc or electron-beam process. Welding studies centered on three major types of joint: tube-to-tube, prbe-to header, and header-to-header. Tw) of the inost important factors found to minimize weld hot cracting wer: stress relieving and preheatinz of components prior to welding. Mechanical bonding techniques were jevelopad to join small-diameter tuting to backextruded end sections. Experiments carried out at $250^{\circ} \mathrm{C}$ in an arzon atmosphere produced helium leaktight joints. Brazine filler metals were developed that are rezso:ably corrosion resistant to bismuth and molten salt up to $700^{\circ} \mathrm{C}$. Techniques involving induction or resistince hentig were developed to braze the several types of joints used in the test and.

The Molten-Salt Pieactor Pr sgram was terminated jefore construction of the test stand was completed. but an unioinid muckup using molybdenum components was ascinbled, and detailed assembly piocedures were worked out. fll of the techniques required for fina: assembly were demonstrated.
\end{abstract}

\section{INTRODUCTION}

A key feature in the conceptual design of the single-fluid molten-salt breeder reactor is the connecting chemical processing plant to continuously remove protsctinium and fission prodicts from the fuel salt (Fig. 1). Piotactinium, the intermediate element in the breeding chain between thorium and ${ }^{23} \mathrm{U}$, has a signifi:ant neutrion capture cross section and must be kept out of the core to obtain a gcod breeding ratio. Rare-earth fission products are also neutron poisoris and must likewise be removed for good breeding. In 1968 the chenical feasibility of a process that uses liquid bismuth containing dissolved li:hium and thorium as reductants to extract protactinium ...ld rare earths 1 rem fuel salt containing both ur:miuin and thorium was demonstrated.' A simplified flowsheet based on this process is shown ini Fig. 2.

One of the requiremeats for the development of the reductive extracticin process is identifying materials that are compatible with both molten fluoride salts and bismuth containing reductants. Hastelloy $N$

I. M. F. Whatky and L. E. McNeex. Molren-Sall Reactor Propram Semianner. Prog. Rep. Feb. 29, 1968, ORNL 4254, pp. 24851. 


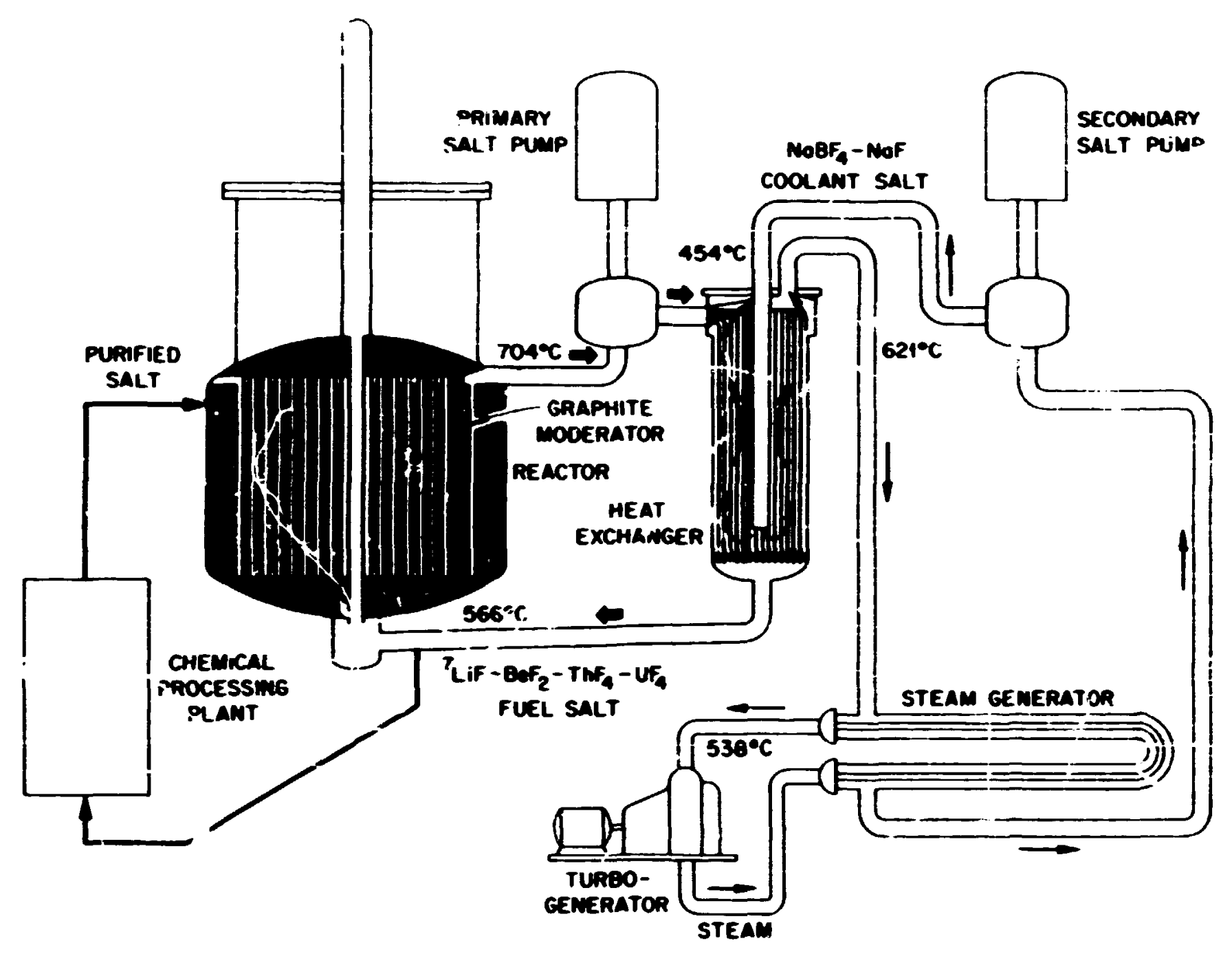

Fie 1. Single-thid, two-rejion molkensalt breeder reactor.

OANL-ONG 71-9004

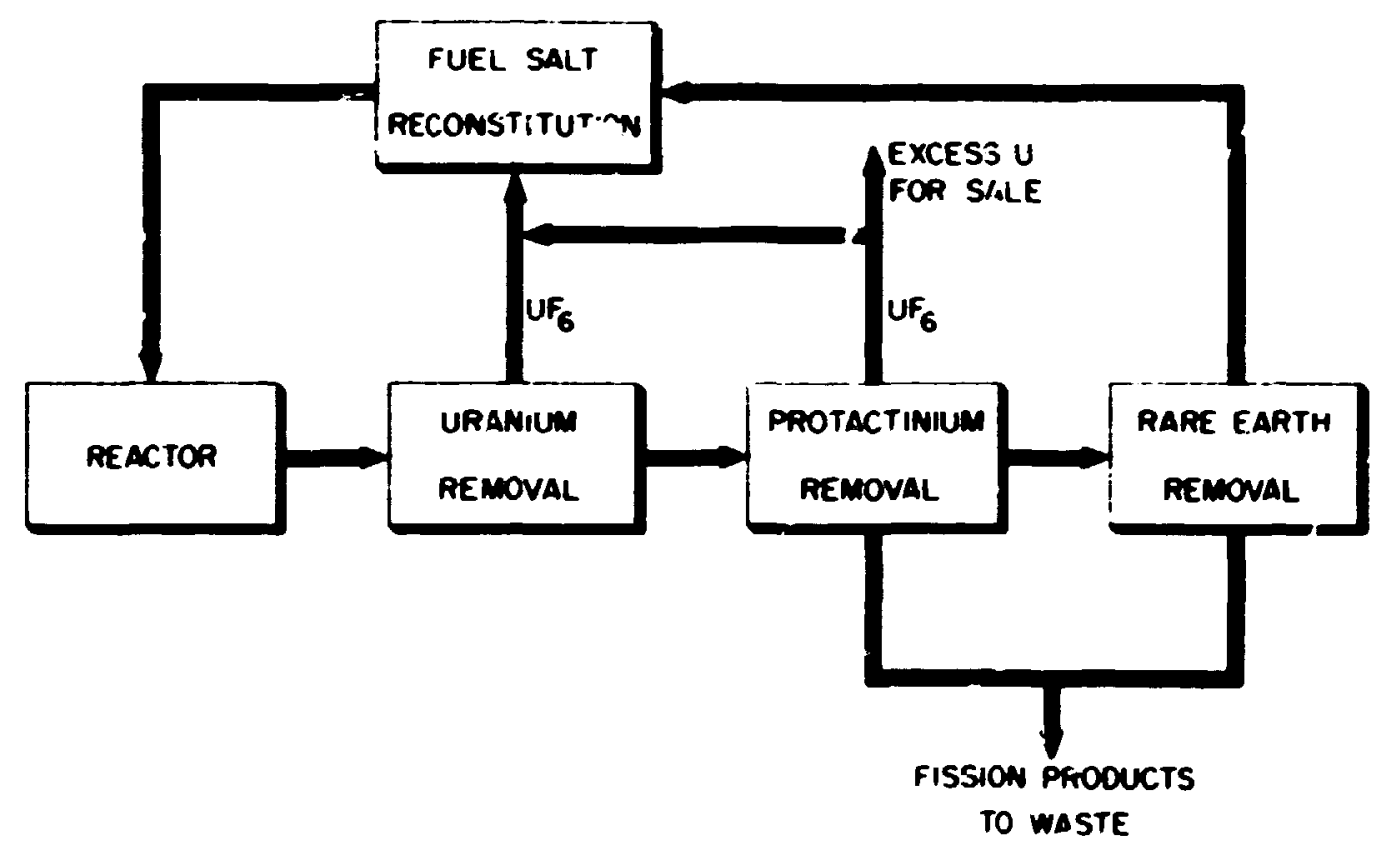

Fic. 2. Simplified fondweet for procesing the foet in a mothen-sult breeder reactor. 
(Ni-7\% Cr- 16\% Mo $5 \% \mathrm{Fej}$ is a like!y material of consi ruction for the reactor because it has excellent con:Datibility with liwiten salts at 560 to $700^{\circ} \mathrm{C}$. However. nickel has appreciable solubility in bismuth at these temperatures and, therefore, is unsuitable for those portions of a processing plant that have to contain liquid msinuth. Other commonly used construction materials such as iron- or cobalt-base alloy's have lower solubilities in bismuth but rapidly mass-transfer under conditions involving a temperature gradient. Several refractury metals (tantalum, molybdenum, tungsten. rhenium) ${ }^{2.3}$ and graphite ${ }^{4}$ appear promising, but each has limitations with respect to either fabricability, oxidation resistance, or compatibility with bismuth and salt.

When it was proposed to build a reductive-extraction column that would be representative of typical equipment and in which distribution coefficients for ve rious elements could be checked and engineering performance data determined, noolybdenum was shooen as the material of construction. We felt that it pussessed the best combination of properties required fer the processing application, namely, corrosion and oxidation resistance, availability, and fabricability. However, no system this complex had ever been constructed of molybdenum, and we foresaw many difficult fabrication problems that would have to be solved.

Molybdenum is a farticularly structure-sensitive material; that is, its mechanical properties are known to vary widely, depending upon how it has been metallurzicall;: processed. The ductile-brittle transition temperature of molybdenum varies from below room temperature to $200-300^{\circ} \mathrm{C}$, depending both upon strain rate and the microstructure of the metal. Maxirnum ductility is provided in the stress-relieved fine-grained coadition, and recrystallization and grain growth are known to reduce 'racture stress and ductility. Interstitial impurities such as oxygen and carbon often segregate at grain boundaries, and this can result in a decrease in grain-boundary inobility which also favers premature fracture and low ductility. 5 However, recent advances in vacuum-melting practices have led to the production of material with improved and more reproducible metallurgical properties. The arc-melted low-carbon, low-oxygen grade of molybdenum, available commercially, affords relatively good control of grain size and interstittal inpurity level. Nevertheless, the use of molybdenum as a structural material requires highly unorthodox assembly procedures and imposes stringent limitations on system design from the standpoint of geomety and ripidity.

\section{DESHGN OF TEST STAND}

The principal molybdenum components of the test stand are the column, disengaging pots, bismuth and salt feed pots, and connecting piping (Fig. 3). The column consists of a 1\%-in.-OD Raschig-ring-packed central column for contacting countercurrent streams of bismuth-lithium and molten fluoride salt. Enlarged end sections (3\%-in. OD pots) are provided for deentrainment and separation of the exit stream from the entering stream. The fluids flow countercurrently through the column because of their difference in density, and they are returned to their respective feed pots by an argon gas-lift system. Flow tes of the fluids are controlled by orifices located in the bottom of the 3\%-in.-OD feed pots (Fig. 4). The orifices are removable, and different sizes may be used to allow a range of flow rates cornpatible with the limited head available in the feed pots. The feed pots contain internal baffles and Raschig rings (Fig. 4) to deentrain

2. H. Shimotake. N. R. Stalica, and J. C. Hesion, "Corrosion of Refractory Metals by Liquid Biamuth, Tin, and Lead at 10S0"C," Thens. Amer. Nuct. Soc. 10, 141-4. (Juse 1967).

3. J. W. Siefert and A. L. Lomer, Jr., "Evalation of Tantahum, Molybdepum, and Bery lium for Liquid Bissuth Service." Comodion 17(10) 47s,-478t (October 1961).

4. Motlen Salt Rextor Prosum Semianum. Mrov. Rep. Feb. 29, 1972, ORNL-4782.

5. Molybdenum Merd, Cismax Moly bidenum Co., 1960. pp. 78-82. 


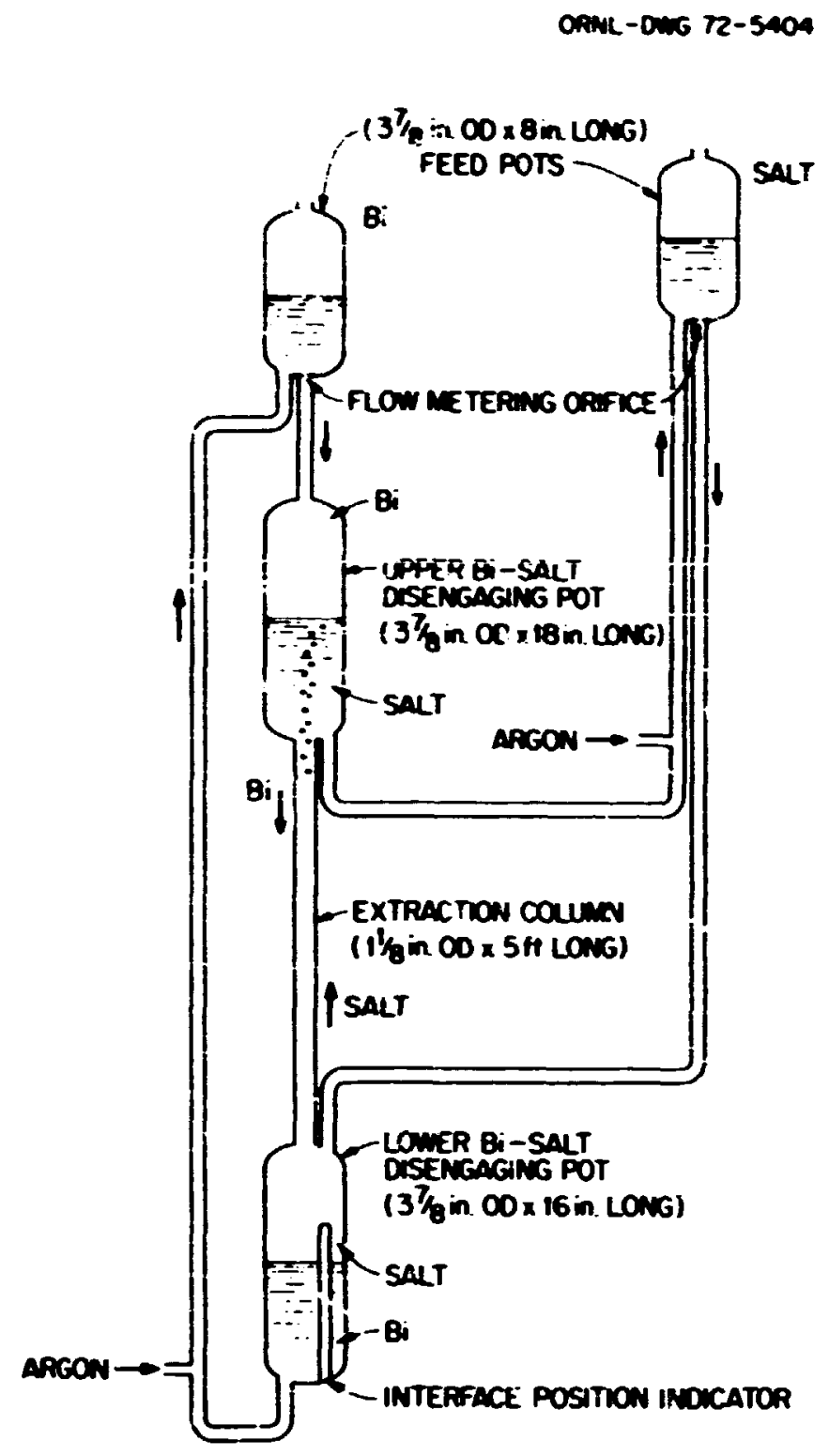

Fie 3. Schematic of molybdenum reduction-extraction test stard. Overall, $1 / 2 \mathrm{ft}$ in dinmeter and $17 \mathrm{ft}$ high.

liquid from the argon in the gas lift and darnp flow surges. The feed pots contain an access port for sampling and for adding thorium or lithium to the system. More complete details on the design of the test stand have been reported elsewhere. ${ }^{6.7}$

One major problem in the fabrication of complex molybdenum equipment is its lack of ducility after recrystanization. For optimum fabricability, it should be subjecied to at least a $50 \%$ reduction in area after recrystallization and then given a stress-relief treatment. A!though we felt that the $37 / 8$-in.-OD pots could be produced by machining from bar stock, material in this size range would have poor as-machined properties because it would have received oniy a limited amount of working. The capacity of available metal-wo:king equipment was lir:ited to using starting or blank material only slightly larger than the required fiivished pots. We chose instead to fabricate these components by back extrus on, a process in which a cylinder with is closed end can be produced by hot working in the range 1200 to $1700^{\circ} \mathrm{C}$.

Although molybderium can be welded, the process generally results in very large grains in both the iusion and heat-affected zones. Molybdenum welds are very brittle at room temperature and have a tendency to lot-crack. We thought that our best chances for successfully welding molybdenum would be

6. E. L. Nicholson, Conceptual Design and Development Program for the Molybdenum Reducrive Extraction Equipment Test Srond, ORNL_CF-71-7-2 (July 197 ').

7. W. F. Schaffer. Jr.. E. L. Nicholson, and L. E. McNeese, Quality Assurance Program Plan for the Molybdenum Reductive fixtraction Equipment Test Stand - Job No. 12172, ORNL-CF-73-1-45 (February 1973). 


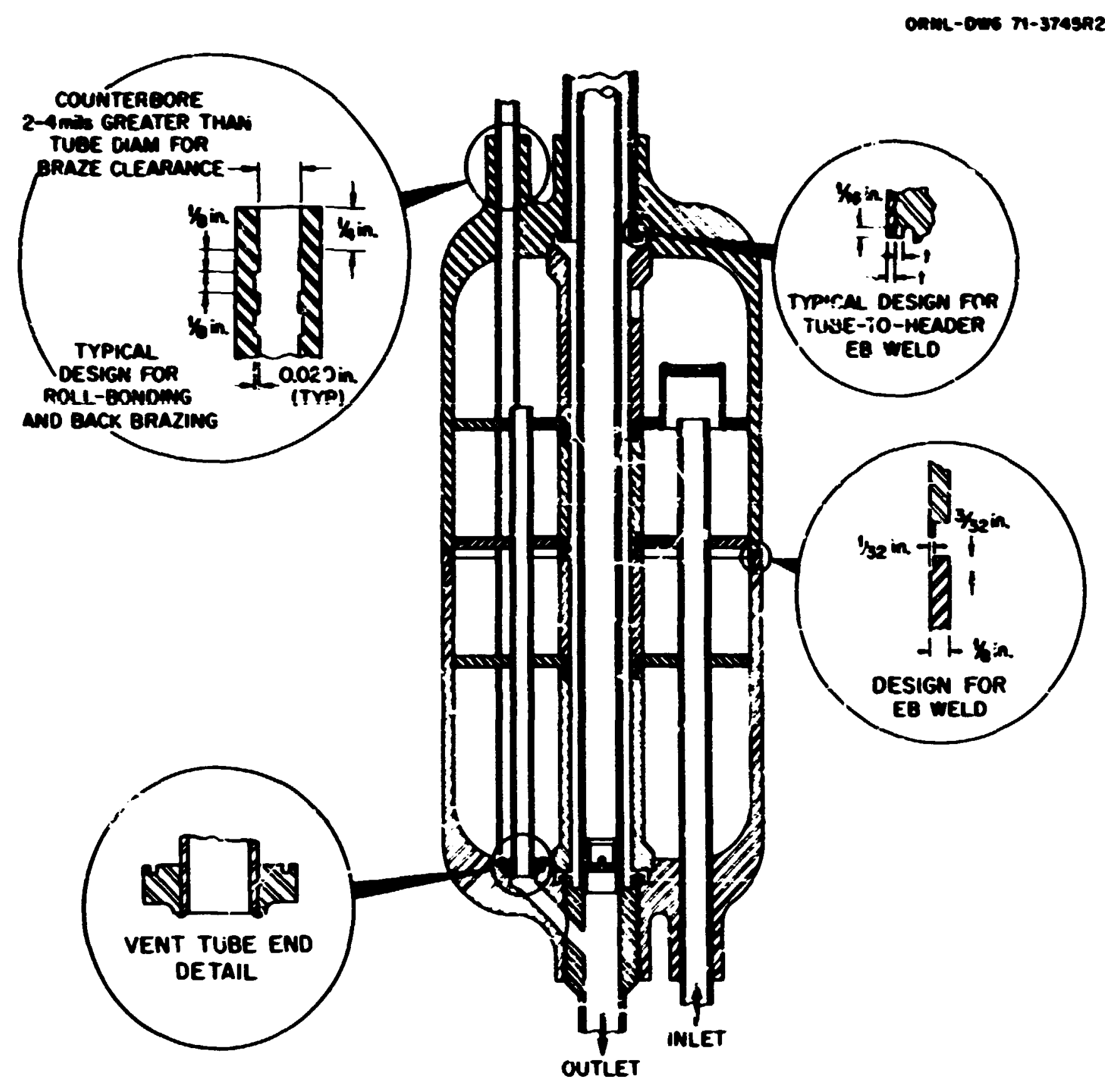

Fic. 4. Feed pot for molybdenum chemical procescing bop.

with the electron-beam process, which minimizes contamination effects, heat-affected-zone problems, and abnormal grain growth. However, electron-beam welding is not applicable for joining lengths of tubing together or for joining the tubing to a pot where the tube passes completely througn the end section. A terhnique using th: gas tungsten-arc welding process with an orbiting elertrode was developed to make the tube-to-tube butt welds, and a mechanical joining technique (roll bonding) was developed to make the latter joints. In addition, reinforcement of all :velded or roll-bonded joints by brazing served to strengthen the joint as well as io add a barrier to fluid leakage if a crack developed. To utilize brazing, hrwever, required the development of a filler metal that would both be corrosion resistant to bismuth and sali and have a melting temperature below $1200^{\circ} \mathrm{C}$, the raximum temperature that we felt could be tulvated hefore the molybdenum would become overly embrittled as a result of recrystallization and grain growth.

The deveiopment work undertaken was concomitant with design of the test stand, and there was : definite interrelation between the two functions. The final loop design represented a compromise tr:tween inginecring requirements and progress made in the development of fabrication and joining prucedices for iiolybdenum. 


\section{FABRICATION DEVELOPMENT}

\section{Primary Fabrication of Molybdenum Components}

\section{R. E. McDonald}

The choice of molybdenum as the constriction material for the test stand presented several fabrication problems. It a:s originally suggested that the pots and the large-diameter heavy-wall tubing be machined from bar stuck. Huwever. our experience was that bar stock more than $13 \frac{3}{4}$ to $2 \mathrm{in}$. in Jeaineter had poor mechmical properties. Most aviilable mec:anical properties data comes from thin sheet $\omega^{r}$ small-diameter rod which has been heavily workel, and we felt that an end cap machined from 4 -ill-diam bar wouid be weak and crack-prone.

Fabricition developınent started before the test-stand design was completed. One method consiciered in making the pois was by forgin: heavy plate to form end caps and then welding them to heavy-wai' extruded pipe. We had previuusly teveloped techniques to fabricate heavy-wall tungsten pipe, and 4-in.-diam by $3 / 8$ in. wall by 50-in.-long sections had been made. ${ }^{8}$ Molybdenum pif " could readily be produced using the sime iechniques. The forged end caps wijuld then be welded or brazed to the large pipe body, producing i.ie pot. and pots made by this technique would have good mechanical properties because of the rechanical working necessary to shape them. Available equipment aided us in the choise of back extrusion for producing the end caps and forward extrusion for producing heavy-wall tubing. The Metals and Ceramics Division at ORNL has available a horizontal cxtrusion press with an extensive tooling inventory. Three-, 4 , 5.6-, and 7-in.-diam containers with stems sere on hand. The water-nitrogen accumulator system was capatle of 1300 tons on the 4-in. stem, and ar: induction billet neater, $50 \mathrm{~kW}$ at 3000 cycles, was capable of heating 4-in.-diam, 10-in.-long billets to $2200^{\circ} \mathrm{C}$ in $45 \mathrm{~min}$.

The first attempt to produce an end cap by back extrusion was made using a 4-in.-ID container with a $\mathrm{ZrO}_{2}$-coated split die having provisions for integrai bosses, a solid die backer, and a 3-in.-diam stem with a 3-in.diam $\mathrm{ZrO}_{2}$-coated tool-steel plunger attached. This is shown schematically in Fig. 5. A 3.950-in.diam moiybdenum blank was heated to $1300^{\circ} \mathrm{C}$ in the induction heates under an argon atmosphere, transferred to the cisitainer, and quickly pushed with the plunger. The blank neatly filled the die and flowed back over the coated plunger. preducing a tin.-OD product. The tooling was conventionally cleared from the contaiier, the die parted. and the plunger extracted. Several back ext. usions we.e made to determine the optimum temperature, boss configuration, and skirt lengths. Back extrusions were successfully made at $1200,1300,1400$, and $1500^{\circ} \mathrm{C}$, and the maximum skirt length we obtained was 4 in. at $1500^{\circ} \mathrm{C}$.

Durirg this phase of development, however, cracks were noted in the hemispherical portion and the skirt ends. Although it was first suspected that they occurred during back extrusion, we noted that fine cracks had been generated on the faces of the blank during machining, and we felt they could have been transierred to the product.

In an effort to understand and elirr nate this cracking problem, a blank was cut lengthwise into two sections. and a $1 / 2$-in. square grid network of grooves was machined into each half. The grid of one half was filled with small-diameter tantalum wires, and the iwo halves were pinned together. The blank was heated io $1650^{\circ} \mathrm{C}$ and back-extruded. The halves of the extrusion were easily parted, and Fin. 6 shows the flow pattern of the molybdenum during extrusion. The flow pattern shows that the cylindric al extrusion blank was first rushed forward. fillink the die cavities to form the bosses. After it bottomed out against the solid die backer. it nowed backward orer the coated plunger to form the skirt. As th free surface of the skirt nows backward between the plunger and the die body, it is essertially undeformed. Therefore, if fine

8. R. I. MiDonald and G. A. Reimann, Floating-Mandrel Extrusion of Tungsten and Tungsten-Alloy Tubing, ORNL.1:10. 
ORNL - DWG 70-3377A

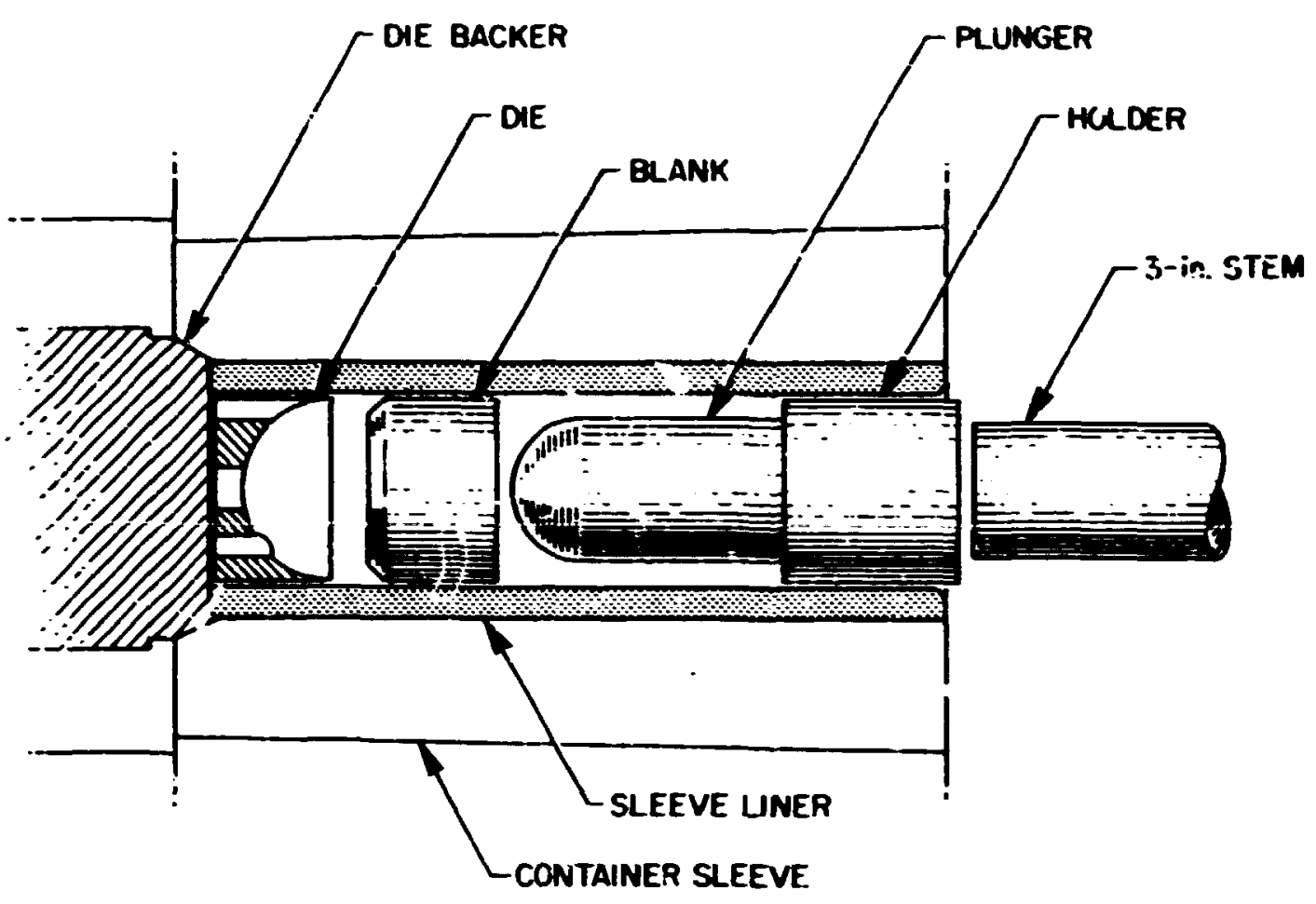

Fiz 5. Tooling used in capaule fabrication by back extrusion.
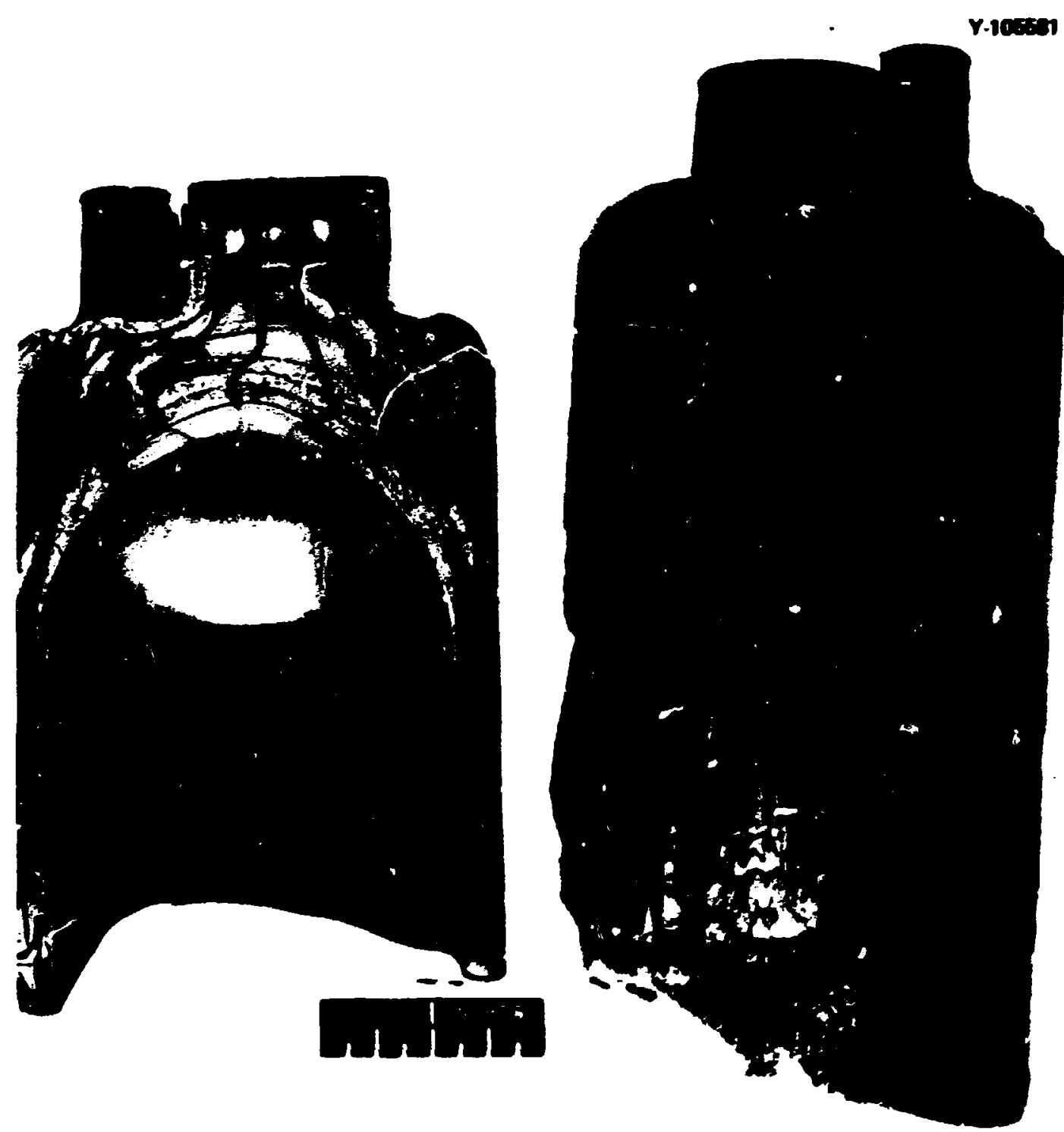

Fig. 6. Flow pattern in a molybdenum back extrusion revealed by a network of tantalum wires installed in half of the original blank. 
cracks exist on the back edge of the starting blank, then cracks in the skirt edge will occur. To minimize this type of cracking, the back edge of the starting blank was radiused and highly polished. A: this point, our machining procedure was modified to require that all blanks be chemically etched and dye-penetrantinspected after machining. Moly bdenum, like tungsten, has a tendency of smearing over cracks during machining or grinding, and unless etched, it is difficult if not impossible to detect fine cracks. If iracks were detected. very fine grinding renoved them prior to acceptance. This change in procedure noticeably reduced cracking in the backextruded product.

While demonstrating that end caps could be made reliably, we noted that fairly long lengths of skirt were extruded back over the piunger. We then decided it would be feasible to back-extride two halves to make a pol. This approacil would require one girth weld instead of the two required to attach the end caps to an intermediate section of pipe, and it would also eliminatc the nee: to extrude $3 \%$-in.-OD, $3 / 8$-in.-wall pipe.

in order to back-extrude the end cap with a long cylindrical section, we thought that it would be necessary either to do it in several steps or to raise the pleheat temperature of the blank. However, this led to further complications. We found that the $\mathrm{ZrO}_{2}$ coating on the plunger stayed intact for only one or two pushes before it had to be recoated because the inner surface of the product was adversely affected. Also, the increase in the preheat temperature to $1650^{\circ} \mathrm{C}$ caused galling and tearing of the outer surface of the extrusion because of a reaction of the molybdenum with the steel container liner (Fig. 6). The lubricant used by ORNL for all extrusions of molybdenum, molybdenum alloys, tungsten, and tungsten alloys is what we term a base-metal oxide lubricant. At the hot working tcmperature of these metals and alloys a liquid oxide forms which is an excellent lubricant (covered by USAEC patent 3,350,907). H.owever, the residence time of the back extrusion in the container is long when compared with that of a converiional fcrward extrusion, and the liquid oxide breaks down as a lubricant as the iémperature of the steel approaches its melting point. We had observed that the surfaces of the extrusion that were insulated from the steel by the plasma-sprayed $\mathrm{ZrO}_{2}$ were not tearing (Fig. 6); therefore the tooling was changed so that molybdenum was in contact only with $\mathrm{ZrO}_{2}$-coated surfaces during extrosion. To do this the 5.6-in.-ID container was used, in which a 5.6-in.-OD, 4-in.-ID, 9-in.-long split die was inserted. The entire inner surface of the split die was plasma-sprayed with $\mathrm{ZrO}_{2}$. At this puint, the end design of the pot was also changed from a multiple-bossed hemispherical head to a large single-boss that head as shown in Fig. 7. Three 8-in.-long back extrusions were inade at preheat temperatures of 1600 to $1700^{\circ} \mathrm{C}$ with a stem load of up to 800 tons. When the length requirement of the hali sections for the icwer disengaging pot was increased to $91 / 16$ in., a new 12-in.-long die was made. Three long blanks were then back-extruded at 1600 to $1700^{\circ} \mathrm{S}$ with stem loads up to $\mathbf{8 0 0}$ tons. These extrusions exhibited good outer and inner surfaces, and skirt cracking did not exceed an inch in length. A typical back extrusion after machining is shown in Fig. 8.

We thus showed that by using existing equipment - the horizontal extrusion press - half sections for the bismuth, salt, and the upper and luwer disengaging pots could be made by back extrusion. A total of 12 back extrusions were produced for use in constructing the molybdenum test stand, and data concerning these products are summarized in Table 1.

The second problem, the production: of the large-diameter heavy-wall tubing for the packed column, was solved using techniques developed under the High Temperature Materials and Tungsten Programs at ORNL. About $6 \mathrm{ft}$ of 1.16-in.-OD, 0.080-in.-wall tubing was required. For this, we used a 4-in.-OD, 1-in.-ID, 7-in.-long billet, which was heated to $1600^{\circ} \mathrm{C}$ and extruded over a $\mathrm{ZrO}_{2}$-costed mandrel at a reduction ratio of 29:1. A second extrusion produced a tube $11 \frac{1}{2} \mathrm{ft}$ in length that was concentric within 0.007 in. tolerance in radius and with excellent outer and inner surfaces. The process used was the ORNL 
Y.10706
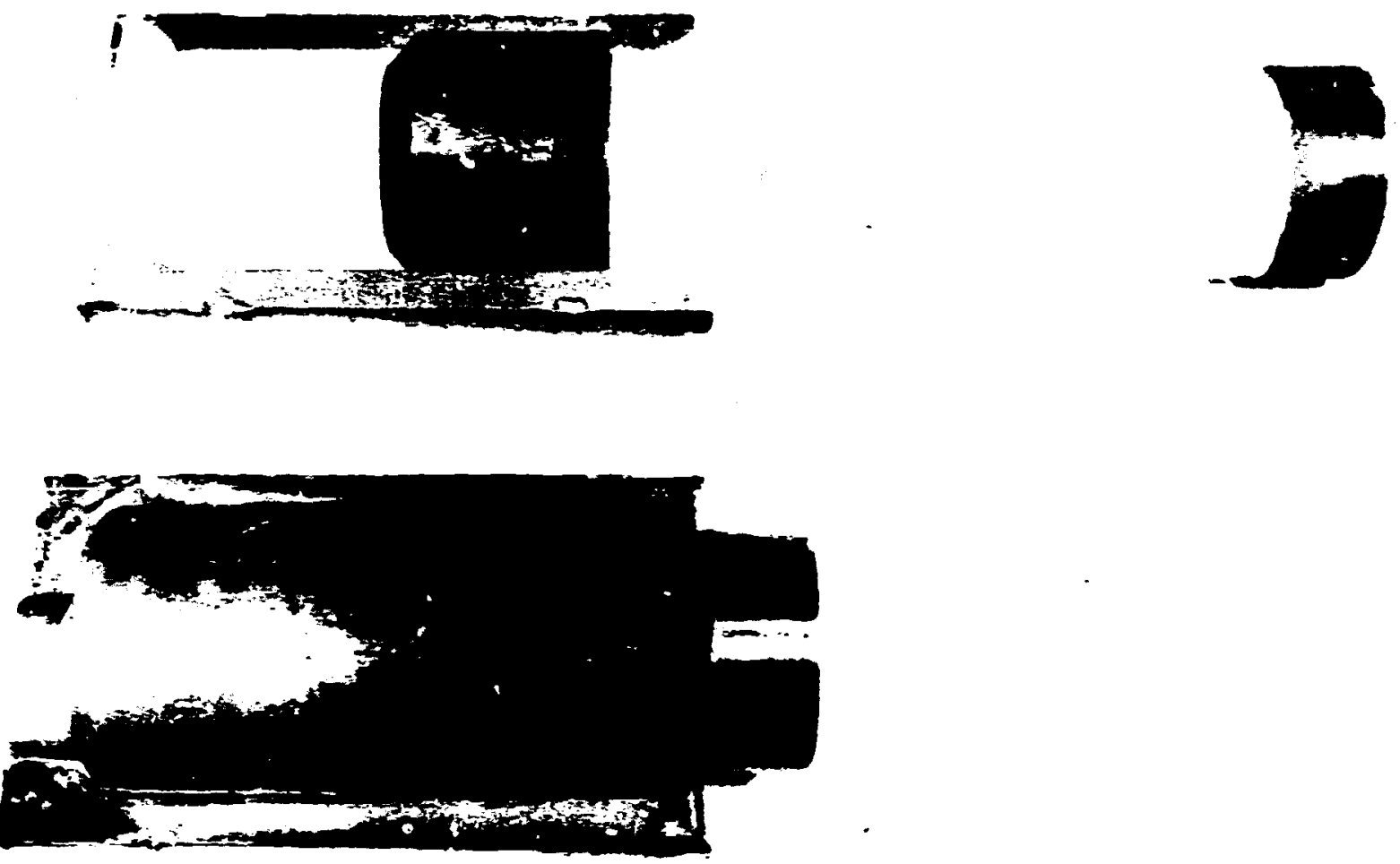

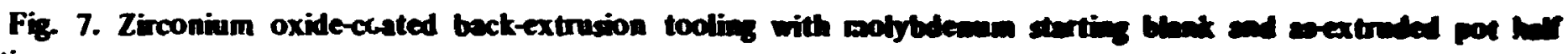
section.

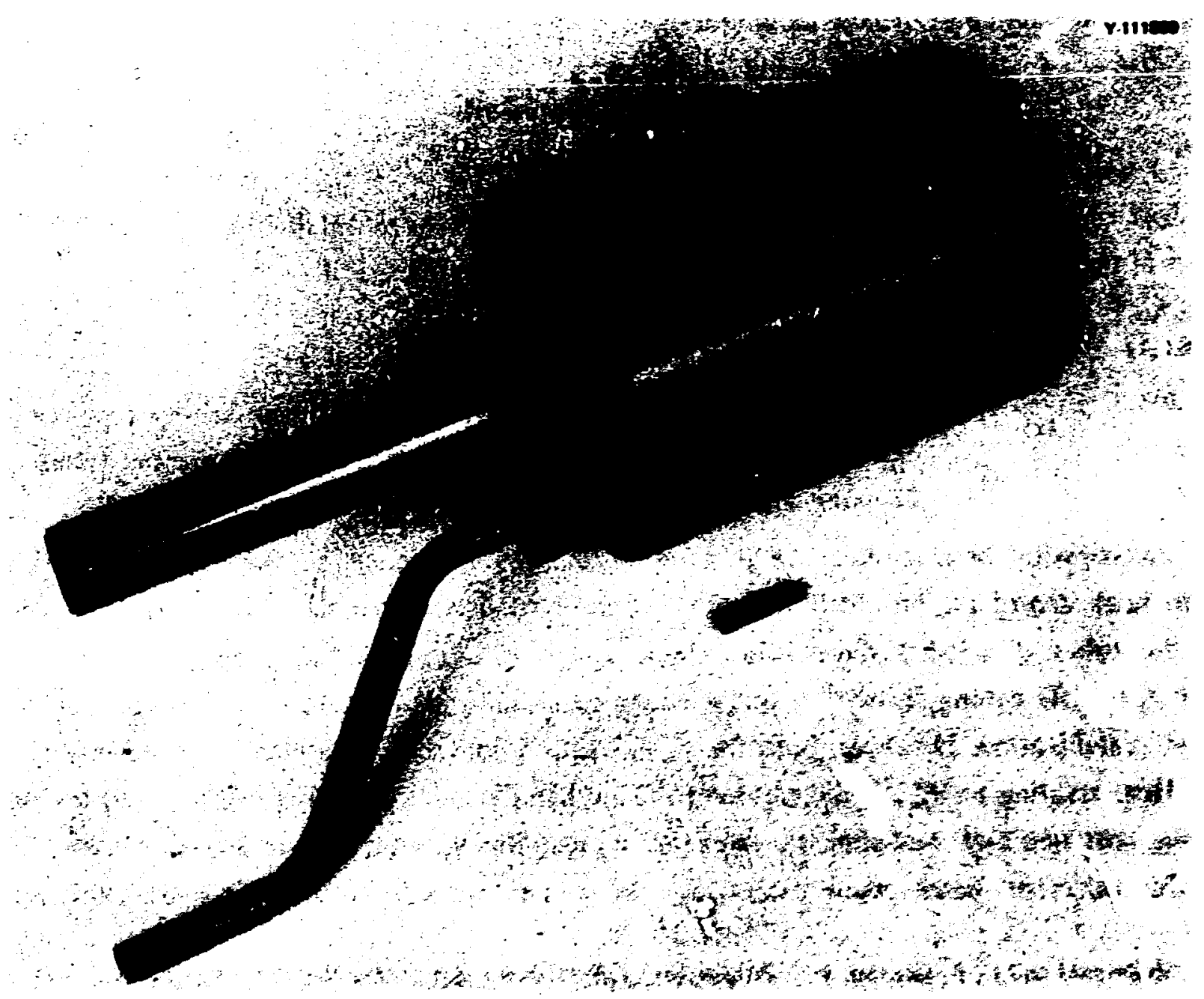

Fi. 8. Example of molybdenum backextreded ball section after machimine. 
Table 1. Molybiemm half sections back-extruded for the molybdenum test stand

\begin{tabular}{|c|c|c|c|c|}
\hline Part & $\begin{array}{c}\text { Extrusion } \\
\text { number }\end{array}$ & $\begin{array}{c}\text { Extrusion } \\
\text { temperature } \\
\left.\text { ( }{ }^{\circ} \mathrm{C}\right)\end{array}$ & $\begin{array}{l}\text { Internal } \\
\text { length } \\
\text { (in.) }\end{array}$ & Results \\
\hline Feed Pot & $119 ?$ & 1600 & 4 & No cracks \\
\hline Feed pot & 1250 & 1600 & 4 & tnd cracks, 3.5 in. usable \\
\hline Feed pol & 1257 & 1600 & 4.5 & End cracks, 3.5 in. usable \\
\hline Feed pot & 1259 & 1600 & 4.5 & End cracks, 4 in usable \\
\hline Spare & 1251 & 1600 & 4 & $\begin{array}{l}\text { End cracks, } 3.5 \text { in. usable, } \\
\text { surface cracks on top }\end{array}$ \\
\hline Spare & 1256 & 1600 & 4 & Surface cracks on top \\
\hline Lower disengaging & 1258 & 1600 & 8 & No stacks \\
\hline Lower disengaging & 1260 & $13 \times 5$ & 8 & No cracks \\
\hline Spare & 1261 & 1600 & 8.5 & Cracks in wall \\
\hline Upper disengaing & 1286 & 1700 & 9 & No cracks \\
\hline Uppet disengaging & 1290 & 1700 & $\mathbf{I I}$ & End cracks, 9.5 in. usable \\
\hline Spare & 1288 & 1700 & 9 & Reextruded, crach in wall \\
\hline
\end{tabular}

floating mandrel technique, which is described in another report," with the lubrication provided by molybdenum oxide.

Even though a scale-up of the test stand would be iequired in construction of an actual chemical processing facility, we feel that we have demonstrated pr:mary fabrication techniques for molybdenum that would be applicable to containers up to 12 in. in diameter and 36 in. long. Fabrication of larger-sized components would require the adaptation of other fabrication techniques, such as ring rolling or power spinning, or the development of new techniques.

\section{Tubing Development}

\section{J. R. DiStefano}

Four sizes of molybdenum tsbing were required, and these were obtained commercially, as listed in Table 2. All of the material was purchased according to the following specifications:

Specification No.

(see Appendix A)

Titie

MET-RM-B208

MET-NDT-3

MET-NDT-4
Tentative Specification for Seamless, Arc-Cast Mo Tubing for High Temperature Service Tentative Sp zcification for Ultrasonic Inspection of Metal Piping and Tubing Tentative Methods for Liquid Penetrant Inspection

Initial investigation of three heats of this tubing revealed differences in microstructure, hardness, and response to heat treatment, but little difference in interstitial concentration (Tabl: 3). Luspeciion of the inside of the tubes revealed surfaces which were rough oi pitted. Metallographic examination of the as-received $3_{\mathrm{a}}$-in.-OD tubing showed it was partially recrystallized. Heating $10925^{\circ} \mathrm{C}$ for $1 \mathrm{hr}$ resulted in complete recrystallization. However, both the $1 / 4$-in.- and $1 / 2$-in.-OD tubing were received in a cold-worked condition. Heat treating to $925^{\circ} \mathrm{C}$ did not alter the hardness or microstructure of the $1 / 4$-in. tubing, but the $1 / 2$-in. tubing softened and was almost completely recrystallized. Since the interstitial lement concentrations in the different heats were essentially the same, we can ascume that the surprisingly low

9. R. E. M. Donald and C. F. Leitten, Jr., "Production of Refractory Metal Tube Shells by Extrusion and Flor.-Tuming Techniques." pp. 85 -92 in Refractory Merals and Alloys III: Applied Aspects, vol. 30, ed. by Robert I. Jaffee (Proceedings of the Third Technical Conference, AIME), Gordon and Breach Science Publishers, New York, 1966. 
Table 2. Molybdenen tubing for chewical procesing boop

\begin{tabular}{|c|c|c|c|c|c|c|}
\hline \multicolumn{2}{|c|}{ Tubinz size } & \multirow{2}{*}{$\begin{array}{l}\text { No. of } \\
\text { heats }\end{array}$} & \multirow{2}{*}{ Identifination } & \multirow{2}{*}{$\begin{array}{l}\text { Stress retief by } \\
\text { manufacture }\end{array}$} & \multicolumn{2}{|c|}{ Source } \\
\hline $\begin{array}{l}\text { OD } \\
\text { (in.) }\end{array}$ & $\begin{array}{l}\text { Wall } \\
\text { (in.) }\end{array}$ & & & & Vendor & Manofecturer \\
\hline $1 / 4$ & 0.020 & 1 & CPM-1 & $1 \mathrm{hr}, 870^{\circ} \mathrm{C}$ & TECO & Superior Tube \\
\hline$y_{8}$ & 0.025 & 3 & CTM-2 & $1 \mathrm{hr}, 870^{\circ} \mathrm{C}$ & TECO & Superior Tobe \\
\hline & & & Crato & None & TECO & TECO \\
\hline & & & CrAs 8 & $1 \mathrm{hr}, 870^{\circ} \mathrm{C}$ & TECO & TECO \\
\hline $1 / 2$ & 0.030 & 2 & CTM-3 & $1 \mathrm{hr}, 870^{\circ} \mathrm{C}$ & TECO & Superior Tube \\
\hline & & & CTM-8 & $1 \mathrm{hr} .870^{\circ} \mathrm{C}$ & TECO & TECO \\
\hline 3 & 0.080 & 1 & Crm-s & $1 \mathrm{hr}, 870^{\circ} \mathrm{C}$ & TECO & TECO \\
\hline
\end{tabular}

- Therme Ekectron Corp., Wobum, Mass.

OSuperior Tube Co., Norristown, Pr.

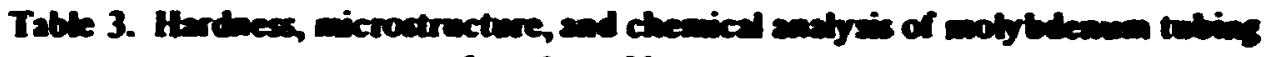
as a fonction of heat trentineat

\begin{tabular}{|c|c|c|c|c|c|}
\hline \multirow{2}{*}{$\begin{array}{l}\text { Size of } \\
\text { tubins } \\
\text { (OD in.) }\end{array}$} & \multirow{2}{*}{ Conduition } & \multirow{2}{*}{$\begin{array}{c}\text { Hardness } \\
\text { DrH }\left(1000_{\text {g }}\right)\end{array}$} & \multirow{2}{*}{ Microstructure } & \multicolumn{2}{|c|}{ Concentration (pp) } \\
\hline & & & & Oxysea & Carbou \\
\hline $1 / 4$ & As received & 233 & Could worted & 69 & $\boldsymbol{\infty}$ \\
\hline $1 / 4$ & I hr at $800^{\circ} \mathrm{C}$ & 258 & Cold wotted & & \\
\hline $1 / 4$ & I hr at $925^{\circ} \mathrm{C}$ & 250 & Cold morted & & \\
\hline $\mathbf{y}_{\mathbf{3}}$ & As received & 200 & Purtially recrystallized (10-15x) & 69 & so \\
\hline 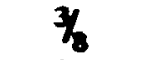 & I hr at $800^{\circ} \mathrm{C}$ & 243 & Partially recrystalized & & \\
\hline 3 & I hr at $925^{\circ} \mathrm{C}$ & 168 & Completely recrystallined & & \\
\hline $1 / 2$ & As received & 242 & Cold worked & 69 & 40 \\
\hline $1 / 2$ & I hr at $700^{\circ} \mathrm{C}$ & 255 & Cold worted & & \\
\hline $1 / 2$ & $1 \mathrm{hrat} 800^{\circ} \mathrm{C}$ & 243 & Cold worted & & \\
\hline $1 / 2$ & I hr at $900^{\circ} \mathrm{C}$ & 236 & Very sighth recrystallized & & \\
\hline $1 / 2$ & $1 \mathrm{hrat} 925^{\circ} \mathrm{C}$ & 206 & Almost completuty recrystallibed (SOX) & & \\
\hline
\end{tabular}

The tubing was stress retievad for $1 \mathrm{hr}$ at $870^{\circ} \mathrm{C}$ before delinery.

recrystallization temperatures for the $3 / a$-in.- and $1 / 2$-in. OD tubing were the result of working prior to heat treating.

To evaluate the ductility of the tubing, we devised a somewhat qualitative test in which a 0.5 -in.fong sample was impact-flattened a predetermined amount at different temperatures using the equipment shown in Fig. 9. The load was applied by a 2300-g weight dropped a distance of $6 \mathrm{~cm}$. To obtain a quantitative measure of deformation, we divided the displacement (original ring diameter minus the minor axis diameter of the tested specimen) by the original diameter of the ring. The results of some of these tests are given in Table 4. The as-received $1 / 2$-in.-OD tubing was "ductile" (no cracks) at room temperature, while we had to heat samples of the $3 / 2$-in.-OD tubing to $150-250^{\circ} \mathrm{C}$ and the $1 / 4$-in.-OD tubing $\$ 0300^{\circ} \mathrm{C}$ before they became ductile.

The behavior of the $1 / 4$-in.-OD tubing was traced to a brittle layer on its insice surface, as inducated in Table 5. Removal of $0.004 \mathrm{in}$. from the inside diameter $(0.002 \mathrm{in}$. from the wall thickness) resulted in lowering the temperature at which acceptable ductility was observed from 2,00 to $i 25^{\circ} \mathrm{C}$; when 0.006 in. 


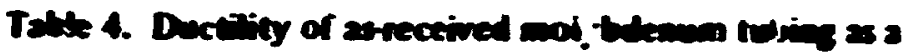
fonction of deformation temerature

Siress retieved I hr ai $870^{\prime} \mathrm{C}^{\circ}$

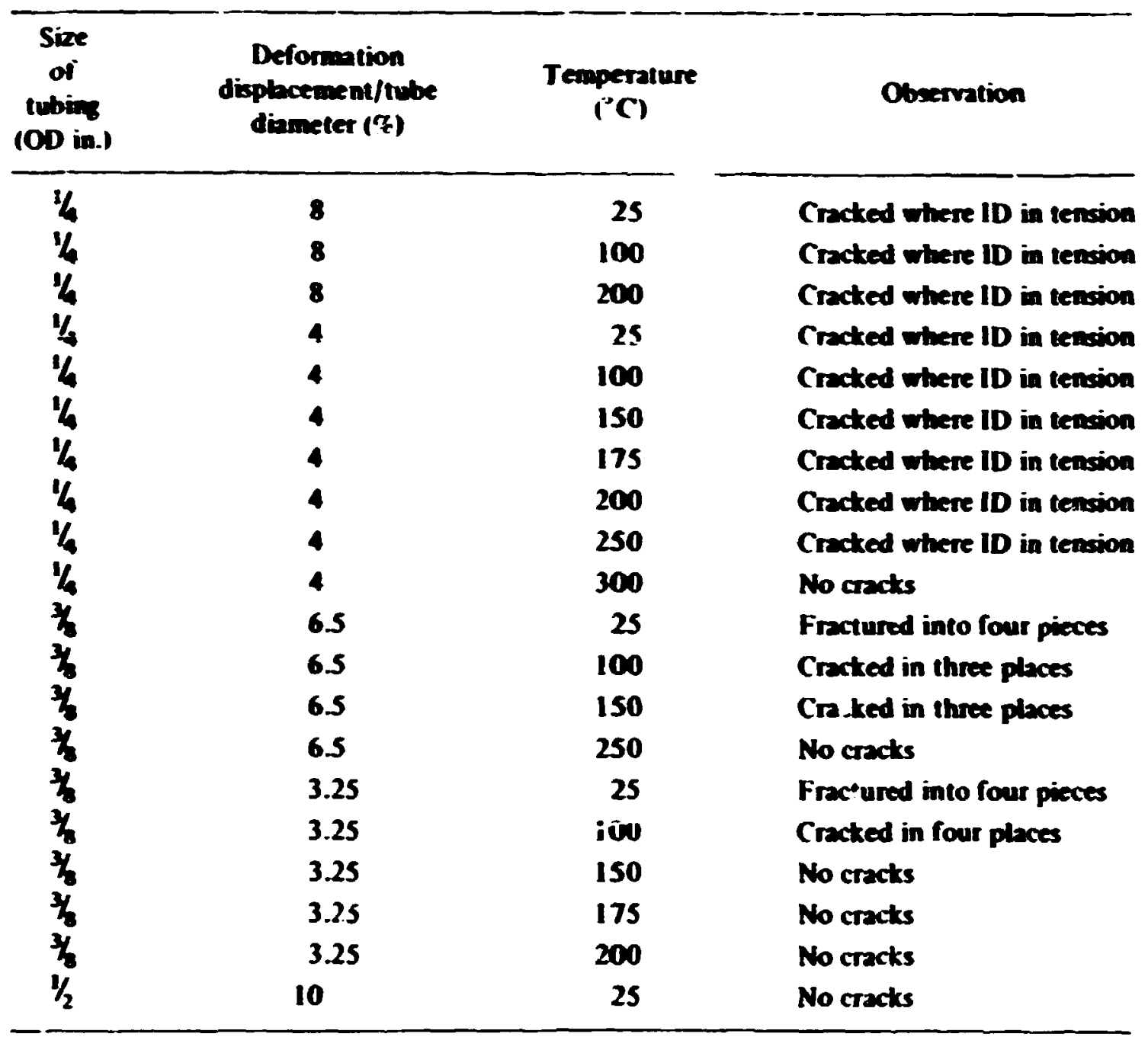

Table 5. Mectanical behavion of $1 / 4$-in. OD tobing as a function of removies incremental byers from the iener surface

\begin{tabular}{cccl}
\hline $\begin{array}{c}\text { Material } \\
\text { removed } \\
\text { from } \\
\text { ID (in.) }\end{array}$ & $\begin{array}{c}\text { Deformation } \\
\text { displacement/tube } \\
\text { diameter (\%) }\end{array}$ & $\begin{array}{c}\text { Temperature } \\
\text { (C) }\end{array}$ & Observation \\
\hline 0.002 & 4 & 25 & Hairline crack \\
0.002 & 4 & 125 & Hairline crack \\
0.004 & 4 & 25 & Hairline cracks \\
0.004 & 4 & 125 & No cracks \\
0.006 & 4 & 25 & No cracks \\
0.006 & 4 & 125 & No cracks \\
0.008 & 4 & 25 & No cracks \\
0.008 & 4 & 125 & No cracks \\
0.010 & 4 & 25 & No cracks \\
0.010 & 4 & 125 & No cracks \\
\hline
\end{tabular}




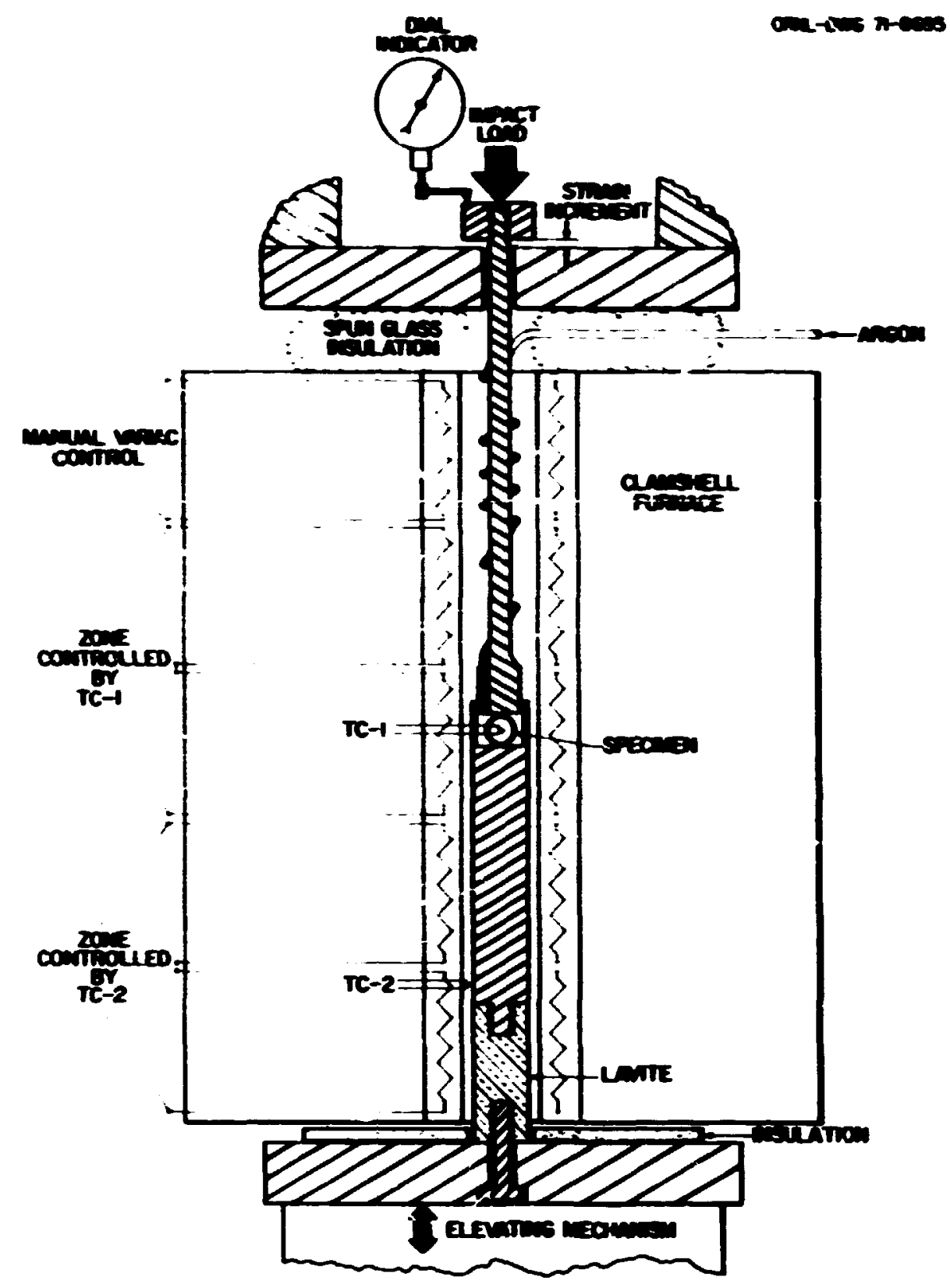

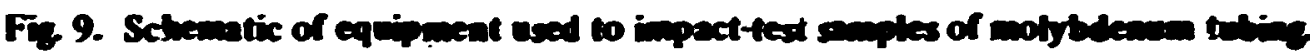

was removed from the inside diameter, the material was ductile at room temperature. Chemical analysis indicated that material from near the inside surface contained higher oxygen and carbon concentrations compared with the bulk sample analyses ( 140 and : 20 ppm, respectively, compared with 69 and 80 ppm). We suspected that contamination of the tubing occurred during fabrication and that it was not removed during subsequent cleaning or heat treating operations.

Removing material from the inside of the $3 / 3$-in.-OD tubing also improved its room-temperature ductility, but its as-received microstructure (partially recrystallized as compared with the cold-worked fine-grained $1 / 2$-in.-OD tubing) led us to believe that the fabrication schedule used in its production might also be responsible for its lack of ductility. Consultation with the manufacturer 10 kd te the following changes in our specifications:

1. Starting tube shell shall have an average grain size of ASTM No. 6. No grain shall be larger than ASTM No. 3.

2. Starting size of tube shell to produce $3 / 3$-in. $O D \times 0.025$-in. wall product shall be 1.125 -in. $O D$ by 0.250 -in. wall or 1.125 -in. $\mathrm{OD} \times 0.187$ in. wall. In either case, no more than two interme Jiate anneals shall be used and the temperature shall be no higher than $815^{\circ} \mathrm{C}$.

10. Thermo Electron Corp.. Woburn. Mass. 
3. Prior to the final stress relief. material stail be ikeaned in an alkaline sulution. The inside surfacie shall then be mechunizally ckeaned by wire brushing and then pikkled to remore 0.001 10 0.002 in. from the wall.

4. Final stress retief shall be $1 \mathrm{hr}$ at $800^{\circ} \mathrm{C}$ in dry hydrogen or vacul $\cdots . .1<5 \times 10^{-5}$ torr).

4 quantity of $y_{3}$-in. OD lubing was purchased acioraing to these modifred specifications and was found to be ductile at room temperature as measured by our flattening test. The $1 / 6$-in. OD tubing that was already on hand was acid etched to remove approximately 0.005 in. from: its inside diamerer. and selected samples were found to be ductile. It should be nuted that, aithough the as-recieived "contaminated" tuting was not ductike in the impact fattening tes:. it could be bent at :oum temperature without fracturing. Sums omples were hent up $1090^{\circ}$ without evidence of cracks. The rate of bending was found to be important. but the data were not quantitated.

Welding studies indicated that a preweld stress-relief hat treatment for i hr at 875 to $900^{\circ} \mathrm{C}$ was desirable to minimize weld cracking: however, samples of $1 / 2$-in.-OD material (CPM-3) became embrittled when heated $10925^{\circ} \mathrm{C}$, and one heat (CPM-6) becami embrittled when heated $10860^{\circ} \mathrm{C}$. Tulsing selected for loop construction was heat treated for $1 \mathrm{hr}$ at $900^{\circ} \mathrm{C}$ in vacuum after ali bends had been made. In this way. we look advantage of the as-received ductility of the material for bending and stili satisfied the requirements for a preweld heat treatment.

\section{JOINING DEVELORMENT Welding}

\section{A. J. Moorkead}

Material sebection and preparation. Molybdenum has several characteristics that make it difficult to fabricate into complex structures by welding. It has a tendency to (1) undergo hut-cracking. (2) develop porosity in the weld fusion zone, and (3) undergo abnornal grain growth. In additivil, it has a ductile-to-brit:le transition temperature in lange-grained microstructures (such as occur in the heac-affected or fusion zones of a weld) well above room temperature, which tan easily cause fracture : it ambient temperature. This latter characteristic makes handling of welded components, such as during subsequent assembly steps, quite difficult. Consideration was given in the selection of the base material and in the design and fabrication phases of the program to ways to overcome or at least minimize thase characteristics. The selection of arc-cast molybdenum with low impurity element levels was significant to the welding development portion of the program. Low impurity levels are very desirable for this metal (especialy $\mathrm{O}, \mathrm{N}$, and C) since ssmall amounts of t'rese elements have been shown to have adveise effects on the ductile-brittle transitiun temperature and weldability of arc-cast molybdenum. ${ }^{11-13}$ Oxygen is especially detrimental, as it forms low-melting eutectic films with molybdenum, and the presence of these films at grain boundaries can cause hot-cracking in welds. Molybdenum produced by powder metallurgy techniques was not considered for the test stand because welds in commercially avaiiabie materials of this type have repeatedly been frund to contain large amoun's of porosity. ${ }^{14}$ Therefore, ine seleciiun of low-carbon, low-oxygen arc-cast base material helped to minimize swo of the detrime:ttal factors in welding molybdenum, namely, hot-cracking and porosity formation. Great care was a! so taken in all subsequent operations to ensure that these

11. T. Perry. H. S. Spacil. and J. Wulff, "Effect of Oxypen on Welding and Brazing Motybdenum." Welding J. 33(9), 442-5-448-s (1954).

12. W. N. Phatte. "Influence of Oxygen on Soundness and Ductility of Molybdenum Welds," Welding J. 35(8), $369-3 \cdot 381-5(1956)$.

13. V. N. Patte. "Effects of Nierogen on the Soundness and Ductility of Welds in Molybdenum," Welding J. 3646). 301-s- 306-3 (1957).

14. N. E. Weare and R. E. Monroe, Welding and Brozing of Molybdenum, DMIC Report 108, p. 3 (March 1959). 
ekements were not introduced into weldments by surface contamination or by an inpure welding almusphere.

In order to pissure that tise welús were not adversely affected by surface contamination. all components were ikaned using the portion: shown below of a compkex ikeaning procedure attributed to Ryan by Thompsion 15

1. Degrease with acetor.e.

2. Immerse for $5 \mathrm{~min}$ in a $6580^{\mathrm{c}} \mathrm{C}$ solution of $10 \mathrm{wt} z$ sodium hydroxide. 5 wi $q$ potassium permanganale. and 85 wi $\%$ distitted water.

3. Rinse in flowing tap water. brushing to remove smut.

4. Immerse for $5.10 \mathrm{~min}$ in a room-temperature solution of $15 \mathrm{vol} \%$ sulfuric acid $\left(95-97 \% \mathrm{H}_{2} \mathrm{SO}_{4}\right), 15$ vel 7 hydrochloric acid ( $37-38 \%$ HCl). 70 vol $\%$ distilled water. plus $6-10$ wt $\%$ chromium trioxide $\left(\mathrm{CrO}_{3}\right)$.

5. Rinse in tap water.

6. Rinse in distilled water.

7. Dry with hot air.

Aithough we did not find any correlation (as far as leak-tight welds were concerned) with the time between cleaning and welding. when parts had been excessively handled after the initial cleaning. we did take the precaution of repeating steps 1 and 4- 7 of the procedure just prior to welding.

After chemical cleaning. all parts used were given a vacuum stress-relief treatment for $60 \mathrm{~min}$ at 875 to $900^{\circ} \mathrm{C}$ at a pressure of $5 \times 10^{-5} \mathrm{~mm} \mathrm{Hg}$ or less. In cur preliminary work, we found tat a stress-relief heat tieatment had a major effect on the weldability of the various forms of molybdenum. For example, one haif of a length of $3 / 8-1 n$.OD, 0.025-in.-wall tubing was cleaned as previously described and then stress relieved in vacuum for $60 \mathrm{~min}$ at $875^{\circ} \mathrm{C}$. The other half of the tube was chemicaily cleaned only. In a series of bead-on-tube "field" welds on these two pieces by the orbiting gas tungsten-arc process, we found that the welds on the cleaned and stress-relieved tube were crack-free. while those on the "cleaned only" tube had extensive center-line cracking. Similar results rccurrec on other sizes of tubing and on back-extruded half sections. We tried several other stress-relief teingeratures to determine the lowest temperature that would produce the desired improvement in weldability and a! the same time have the kast effect on base-metal ductility duc to recrystallization. A temperature of $875 \mathrm{tc}, 900^{\circ} \mathrm{C}$ was apparently optimum from a weldability standpoint for these components. and it had little effect on the base-metal microstructure, as shown by Fig. 10. The combiriation of the chemical and thermal treatments left the components with surfaces that were lighter gray in color than in the as-received condition. and there was no noticeable grain-boundary attack by the etchant.

We:ding procedure development. Procidures were developed fer welding three major joint types for the test stand. two of which are illustrated in Fig. 4. A "tube-to-header" type of joint was required in seven locations in which a line ierminated in he end of a back extruded half section. A joint which we refer to as a "cylindricai girth" joint was welded to attach pairs of half sections together to form the four vessels or pots. Many welds of the "tube-to-tube" type were required to attach various lines to stubs projecling from the pots or to one of the six tees. Fach of these joint types will be discussed separately below.

15. E. G. Thompson, "Welding of Reactive and Refractory Metals," Welding Rerearch Council Bulletin 85. p. 7 (February 1963). 


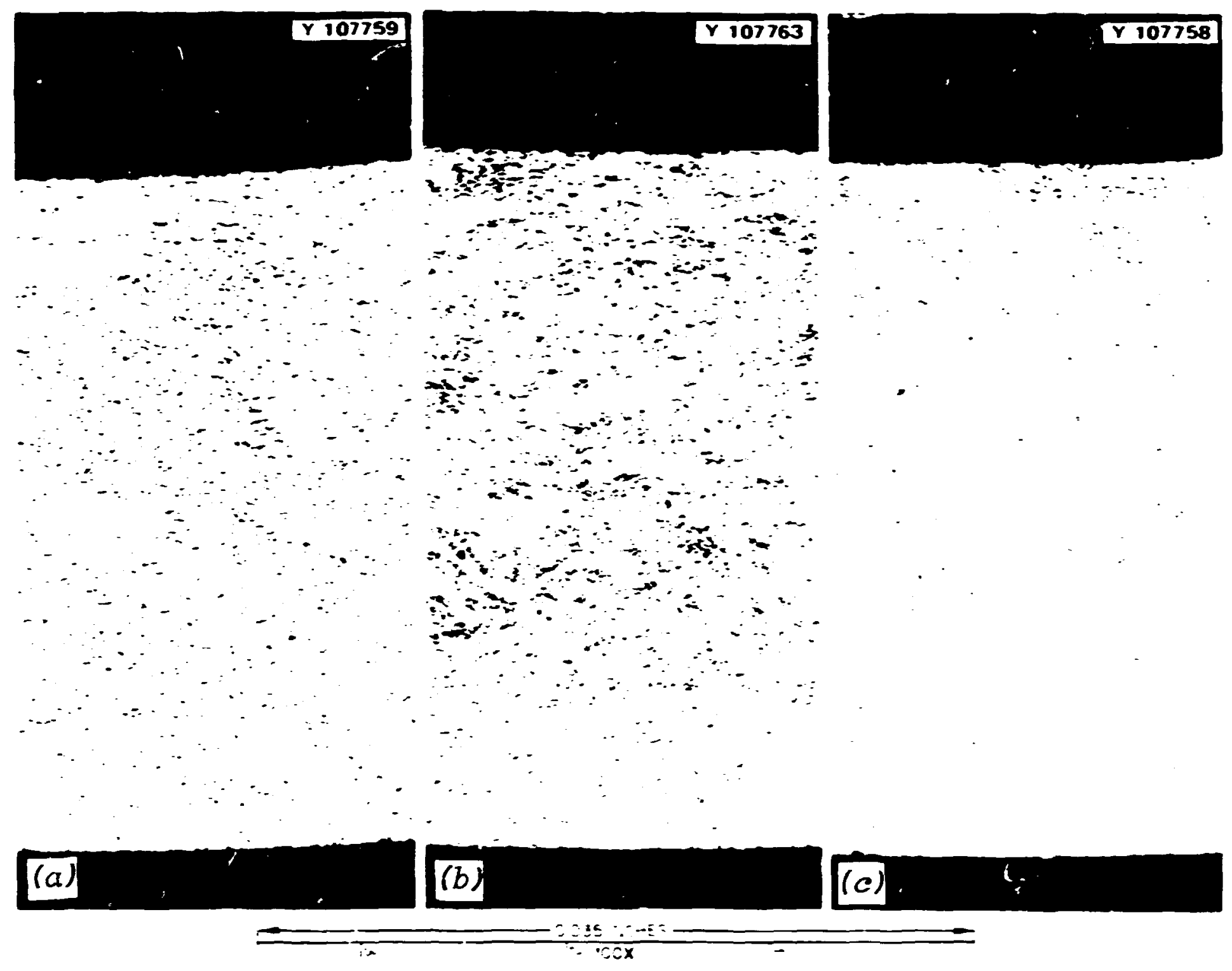

Fis 10. Effect of heat treatment (in vacuum) on the microstructure of $1 / 2$-in.-0D. 0.030-in.-wall molysdemum tubing Elchant: 50 vol '; $\mathrm{H}_{2} \mathrm{O}_{2} \cdot 50 \mathrm{vol} ' ; \mathrm{NH}_{i} \mathrm{OH}$. (a) As receivet. DPH $241:(h) 60 \mathrm{~min}$ at $900^{\circ}($. DPH $23 n:(c) 60 \mathrm{~min}$ at $925^{\circ} \mathrm{C}$. DPH 206.

Tube-to-header joint. There are seven major tube-tu-header joints in :he test s'and. Four join 0.875-in.-OD. 0.080-in.-wall tubing (which is machined to 0.050-in. wall in the joint area) to the feed pots: iwo attaih 1.1 25-in.-OD. 0.060-in.-wall. 7.25-in.-Iong stubs of the packed column to the disengaging pots: and the seven:h attackes a 5.25-in.-Iong machined tube (with a $1 / 2$-in.-diam section at the weld) to the upper disengaging pot. There are also oiher miscellaneous joints of this type in the stand: for example, it was used in attaching the weirs io the heriaontal baffle plates shown in Fig. 11.

To facilitate making this type of weld between the massive bosses on the extruded half sections and the. relatively thin-walled tube. a groove or trepan was machined inside the pot around the hole to producio a corner-fla ige joint, as previously illustrated in Fig. 4. This design provides a good heat balance between the two components and excellent mechanical support for the weld. Its major drawbacks are that it is relatively inaccessible for welding or nondestructive examination. The use of the electron-beam process overcomes the accessibility problen for weiding. and has the added benefit that it minimizes aborormal grain growth in the fusion zone because it is a process with a high energy density and a low total energy input. Because this type of joint is difficult to inspect by radiography or ultrasound, we relied on close parameter control. fluorescent dye penetrant inspection. and/or helium leak detection as our quality assurance techniques for these welds. 


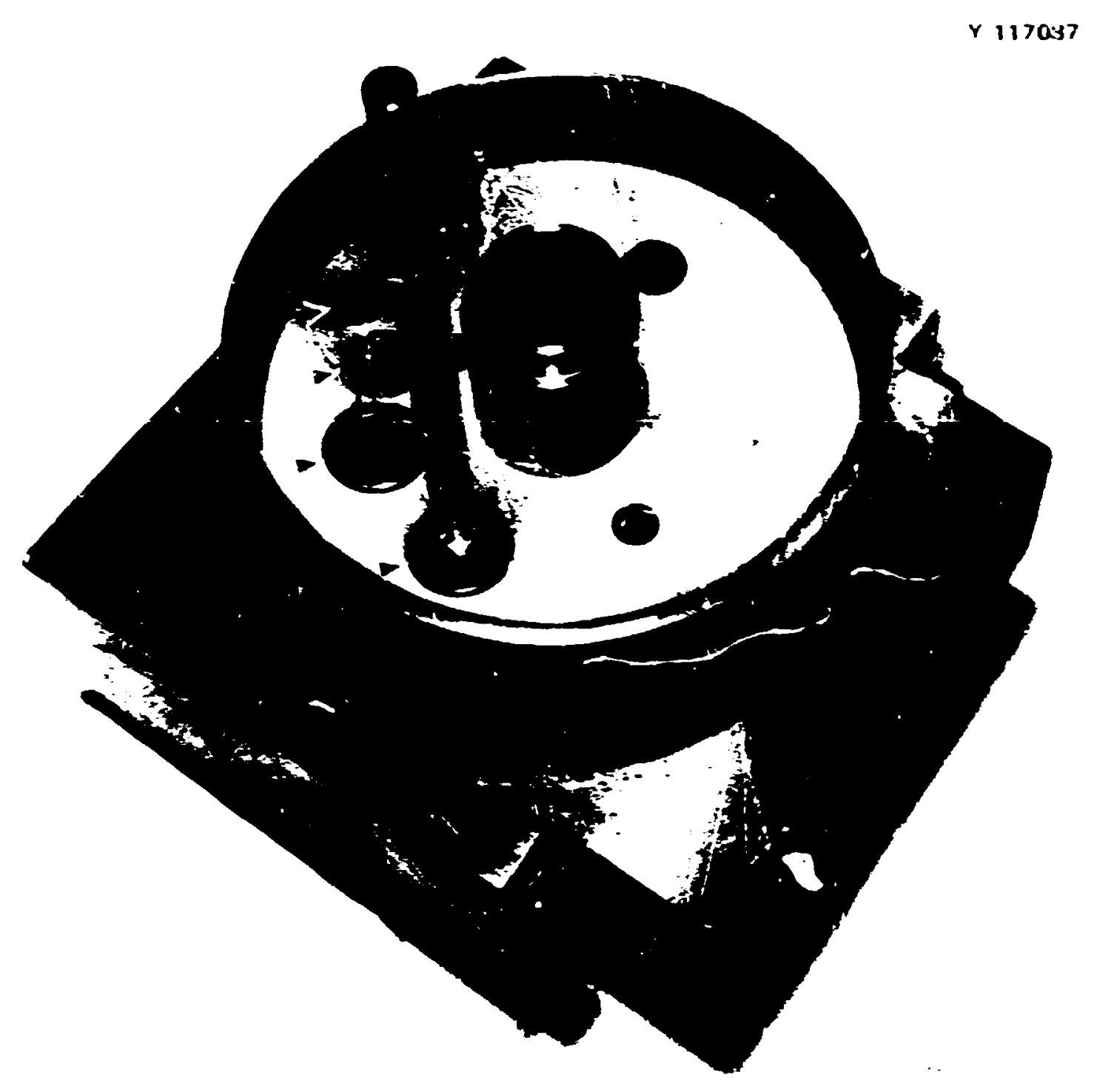

Fig 11. Weirs electron-beam: welded (at arrowheads) to one of the bafine plates showil installed in the upper half of the bismuth feed pot.

Procedures were developed for electron-beam welding tube-to-header joints in tube sizes of $1 / 4,3 / 8.1 / 2$. $7 / 8$. and $1 \frac{1 / 8}{8}$ in. outside dianeter. The parameters for welding all of these sizes of tubing are given in Appendix B. and an example of these two welds is shown in Fig. 12. The eleciron-beam welder used is of the high-voltage, low-current type ( $50 \mathrm{kV}, 0.040 \mathrm{~A}$ max) with a chamber 36 in. wide. 23 in. deep. and 24 in. high. In our preliminary welds, in which that plates simulated tlie vessel ends. we made uelds both by the conventional method of rotating the work under the ceam and by using a simple system for manually rotating the beam in a circle (up $105 / \mathrm{s}$ in. in diameter) on the workpicc:. Although we made acceptable welds using both techniques. we had greater difficulties in making reproducible welds with the rotating-beam technique: so all subsequent prototype welds were made by rotating the joint rather than the beam. This iatter technique was soinewhat complicated for the two vent tube joints, which were located away from the center line of the pot. as seen in Fig. 13. However. this, was compensated for by a simple fixture with cross licies for centering the weld under the beam. A close-up of a 0.375 -in.-diam tube-to-header weld is shown in Fig. 14, and a phocomicrograph of a helium leak-tight weld joining a 1.125-in.-OD, 0.060-in.-wall tube to a back-extruded molybdenum hieader is show'n in Fig. 15. 


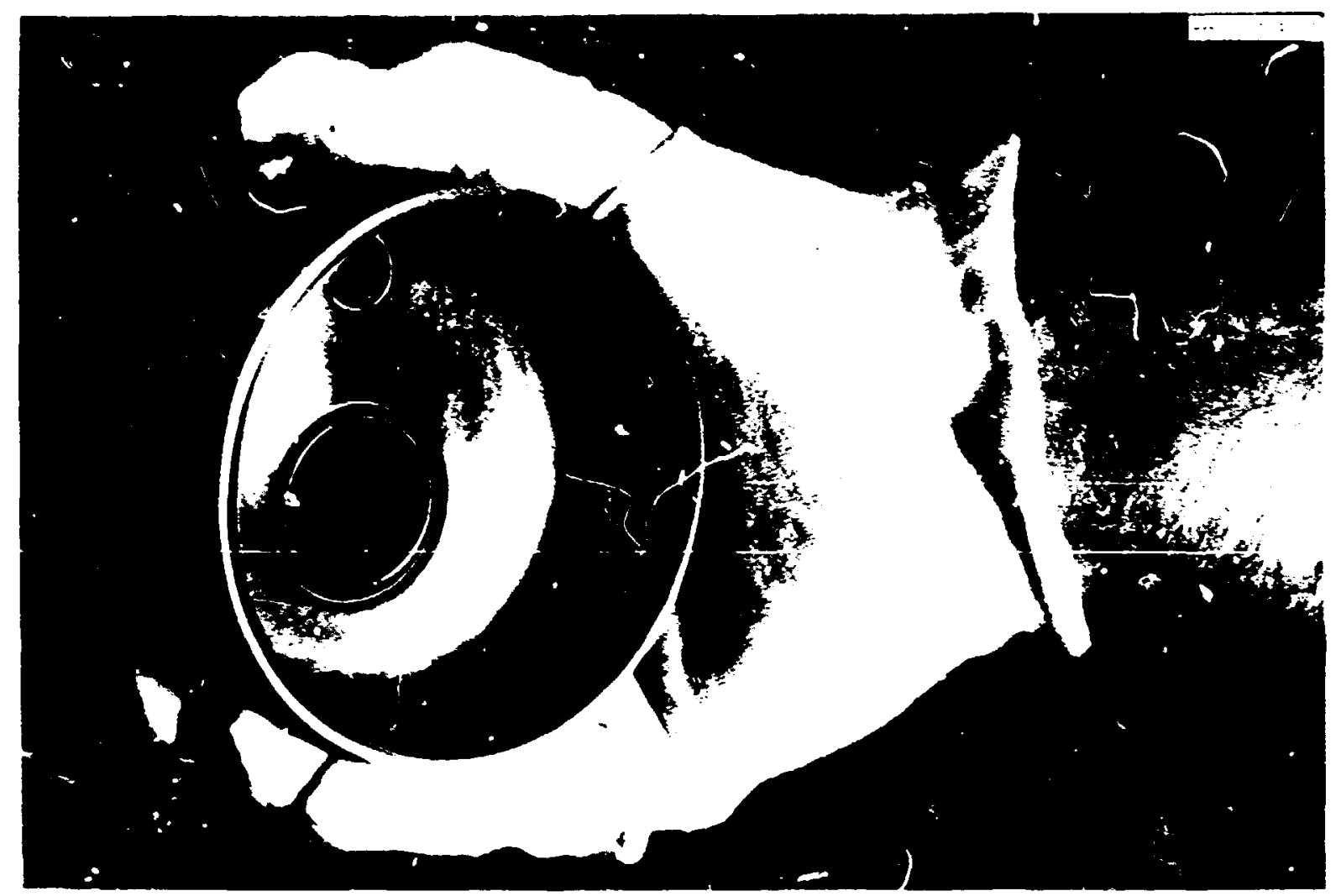

Fig. 12. Ra:kextruded half section with (wo tube-to-header welds made by the electron-beam process.

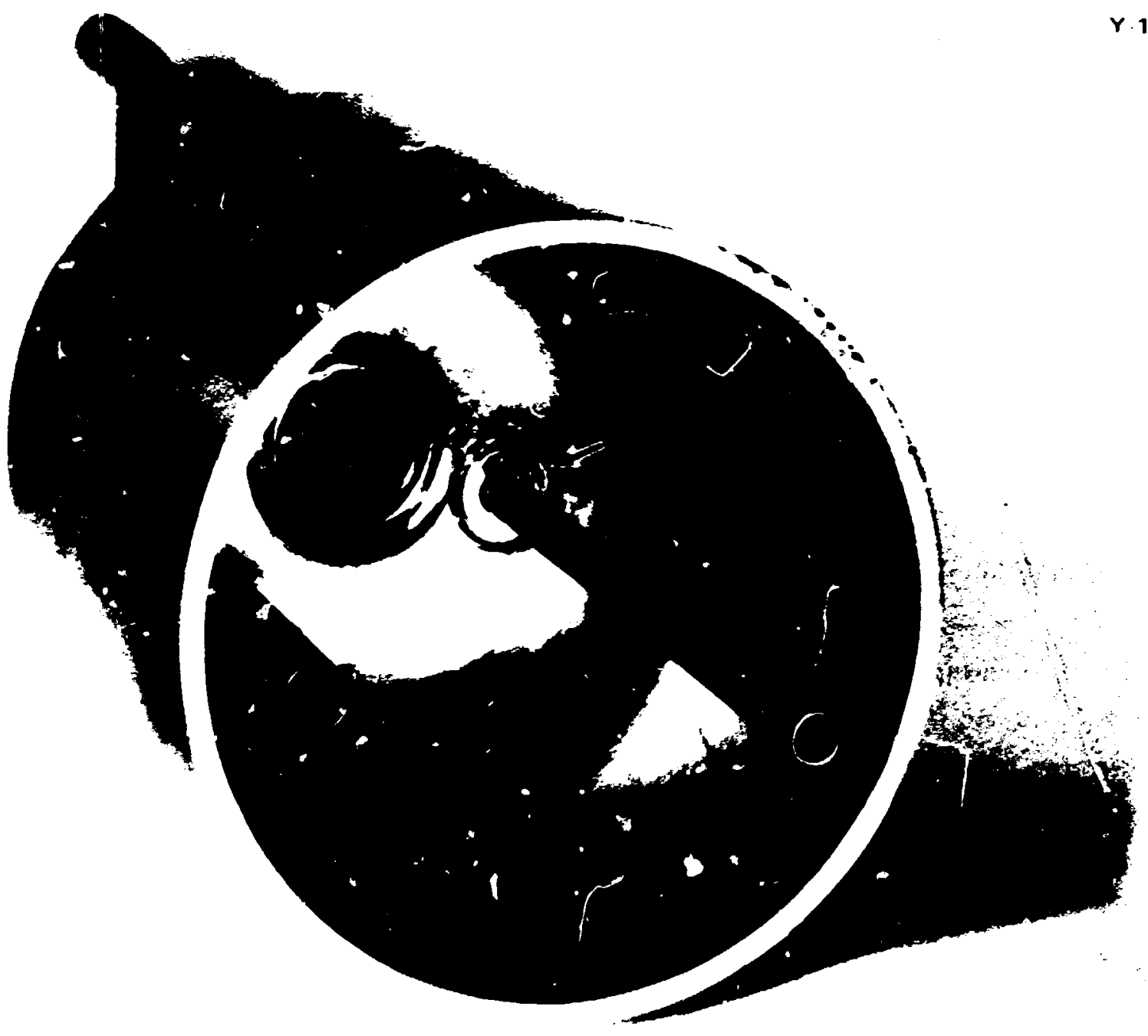

Y.111689

Fig. 13. Off-centered vent tube weld (arrow) liade by welding a "washer" to the tube and then welding the washer to a lip in ihe feed pot bottom. 


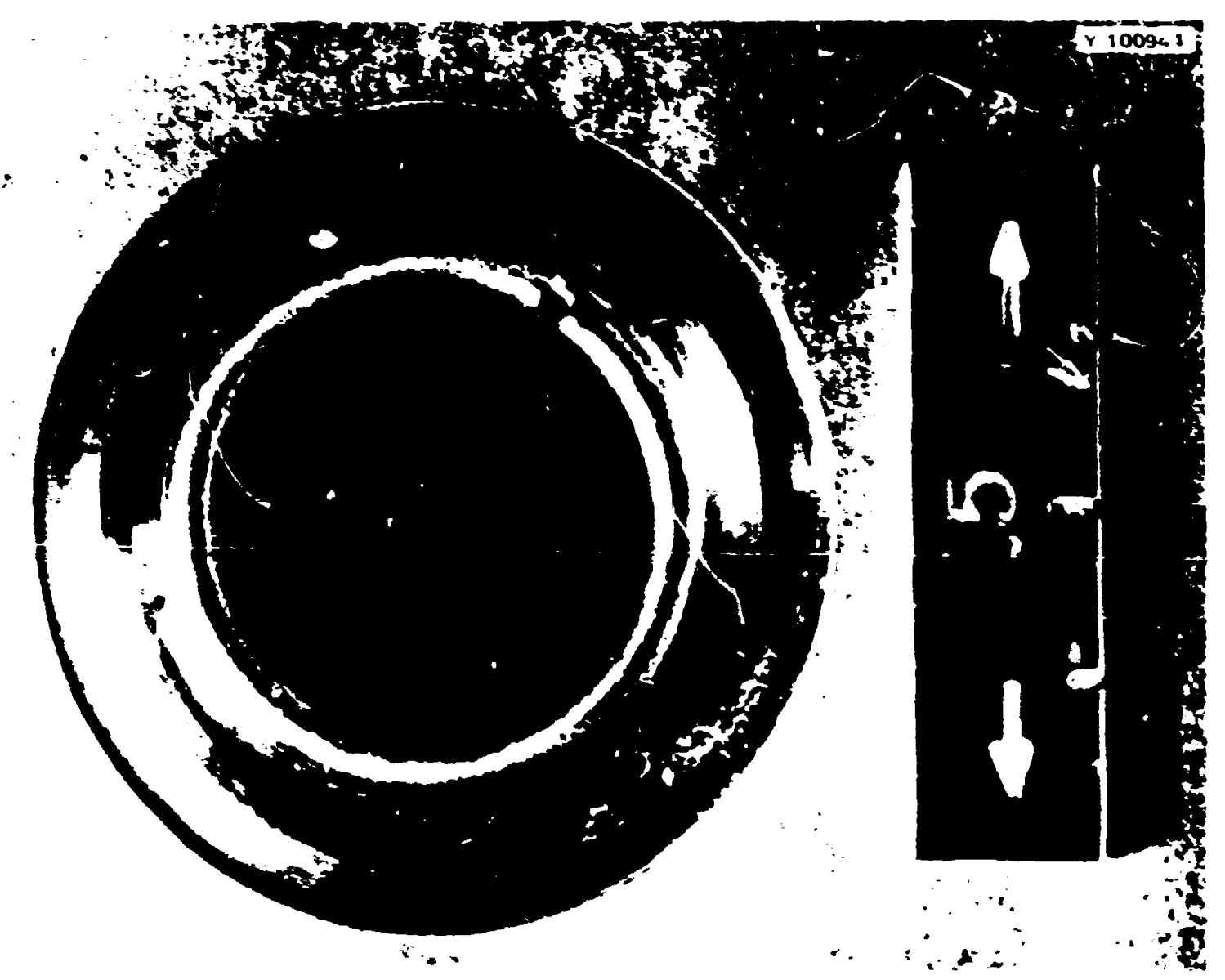

Fig. 14. Close-up of a $3 / g$-in-diam tube-to-header weld, showing the machined trepan.

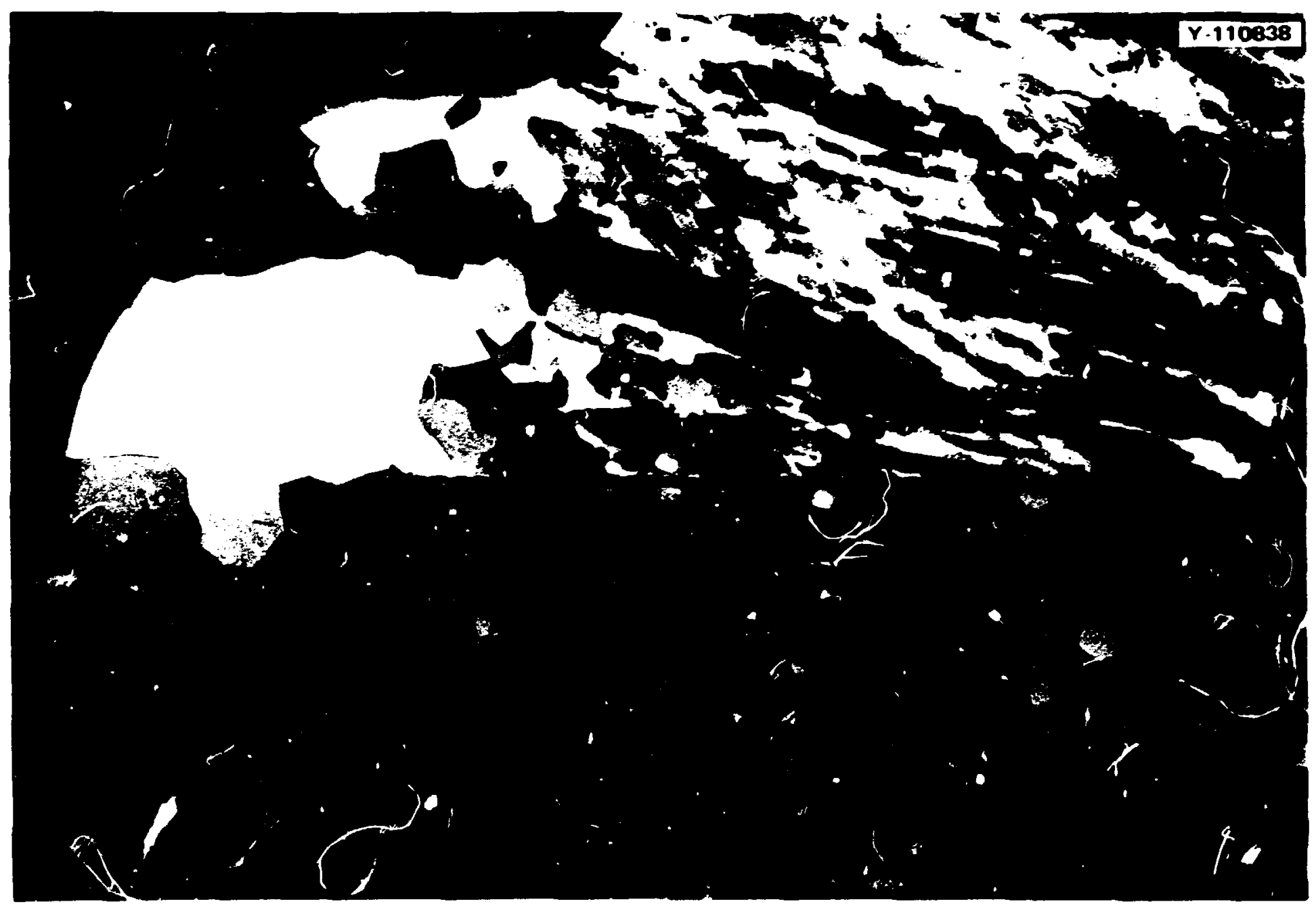

Fig 15. Cross secition through a weld joining a 1.125-in.-OD tube to a has section. Etchant: 20 vol \% $\mathrm{H}_{2} \mathrm{O}_{2}-10$ vol $\%$ $\mathrm{H}_{2} \mathrm{SO}_{4}\left(96 \% \mathrm{H}_{2} \mathrm{SO}_{4}\right)-7 \mathrm{C}: 2 . \% \mathrm{H}_{2} \mathrm{O} .29 \mathrm{x}$. 


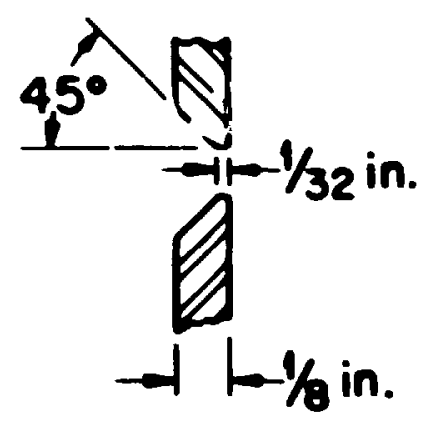

Fig 1. . Joint design used for connecting back-extruded half sections by the gas tungsten-arc process A run: opening of $1 / 8$ in. was typically used.

PHOTO 1942.71
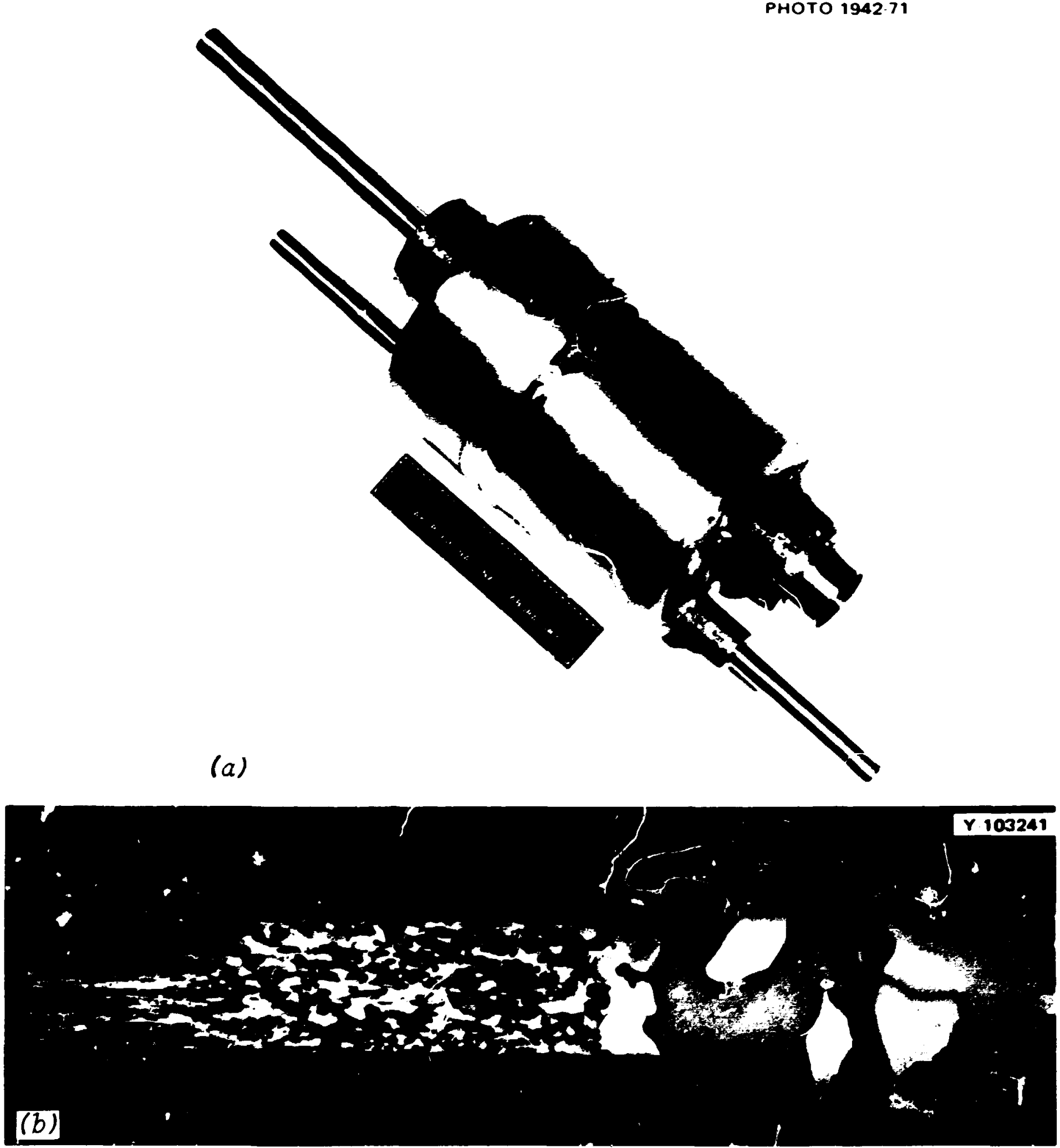

Fig 17. Manua! gas tungsten-arc wed joining back-extruded molybdenum half sections. (a) ('ompleted posi. (h) ('ross

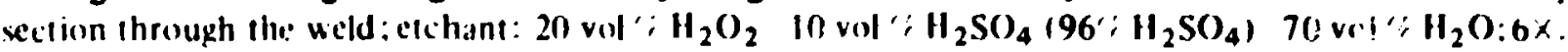




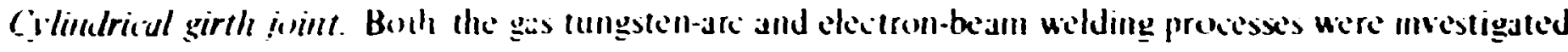
for the welds reguired to join two half sections to torm eath of the four vessels. The joint design used for the gas thensten-are welds is shovin in irg. 10. The lungsten-are welds were made manually in a vacuuntpurged. argon-bakfilled glowe sox. This chamber lias the bask dimensions of 36 in. in inside diamker and 50 in. in kength, but with available extensions the kengih ën be increased to over $12 \mathrm{ft}$. The cliamber was evacilated to a pressure of $5 \times 10^{-5} \mathrm{~mm}$ Hg or kess prior to backtilling with argon of $\left(99.947^{\prime}\right.$ minimum purity by volume. Filler metal was 0.060-in.-diam lew earbon. lovoxygen molybdenum wire prepared commercially from cast stock. The electrode was $2 \%$ thoriated tungs:en. 1/8 in. in lial..ster. Sto auxiliary preleating was required for the gas tungsten-are welds. Evidently the high conductivity of the moly bdenum piomutes a rapid distribution of heat throughout :he parts (i.e.. preleat:) before the lusion temperature is reached at the joint. A photograph of one of the gas tungstent-are eylindrical girth welds (which had a helium leak late less than $1 \times 10^{-8} \mathrm{~atm}^{3} \mathrm{~cm}^{3} \mathrm{sic}^{-1}$ ) and a cross section through it are shown in Fig. 17. Note that althongl! : !is weldment has undergone abnormal grain growth. radiugraphically there was no evidente of porosity. and only two small cracks $(0 n$ the inner surface in the heat-aflected ae:e) were detecied by iluorescent penetrant inspection.

Electron beam girth welds were made wising the rotary hixture shown in Fig. 18. A general requirement for welding with the piocess. if filler inetal is sot added. is that the joint must be held tightly together so that oalcsience will ociur and so that the resulting weld bead will not be underfilled. The harmful effecis of an underfilled. conceave weld bead are especially pronounced in crack-sensitive materials such as

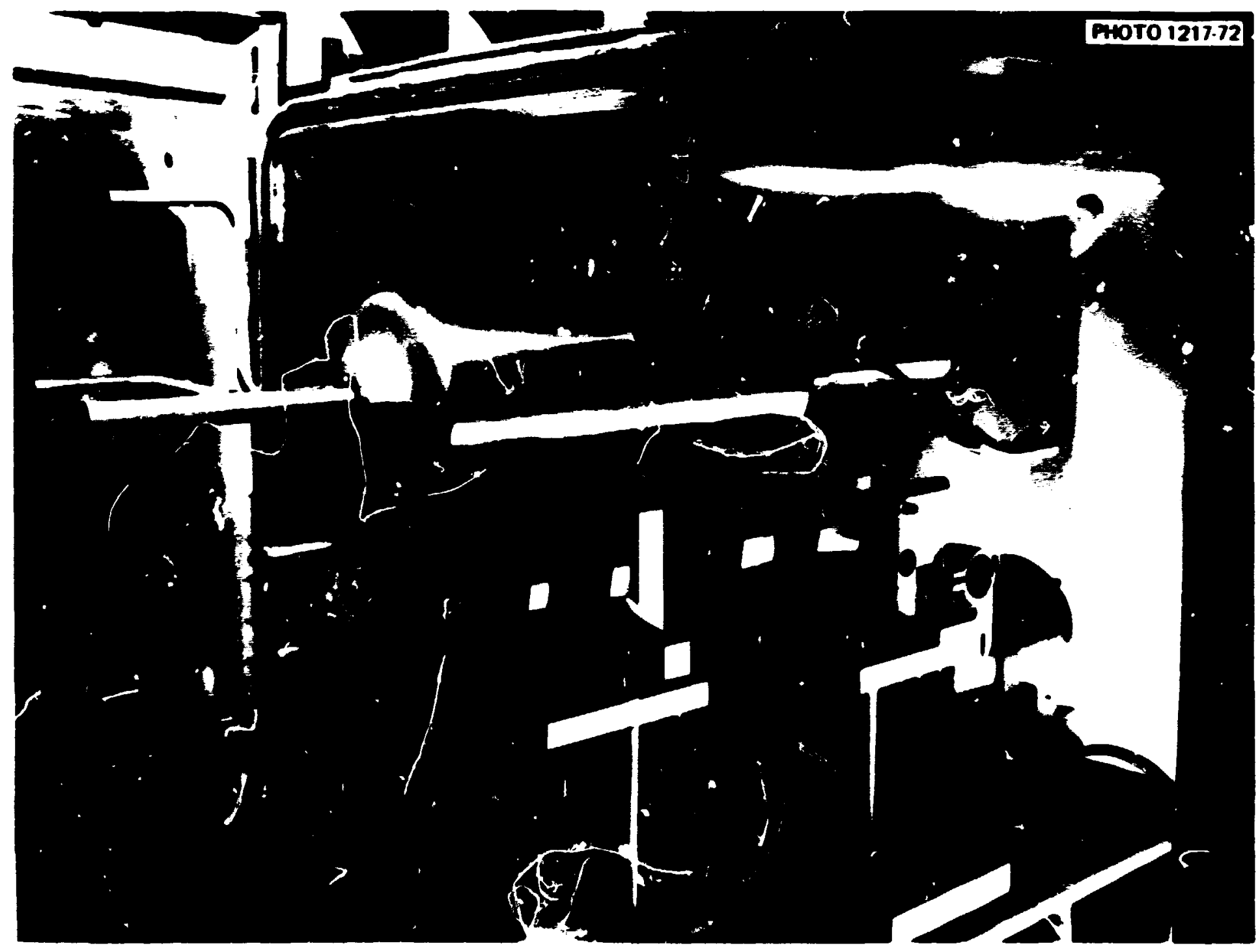

Fi. 18. Molybdenum pot formed by an eketron-beam gith weld joinng two back-extruded hall secions. 
molybdenum. Unfurtunately. the complex geometry of the vessel half section: . with their protruaing tubes and internal bathe platis. made the application of end loading by conventiona' means (such as external pots or internal rods) quite dititicult. To overcome this problem, a technique uas developed in which three 0.032-in.-diam molybdenum pins througin the step joint were used to hold the halves in intimate contact during welding. These pins were subsequently fused into the weld.

Parameters for joining molybdenum vessel half sections using the electron-beam provess are listed below. The welds were made using a self-acielerating triode desigi electron gun (5-32). Manual beam currellt downslope was used at the end of the weld to prevent crater formation.

1. Joint type - step (illustrated in Fig. 4).

2. Joint thickness 0.094 in.

3. Accelerating potential $-150 \mathrm{kV}$.

4. Beam current $12 \mathrm{~mA}$ preheat and $25 \mathrm{~mA}$ weld.

5. Number of ra. lutions 6 for preheat $(2$ preheat passes on either side of and $I$ in. away front the joint. and then 2 passes on the joint itself) and $1 \frac{1}{4}$ for weld.

6. Traval speed - $32 \mathrm{in.} / \mathrm{min}$.

7. Focus - 0.015 A defocus.

8. Work dista 7 ce -4 in.

Note that in :'its procedure, extensive preheating was carried out with the defocused beam prior to welding. A photomicrograph of a cross seition through a preliminary electron-beam girth weld in which peitetration through the step was not achieved is shown in Fig. 19.

Tube-to-iuót Rutt Joint. Tube-to-tube welds joining five sizes of molybdenum tubes were successfully made in an argon-filled glove box by the gas tungsten-arc process both manually and ising an autumatic orbiting-arc technique. Using either technique, we were readily able to produce we:ds that were helium leak-tight and that had little or no porosity as shown by radiographic and metallographic examination.

However, the orbiting-arc technique was of particular interest after we found that our welders had considerable difficulty in making manual butt welds in thin-walled molybdenum tubing without excessive root reinforcement and withoit misalignment. These problems were compounded by the necessity of making the we'ds in a glove box, which reduces the senses of sight and touch. Several commercial orbiting-arc weld heads were evaluated, ircluding the head shown in Fig. 20. In this unit the tungsten electrode is carried aronnd the tube (which rcmains stationary) by a copper ring, which also holds a set of boron nitride gas cups. Inert gas is fed through the handle to provide an atmosphere suitable for welding in the cavity formed by the cups and body housing. The electrode carrier is rotated $b_{5}$ a small dc motor (with tachometer feedback) in the handle. The tubes are held together and in alignment by a pair of clamshell clamps, which have removable inserts in adapt to the various tubing sizes. In order to further reduce any stresses applied to the weld (such as by tube misalignment), we used several sizes of auxiliary yoke-typi fixtures ouiside the weld head clamps, such as the one shown in Fig. 21. Devices of this type are invaluable, as molybdenum weldments are highly susceptible to cracking under the influence of even small stresses. The $1 / 4,3 / 8$, and $1 / 2$-in.-diam tute-to-tube welds were made using a magnetic amplifier power supply with capabilities for programming both variations in the welding current and in the rotational speed of the orbiting electrode carrier. The $7 / 8$ - and $11 / 8$-in.-diam tube-to-tube welds were made with another programmable power supply, but we did not have a power supply available for varying the speed of the stepping motor in the orbiting-arc head used for the larger sizes of tubing. 


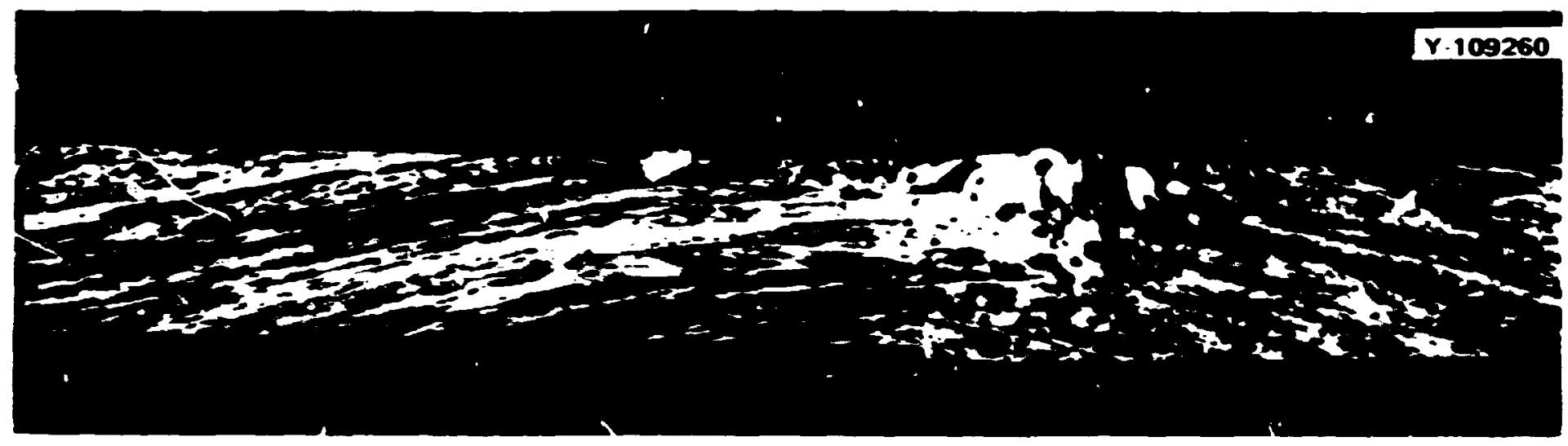

Fis 19. Cross section throogt electronberm cyliadrical ginth weld stown in Fis. 18 . Elctant: 20 vol $\% \mathrm{H}_{2} \mathrm{O}_{2}-10$ vol

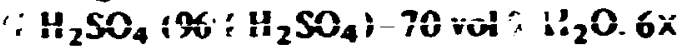

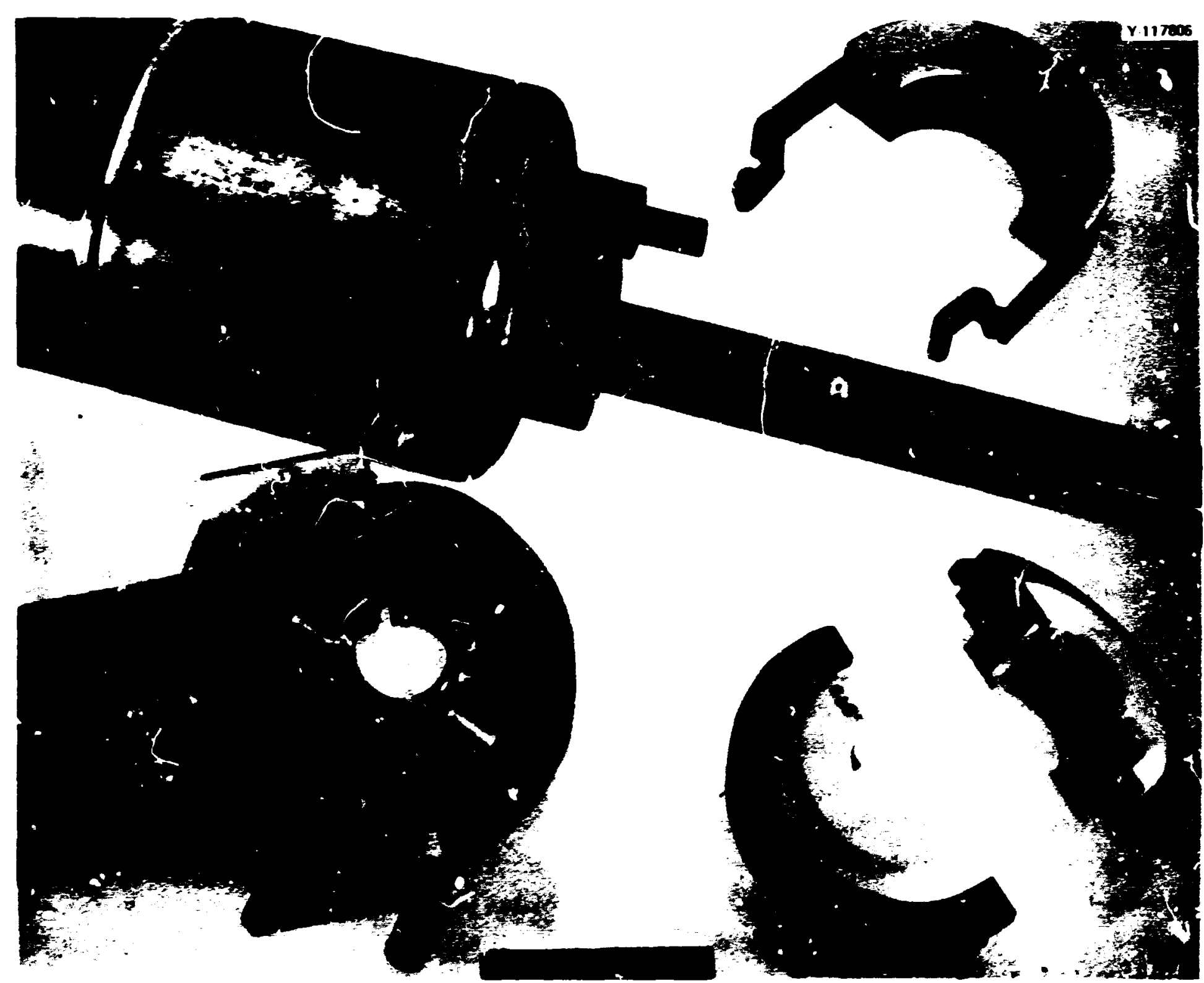

Fi. 20. Orbitingarc weld head and $7 / 8$-in.diam sobeto-tubi batt weld.

Figure 21 :!r shows a fealur: which we added to the orbiting-arc head to permit us to make molybdenum welds outside the con.inement of a glove bcx: noided rubber sleeves which seal tightly around the head and the tubes. Witt ou: these sleeves we were unable to make crack-free welds outside the inert gas chamber (i.e., in the "field"), whereas with the shoeres we were able to make helium leak-tight welds in the $1 / 4-, 1 / 3-$, and $1 / 2$-in.-diam tubes. However, the results were not as reproducible with the field 


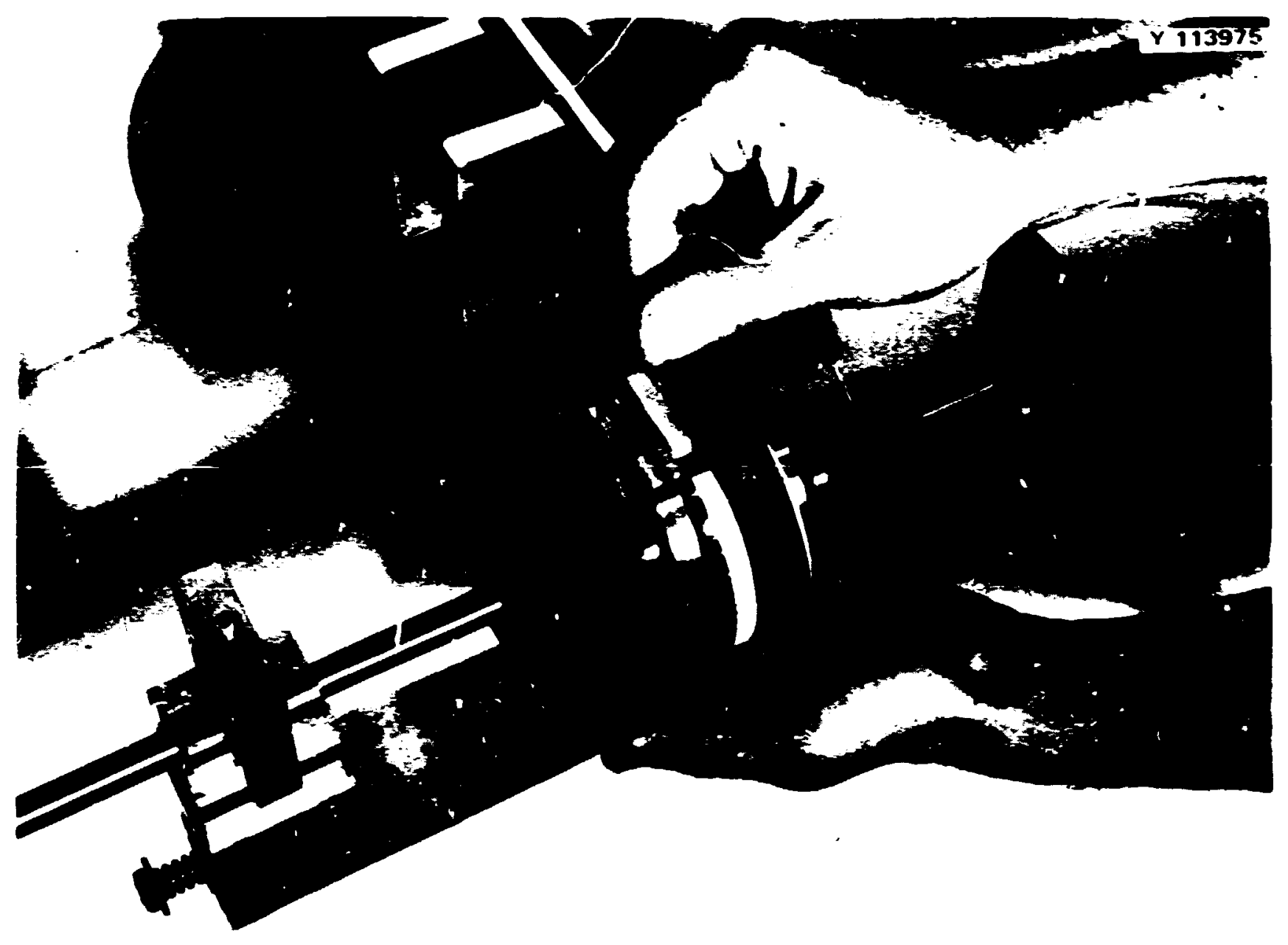

Fi. 21. Orbiting-arc weld head with aitached nubber sleves for welding molybdemm thbing ontside a glove box with yoke-type faxture.

welding technique as with the orbiting-arc unit inside the glove box. Therefore we controlled our assembly procedure and sequence so that a minimum of field welds would be required in construction of the test stand, as exploined later in this report.

Weld inserts (such as the one shown in Fig. 22 between two tees) were used in the orbiting-arc welds to aid in controlling root reinforcement and joint misalignment. Because ir prctrudes slightly above the tube surface, it has the additional function of providing a small amount of filler metal for the joint. thus producing convex weld beads, which we have found to be less prone io cracting than concave bearls.

The parameters for butt welding the tui:ng are given in Appendix $C$. The important features of the welding cycles are the relatively long portion at a lower "initial current," which provides preheating without fusion of the joint: and the gradual increase in rotational speed (in the cycles for the $1 / 4-3 / 8-$ and $1 / 2$-in.-diam tubes), which minimizes "weld-bead-widening" that occurs in tube welds as the overlap portion is approached. A cross section through a tspical tube-to-tube butt weld made with the orbiting-arc process is shown in Fig. 23. 

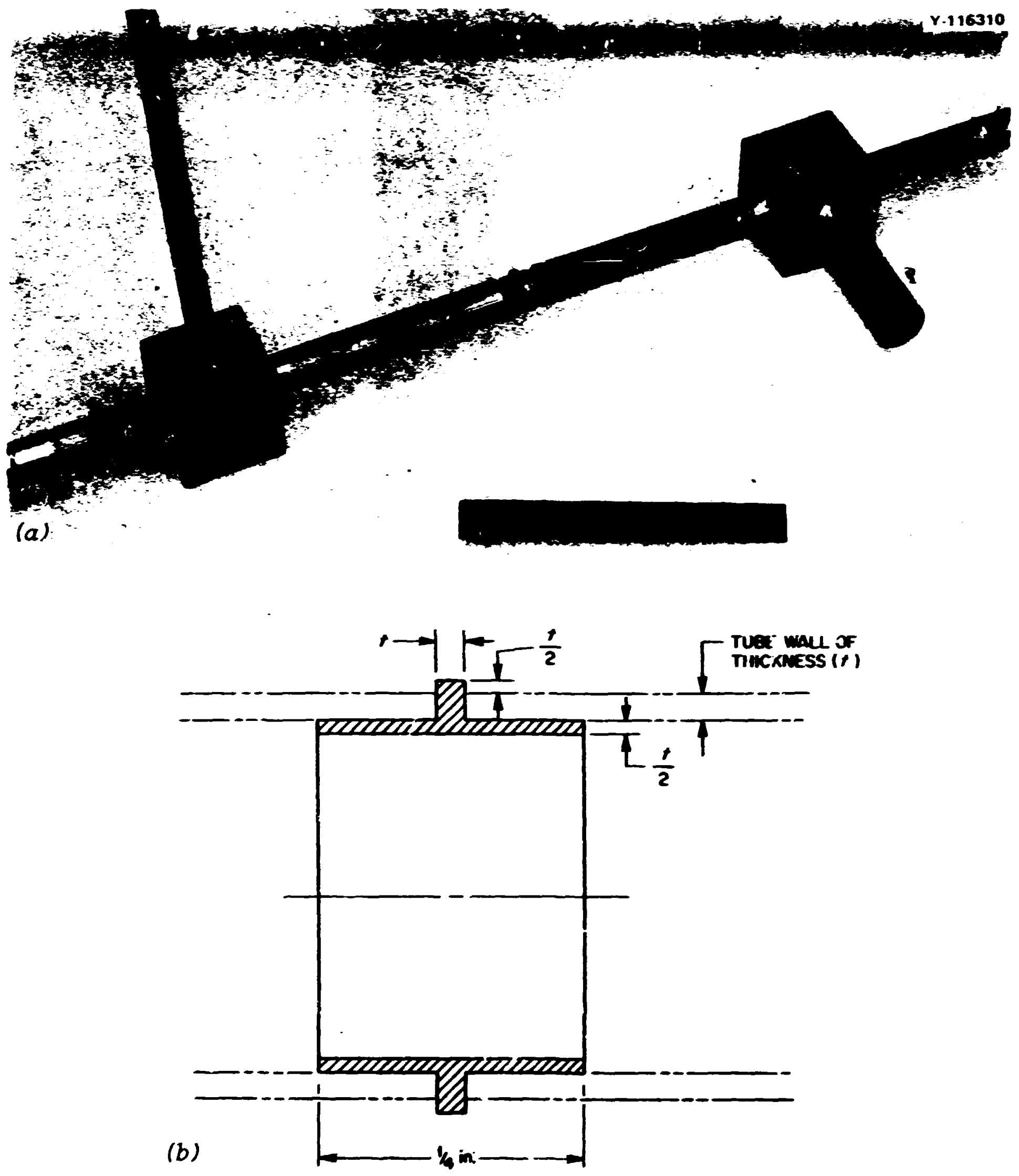

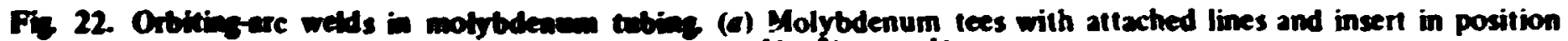
prior to assembly for welding. (b) Design of typica! insert for $1 / 4-$, $1 / 2-$ and $1 / 2$-in.-OD tube-10-1ube welds. 


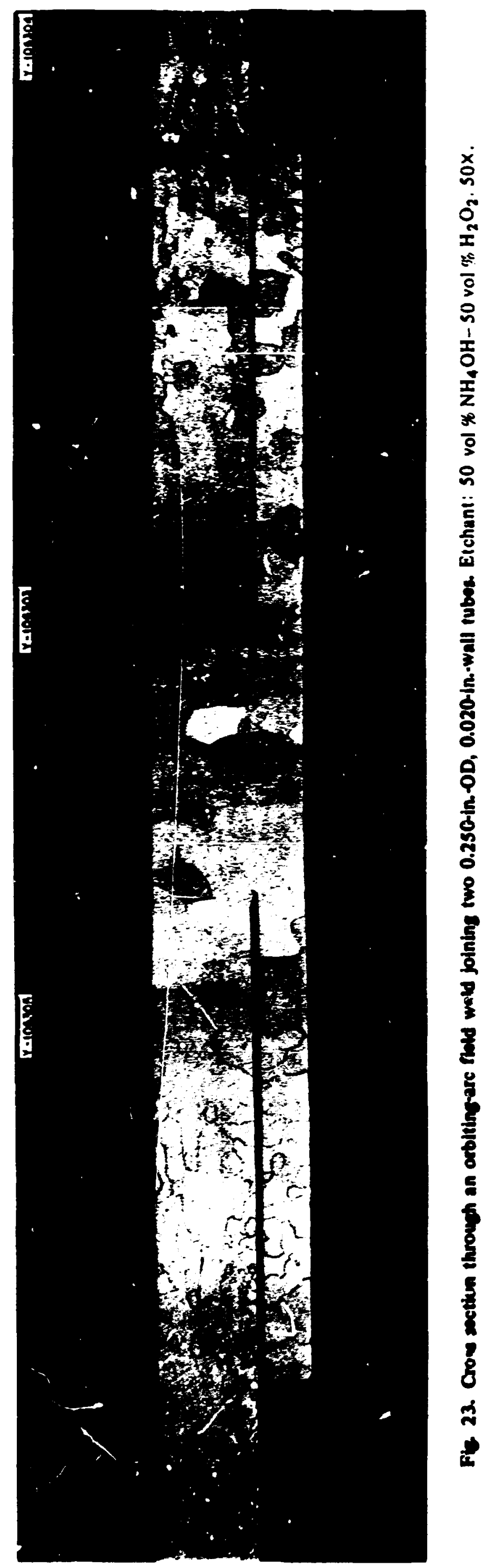


Brazing

N. C. Cole

Filler metal development. In building compkx structures from ،lloly bdenum, bra/ing is attractlv: fron: two standpoinis: (1) as a replakement for brittle welds and (2) as a reinforcement for welds. But to avoid severe loss of ductility to he base metal, the filler metal must flow below i $200^{\circ} \mathrm{C}$.

Several commercial brazing filler metals will braze molybdenum, but they are rich in such metals as nickel. copper, silver. or gold, which are not corrosion resistant to molten bismuth at $700^{\circ} \mathrm{C}$. In addition. silver is not resistant to corrosion by molten fluoride solts. Unfortunately. few materials at:quately resist attack by bismuth. The refractory metals. such as mulybdenuin. tantalum. rhenium. and tungsten. possess the best resstance; however. it is difficul! to depress the melting point of a refractory-metal-based alloy below $1200^{\circ} \mathrm{C}$ without completely sacrificing its corrosion resistance by the adaition . ? large amuunts of alloying elements.

Under certain conditions. iron and some of its alloys are reasunably compatible with bismuth. By alloying iron with smill anounts of selected elements. we were able to depress the melting point of iron-based filler metals to below $1200^{\circ} \mathrm{C}$. Figur: $24 a$ shows portions of the binary diagrams:6.17 of Fe-C. Fe-B. and B-C. The diagrams show that $I$ to $4 \% \mathrm{~K}$ or $\mathrm{C}$ added to $\mathrm{Fe}$ depresses its melting point significantly. By adding smill per:entages of buth boron and carbon to iron, we were able to depress the melting point below $1150^{\circ} \mathrm{C}$. We also felt that the addition of molybdenum to the filler metal would enhanie its corrosion resistance to bismuth and minimize dissolution of the molybdenum base metal during brazing. Even with the addition of molybdenum. we fourd we could still keep the melting point of the alloy below $1200^{\circ} \mathrm{C}$. Figure $24 b$ shows the binary phase diagrams: 6 of Fe-Mo, Fe-B, and Mo-B. Since the tempeitures of the liquidus and solidus of the Fe-Mo diagram decrease as the molybdenum content increases from 0 to $35 \%$. we were able to add as much as $25 \%$ Mo to the Fe-C-B ternary alloy without raising the melting temperature above $1175^{\circ} \mathrm{C}$. From various wettability and flowability sests we found that additions of $15 \%$ Mo. $4 \% \mathrm{C}$, and $1 \% \mathrm{~B}$ gave the optimum composition. In an attempt to further depress the melting temperature, we added small amounts of germanium. Adding $5 \%$ Ge depressed the melting point to $1050^{\circ} \mathrm{C}$ and, as a bonus, also improved flowability.

To determine mechanical properties of brazed joints made with these experimental filler metals, we shear-tested two of the most promising compositions. Miller.Peastee shear test spacimens 18.19 were brazed with alloys $\mathrm{Fe} 15 \% \mathrm{Mo}-5 \% \mathrm{Ge}-4 \% \mathrm{C}-1 \% \mathrm{~B}$ and $\mathrm{Fe}-15 \% \mathrm{Mo}-4 \% \mathrm{C}-1 \% \mathrm{~B}$. They were pulled with a tensile machine at a strain rate of $0.002 \mathrm{in} . / \mathrm{min}$ at both room temperature and $650^{\circ} \mathrm{C}$. Average test results are shown in Table 6. Room-temperature shear strengths of these alloys were greater than 30,000 psi. and these compare favorably with base-met-l shear strengths of abot: $45,000 \mathrm{psi}$. At $650^{\circ} \mathrm{C}$ the shear strengths of the joint brazed with Fe-Mo-Ge-C-B averaged 29,000 psi, whereas those with Fe-Mo-C-B were 18,001$)$ psi. This lower strs th is, however, more than ddequate for most applications. The ductilities of joints brazed with both brazing alloys were outstanding at $650^{\circ} \mathrm{C}$ (elongations of 42 and $50 \%$ ): and even at room temperature. where welded molybdenum is brittle. the elongations of the brazed joints were at least $10 \%$.

16. M. Hansen. Consstitution of Binary Alloys, 2d ed., McGraw-Hill. New York. 1958.

17. R. P. Eliol. Constitution of Binary Alloys. First Suppleiöen!, McGraw-Hill. New Yurk, 1965.

18. F. M. Miller and R. L. Peaslee. "Proposed Procedure for Testing Shear Strength of Brazed Jomts." Welding J. (.V.Y.) 37(4), 144-s 150-s ! 1953).

19. R. G. Gillitand and G. M. Slaughter. "The Development of Brazing Filler Metals for High Temperature Cervice." Wriding J. (N.Y.) 48(10). 463-s-468-s (1969). 

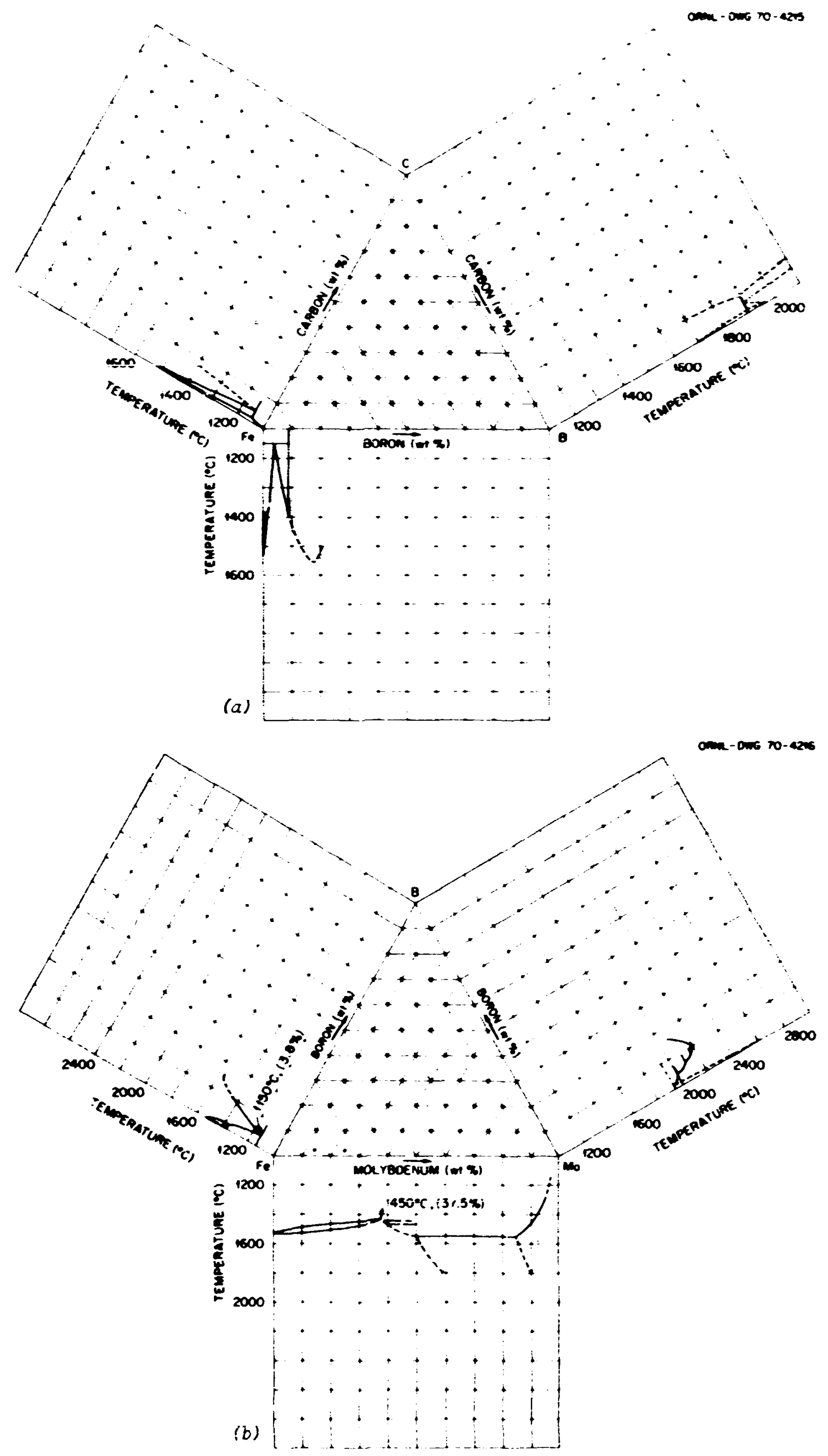

Fig. 24. Portions of binary diagrams used to select alloy compositions for brazing studies (a) Fe-C. Fec-:, B-(; (h) Fe-Ho, Fe-B. B-Mo. 
Table 6. Mechanical properties of braked moly bdenum joints

\begin{tabular}{|c|c|c|c|c|}
\hline \multirow[b]{2}{*}{$\begin{array}{c}\text { (umpusition of brazing alloy } \\
\text { (wt' 'i) }\end{array}$} & \multicolumn{2}{|c|}{ Shear strenpth (psi) } & \multicolumn{2}{|c|}{ Elongation ( i) } \\
\hline & $\begin{array}{l}\text { Room } \\
\text { temperature }\end{array}$ & $650 \mathrm{C}$ & $\begin{array}{c}\text { Room } \\
\text { temperature }\end{array}$ & $6500^{\circ}$ \\
\hline Ife - IS Mo 5 (ie $4 \mathrm{C}$ - B (42M) & 30,000 & 27,000 & 10 & so \\
\hline Fe - is Mo $4 C-1 B(35 M)$ & 31,000 & 18.100 & 11 & 42 \\
\hline
\end{tabular}

The experimentai brazing filler metals listed in Table 7 were tested in bismuth and fluoride salts at $700^{\circ} \mathrm{C}$. All brazes survived the fluoride salt therma! convection loop tests with no metallographically jetectabie corrosion anter $i \hat{0} 3 \mathbf{z} \mathrm{h}$. $A$ typicai exampie of the after-test appearance of th:se ailoys is shown in Fig. 25.

For chemical processing applications, compatibility of the braze specimens with bismuth was considered the most stringent requirement, since the solubility of pure iron in bismuth is $50 \mathrm{ppm}$ at $600^{\circ} \mathrm{C}$ and it is known to undergo temperature gradient mass transfer in liquid bismuth. ${ }^{20,21}$ Molybdenum tc-joint samples brazed with four of the iron-based filler metals (Tabie 7) were exposed to static bismuth for $671 \mathrm{hr}$ at $600^{\circ} \mathrm{C}$. The most extensive dissolutive attack occurred in the fillet area of the sample brazed with the $\mathrm{Fe}-4 \% \mathrm{C}-1 \% \mathrm{~B}$ alloy. The area between the vertical and horizontal areas of the tee was more resistant to attack, and electron beam microprobe analysis showed that this area contained $15 \% \mathrm{Mo}$, no doubt as a result of alloying during brazing. Furthermore, the specimens brazed with filler metals containing molybdenum were considerably more resistant to dissolution in the fillet areas.

Seven lap-joint specimens brazed with the four brazing filler metals were also exposed to flowing bismuth in a quartz thermal convection loop at 600 to $700^{\circ} \mathrm{C}$ for $2000 \mathrm{hr}$. All seven specimens were intact after testing. Three had been placed in the hot leg and four in the cold leg of the lonp. (The Fe-C-B braze was placed only in the cold leg.) Weight-change data were not obtained, since some bismuth adhered to the specimens after test. Chemical analyses of the bismuth drained from the loop indicated that the amounts of iron and molybdenum, if present, were below the limit of detection, $3 \mathrm{ppr}$. Metallographic examination indicated the presence of one or more layers on the surface of each of the braze fillets. Microprobe analyses showed that the outer layer was rich in iron and the layer immediaicly under it was rich in molybdenum.

20. A. J. Romaro, C. J. Klamut, and D. H. Gurinsky, The Investigation of Contoiner Materials for Bi and Pb Alloys. Part! Thermal Convection Loops, BNL-811. Brookhaven National Laboratory (July 1963).

21. B. R. T. Frost, C. C. Addison. A. Chil:y, G. A. Geach, P. Gross. J. A. James, G. J. Metcalfe, T. Raine, and H. A. Suluman, "Liquid Metal Fuel Technology," Proceedirizs of the Second United Nations International Conference on the Peaceful Uses of Alomic Energy. Genesa, 1958, 7, 139 ..65, United Nations, New York, 1958.

Table 7. Characteristics of experimental fither metals for braxing molybdenum

\begin{tabular}{lcll}
\hline Composition (wt \%) & $\begin{array}{c}\text { Brazing } \\
\text { tempersture } \\
\text { PC) }\end{array}$ & $\begin{array}{c}\text { Wettability } \\
\text { and } \\
\text { flowabilit; }\end{array}$ & Joint integrity \\
\hline Fe-4C-1 B & 1150 & Evor!.ent & Good \\
Fe-15 Mo-4 C-1 B & 1150 & Excellent & Good \\
Fe-25 Mo-4 C-1 B & 1175 & Excellent & (a) \\
Fi:-15 Mo-5 Ge-4 C-1 B & 1050 & Outstanding & Good \\
\hline- & & &
\end{tabular}

a Some tendency for cracking along base-metal-tra: e-metai interfac:. 

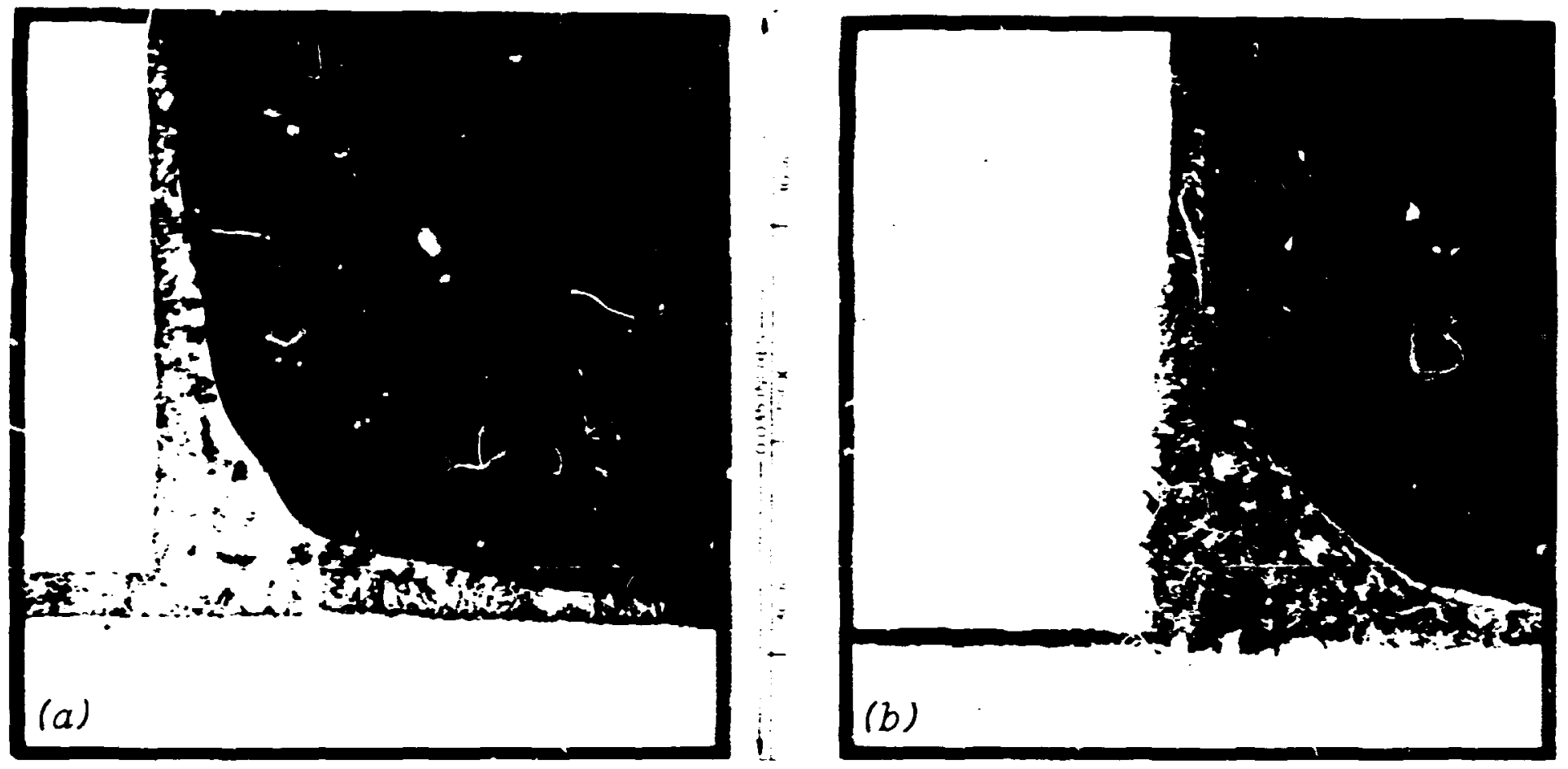

Fi. 25. Cross section of a molybdenum lap joint brazed with 35M (Fe-15\% Mo-4\% C-1\% B). (a) As brazed. (b) atter testing in fluoride salts at $700^{\circ} \mathrm{C}$ for $103^{\prime} \mathrm{hr}$.

Phases within the braze and along the interface between braze and base metal were also rich in molybdenum. Also, certain areas were enriched in bismuth, and it is interesting to note that shose crcas were associated with the regions of high molybdenum concentration. It appears that a complex intermetallic compound formed containing molybdenum, bismuth, and other unidentified clements. Because of limita:ions of the niicroprobe equipinitent, we were unable to analyze for the prasance of boron and carbon, the othcr elements alloyed in the brazing filler metal.

The results for eacis specimen vere much the same except that a larger amount of jismuth was found in the fillet of the $\mathrm{Fe}-4 \% \mathrm{C}-1 \% \mathrm{~B}$ brazement. However, the fillct was still intact, contrary to the results obtained in the static capsule test reporied above, where dissolucion occurred. We feel that the layers rich in iron and l:olybdenum near the surface may have passivated the underlying material in this test.

After reviewing all filler metal requirements and the data generated on eact of the alloys, we selected the composition Fe $-15 \% \mathrm{in}$ - $5 \% \mathrm{Ce}-.4 \% \mathrm{C}-1 \% \mathrm{~B}$ as the filler inetal for brazing those sections of the chemical processing test stand that wou'd contain bismuth.

Development of techniques for brazing. Brazing techniques were develuped for two purposes: to provide rainforcement of the weld ar: 'ne, $w$.ch is brittle at room temperature, and to serve as a backup seal should a leak develop through a cracked joint. In bivilding a complex system of material that has the impact xensitivity and reactivity (with oxygen) of molybdenum, many unique techniques had to be developed to ensure reliable brazed joints. Since specific brazing techniques were needed for the variety of joints required, much of our svork vas necessarily devoted to basic joint design and process develo,pment and improvenient. We developed several methods of brazing using both te istance furnaces and high-frequency is,duction as the heat sources.

Furnace brazing large pots. The four vessels with attached tubes were brazed in a re;istance-heated vacuum furnacs with hot zone of $7 \times ? \times 30 \mathrm{isi}$. In each end of the pots, two or more short lengths of tuhir $g$ which were joined to the pots by roll bond or welding were back-brazed. At the same time, a split ring was brazed around the girth welds joining the two half sections. These subassemblies were brazed at $10^{-5}$ torr by heating at a raie of $5^{\circ} \mathrm{C} / \mathrm{min}$ until flow of the brazing alloy was achieved. The temperature was monitored by several thermocouples placed at various locations througioul the firnace. The parts were 
positicaled in :he furnace so the flow of tii: tiller metal could be observed igur: 26 shows an example of a $3 \%$-in. diam molybdenum pot in which :ubing joined by roll bonding or weluing was back-braked. and a split ring covering the girth velu was brazed into place.

In our preliminary work, we learned that a iont gap of at least 10.001 in. was necessary to ensure proper flow of the brazing filler metal into the joint. However. 'he joint preparation for roll bonding and welding required a tighter fit. Thersfore, the portion of the joint to be back-brazed was counterbored an extra 0.001 to 0.002 in. on the radius to a dep h of "'s in. Filler metal feeder holes werc irilled inio the bosses of the vessels to serve as reservoir; for the brazing ailoy powde and to ensure that une filler metal did not prematurely llow' awdy from the joint until the thick-walled boss reached the malting temperature. We were concerned that if the filler netal were placed in tie fillet area and the thin-walled tubing reached the brazing temperature faster than the heavy pot. the filler metal might flow along the hotter tube (and away from the joint) rethe, than into the joint. Although the procedure generally was satisfactory, cracking of the brize metal in the feeder holes proved to be a significant probiem. Cracking was detected by a helium leati-check on the brazed joint and probably was the result of shrinkage strese is as the braze alloy solid.iied. To avoid this problem a wire was inserted intu the small-diameter onrtion of the feeder hole before the filler metal was added. and a molybdenum cap was brazed ovir the outer end of the reservoir.

Fumace brazing of nozzle bodies. Several nozzle bodies extended through the stainless steel flange of the test stand. The bodies were made of nickel or stainless steel and were brazed to at least one molybdenum 'me. The joint design included a combination of trepans aiıd feeder holes t's obtain proper flow nf braziıg filler metal into the joir.t. We successfully brazed several mockups o.' these dissimilar metal joints (Fig. 27).

Since a small amount of bismuth vapor could reach the stainless steel nozzle body in the area of the body-to-molybdenum-tube biare, it was to be brazed with the iron-based filler me,tal. None of the nickel nozile bodies were to be exposed to bismith, so they could be brazed with a commercial brazing filler mital. Several filler metals were evaluated for thu latter use, and $A:-18 \%$ : il was selected because it flowed adequately. Each of the nozzle brazes was to be made vertically in a vacuum furnace by resistance heating in the area of the nozzle only. To aroid several aduitional velded and brazed joints in the molybdenum tubing, an extension was added to the iurnace :o accommodate tubing up to $6 \mathrm{ft}$ long.

Glove box brazing. For brazing of sections of the 17-ft-long test stand that would not fit ir:to any available furnace, it was necessary to design ind build portable furnaces for localized hea.ing in a glcse box. The controlled atmosphere of the glove box was utilized to prevent oxidation r,f all pcrtions of the assembly that were heated during the brazing operation. We investigated two types of localized heatir,g sources: „esistance and induction. Each has merit for different braze joints, depending or: the size and location.

Two types of resistance-heated furnaces were huilt, both utilizing tantalum heating elements. One had a helical heating element for brazing those joints over which it could be slipped on and off. The other had a split tantalum-sheet heater which could be opened and plared over the welded joint in situ and then removed after 'urazing. This featurc was necessary on sections where the firnace could not be slippid over a large or complex section to reach the braze region.

We investigated induction heating for $u \approx$ in botn inside and outside an atmosphere chamber. We experienced prob!ems with arcing in the glove box under argon or helium atmospheres as well as in vacuum when the brazing alloy binder (used for preplacing the filler metal) volatilized. We overcame this difficulty by installir.g an auxiliary trancformer to reduce the high voltage from the power supply to low vo'tage and high amperage at the coil. With this new attaihment, we were able to braze inside the glove box in argon or heli'ım without arcing problems. By changing the gevilie iigy of the copper leads from thin-walled tubing to 


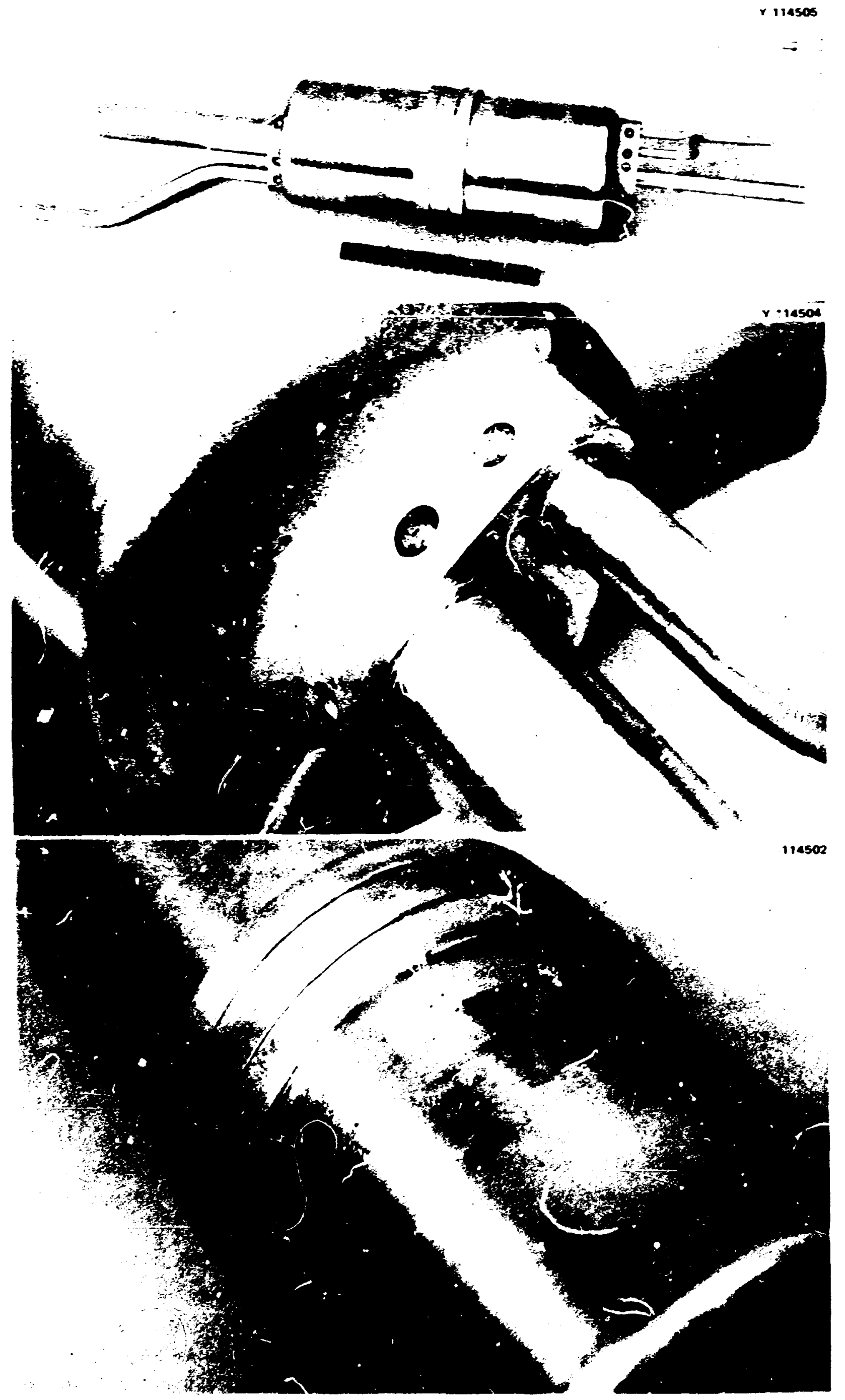

Fig. 26. Molybdenum pot after back-brazing of tube-to-header joint and brazing of ring wound cylindrical girth weld. 


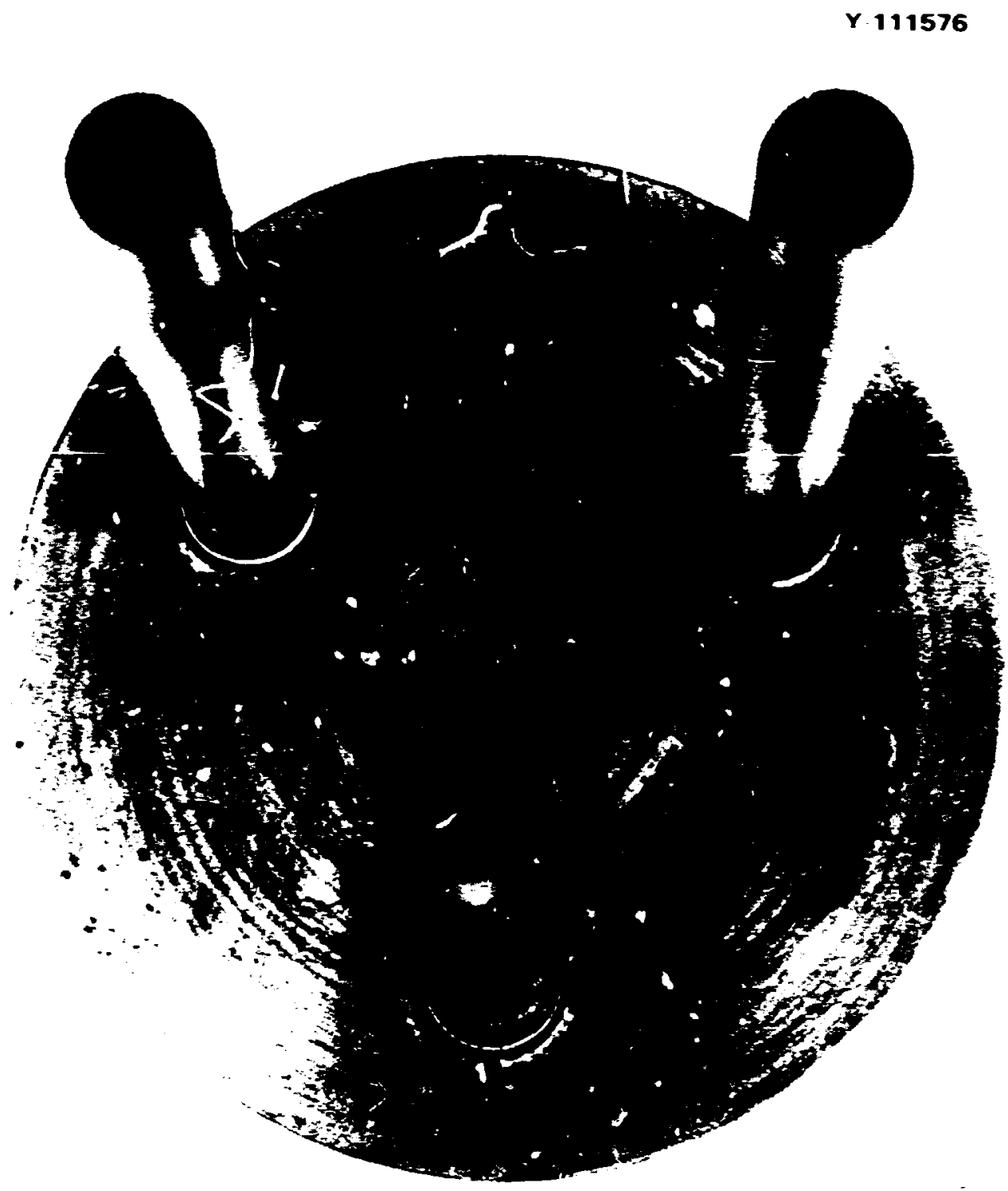

Fig. 27. Mockup of stainkess steel nozze body brazed to molybdenum tubes Body diameter, 2 in.

closely spaced bus bars, we were able tc easily achieve trazing temperature on even the largest size of tubing with attached heat sinks. Figure 28 shows a split sleeve brazed around a weld joining a length of $11 / 8$-in.-diam tubing to a stub attached :o a prototype vessel. A helical induction coil was slipper over the sleeve, and brazing was completed in $35 \mathrm{~min}$ by heating only the immediate area of the part. The heatirg rate was closely controlled, and the brazing temperature was monitcred by a thermocouple placed unde: the edge of the split sleeve. Alternatively, we brazed this same $1^{1 / 3} 8$-in. diam configuration by heating locally with a portable resistance furnace. The portable resistance furr.:e is also capable of brazing all of the smaller tube-to-tube joints, provided that there is enough space arcund the tubing for the 3-in.-diam, 5-in.-long insulated heater and that the assembly will fit into a vacuum chamber.

Field brazing. Seven tubes have to be joined in the field to connect the subassemblies. Tubing of the size $1 / 4-, 3 / 8-, 1 / 2-$, and possibly $1 / 8$-in. outside diameter will first be welded and the split sleeves back-brazed on site In this regard, we field-brazed (bv induction) sleeves on mockups of all of these sizes of tubing. We surrourded the part to be brazed with a quartz tube placed inside the inn'sction coil. Helium gas flowed over the heated area to protect the braze from air. However, the induction coil was still operated in air. When the inciuation unit was ac ivated, the 2-in.-Jong section of tuoing with the split sleeve was quickly brought to uraziris temperatire. Because of the small mass of material being heated, adjace, it areas remain d relatively coui, arid the enire brazing cycle took less than $5 \mathrm{~min}$. 


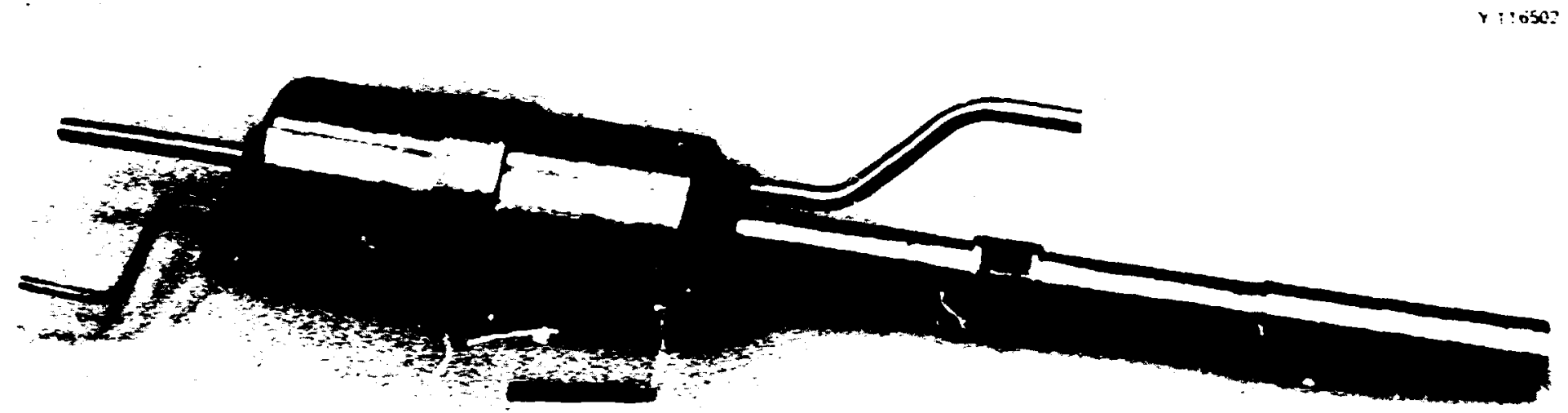

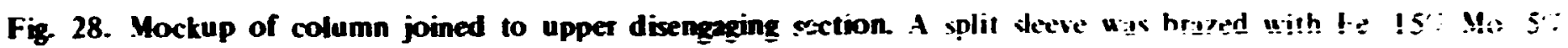
Ci: 4', C I': B over a tungsten-arce weld.

We have also investigated the use of split induction coils. Split coils have an advantage in removability. as described for the split resistance heater. With a l-in. split coil. we reached brazing temperature an a $1 / 2$-in.-diam tube and nutching split-sleeve assembly. Unfortunately. the 1-iri. split coil did not couple well enoug! electrically with other sizes. As a result, we obtained additional split coils for the other sizes of tubing. both smal!er and larger. but this phase of our investigation was not completed.

\section{Mechanical Couplings}

\section{J. R. DiStefano}

Although little was known relative to mechanical couplings of molybdenum, we felt that such joints would be desirable because tiey would (1) allow relatively easy repla'errent of components in case of a failure and (2) allow us to avoid making a uiffic:lt tube-to-header weld in locations where a tube passed through the end section of a fee' pot.

To investigate resealable joints. experimental metal seal couplings for $1 / 4$-in.-OD tubing sere obtained f:om Gamah Corporation 22 and Aeroquip Corporation. ${ }^{23}$ Both of these couplings used molybdenum seal rings, but a threaded nut applied the force that sealed the Gamah joint, while an external compressive force was required te seal the Aeroquip joint and then a gate or pin used to maintain the compressive forc: on the metal seal ring. This latter design is aimed at remote appications and is attractive because molybdenum components eas!ly gall and a threaded nut is particularly susceptible to this problem. However, problenis ericountered in sealing the Aeroquip joint resulted in our cracking one of the molybdenum components, and further evaluation was discontinued.

in additional experimential coupling was built at ORNL with the design showil in Fig. 29. The components of this coupling were all made of molybdenum, but the seal gasket was made of a laminated carbon pioduct called Grafoil. ${ }^{24} \mathrm{Grafoil}$ is a low-density grapt.ıte foil $\left(70 \mathrm{lb} / \mathrm{ft}^{3}\right)$ that is useful as a !gasket material: its compressive modulus increases from $\mathbf{7 0 0 0}$ to $\mathbf{5 0 . 0 0 0}$ psi as load is applie.. Both this cospling and the Cantiah coupling were tested for tightness by measuring their helium leak rates before anc after thermaliy cycling from room temperature to $650^{\circ} \mathrm{C}$. Each was leak-tight $\left(<5 \times 10^{-8} \mathrm{~atm} \mathrm{~cm}^{3} \mathrm{sec}^{-1}\right)$ prior to being thermally cycled ten times to $650^{\circ} \mathrm{C}$. After thern'al cy-lirg, the ORNL-designed joint remained leak-tight, but the Gamah joint had a helium leak rate of $5 \times 10^{-6} \mathrm{~atm} \mathrm{~cm}^{3} \mathrm{sec}^{-1}$. It was disassembled and returned to the company, and no iurther evaluation of this joint was made. We disassembled tie Grafoil

22. Gamah Corp., Santa Monica, Calif.

23. Aeroquip Corp. Marman Division, Los Angeles, $C a$ lif.

24. Registered trademark of Union Carbide Corn. 


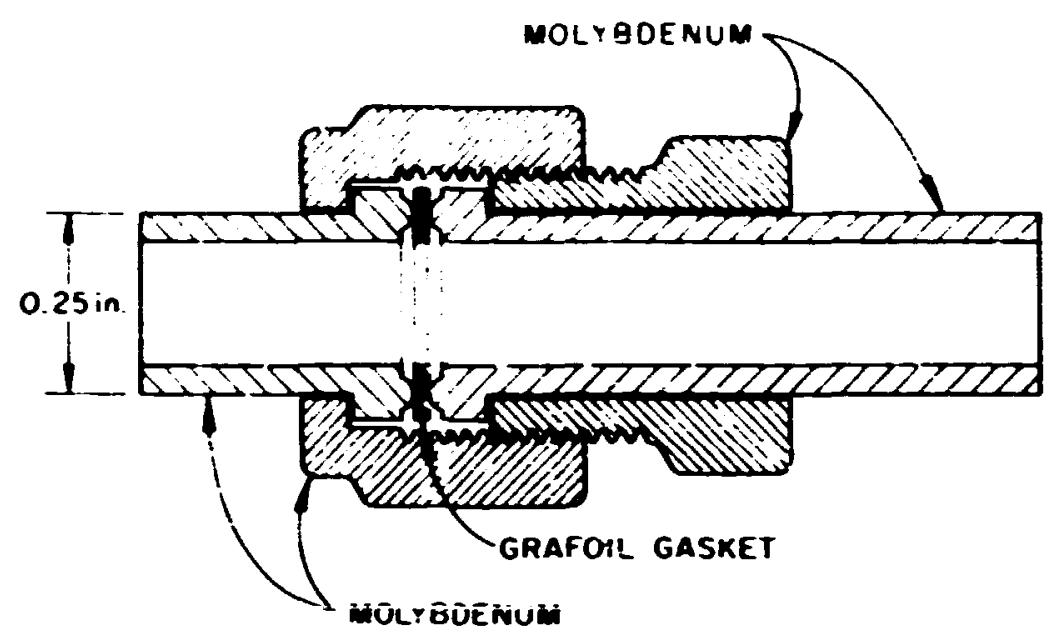

Fig. 29. Molybdenam mechanical coupling.

sca! ring coupling. resealed it, and then thermally cycled it several more times. It continued to be helium leak-tight $\left(<5 \times 10^{-8} \mathrm{~atm} \mathrm{~cm}^{3} \mathrm{sec}^{-1}\right)$ as before. This coupling was more easily disassembled than previous joints because of its modified rounded thread design. Although resealable couplings of this type were demonstrated to be experimentally feasible, they were not included in the final design of the test stand because of space and cost limitations.

In addition to joints that can te disassembled, mechanical tube-to-header connectious were developed for attaching certain lines, as indicated in Fig. 4. Two techniques, magneforming and roll bonding, were investigated. In magneforming, magnetic pressures of up to 50,000 psi resulting from current discharged through a coil from a capacitor bank are applied in pulses of 10 to $20 \times 10^{-6} \sec$ duration. No direct mechanical contact between the machine that applies the force and the work is involved. Four tube-to-tube joints in which one tube fitted inside the other were fabricated, but the lowest helium leak rate for these joints was $2 \times 10^{-5} \mathrm{~atm} \mathrm{~cm}^{3} \mathrm{sec}^{-1}$ at room temperature.

In roll bonding, a tool containing expandable rollers mechanically forces the two surfaces together. Tube expanders were obtained commercially, and some of them are shown in Fig. 30. These tube expanders were specially made to meet the length requirements for joining $1 / 4-3 / 8^{-}$, and $1 / 2$-in.-OD tubes to the back-extruded half sections. The long lengths were required because some of the tubes to be bonded extended into the pots ior some distance, and bencis on the exit cond pievented access from that direction. The tool expands inside the tube to force the tube wall partially onto the lands formed by grooves machined inside the boss, as shown in the upper left-hand portion of $\mathbf{F}_{\mathbf{L}_{i} \text { - }} 4$.

In order to lessen the chances of splitting the tube during bonding, joints were made at approximately $250^{\circ} \mathrm{C}$. Although soll bonding $\mathrm{v}$ as first done successfully in ai at this temperature, an inert atmosphere is required to prevent cur.tamination of areas that must be subsequently welded or biazer. Therefore, further roll-bonding development was carried out in an inert-atmosphere chamber, as shown in Fig. 31. Leak-tight joints $\left(<\mathrm{I} \times 10^{-7} \mathrm{~atm} \mathrm{~cm}^{3} \mathrm{sec}^{-1}\right)$ were made at $250^{\circ} \mathrm{C}$ using Necrolene 25 plus molybuenum disilicide as a lubricant inside the tubes under the following ronditions:

$\begin{array}{cc}\begin{array}{c}\text { Tube outside diameter } \\ \text { (in.) }\end{array} & \begin{array}{r}\text { Torque } \\ \text { (in.-1b) }\end{array} \\ 1 / 4 & 10-12 \\ 3 / 8 & 30-35 \\ 1 / 2 & 55-60\end{array}$

25. Traje name for high-temperature lubricint marketed by Crawford Emulsions, Pittsburgh, Pa. 


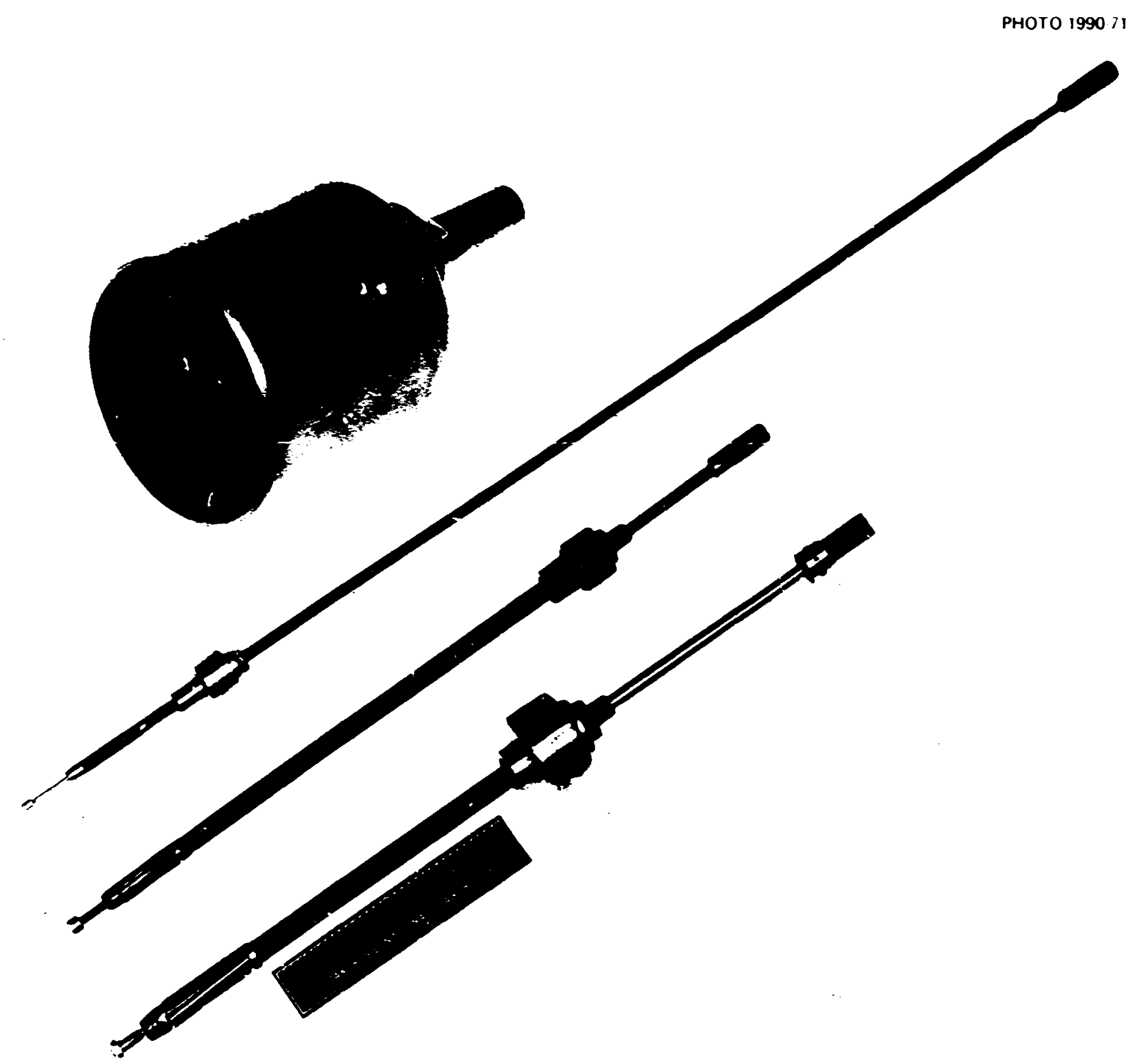

Fig 30. Tube expanders for roll bonding.

The torques listed are approximately the highest values that could be achieved. Attempts to increase the torque were generally unsuccessful, as the tube expanders began to slip and the molybdenum tubing began to flake on the inside surface. These joints were also leak-tight after being the imally cycled ten times from roum temperature to $65 \mathrm{C}^{\circ} \mathrm{C}$.

Brazing was to be used to strengthen the roll-bonded joints, but since the filler metals developed were not completely resistant to attack by bismuth, we also investigated the application of a tungsten or molykdenum coating around the joint on the inside of the vessel. The coatings were applied by chemical vapor deposition techniques using hydrogen reduction of $\mathrm{WF}_{6}$ and $\mathrm{MoF}_{6}$ at about 600 and $900^{\circ} \mathrm{C}$ respecively. ${ }^{26.27}$ Several mockups of a roll-bonded tungsten-coated anci brazed joint were made, and a section through a typical joint is shown in Fig. 32. Higher-magnification enlargements indicate the extent of

26. J. I. Federer, "Chemically Vapor Deposited Coatings," MSR Program Semiannur. Progr. Rep. Feh. $28,1971$. ORNL-4676, pp. $231 \cdot 33$.

27. J. I. Federer, "Chemically Vapor Deposited Coatings," MSR Program Semiannu. Progr. Rep. Aug. 31 . 1971. ORNL-4728, pp. $176-77$. 


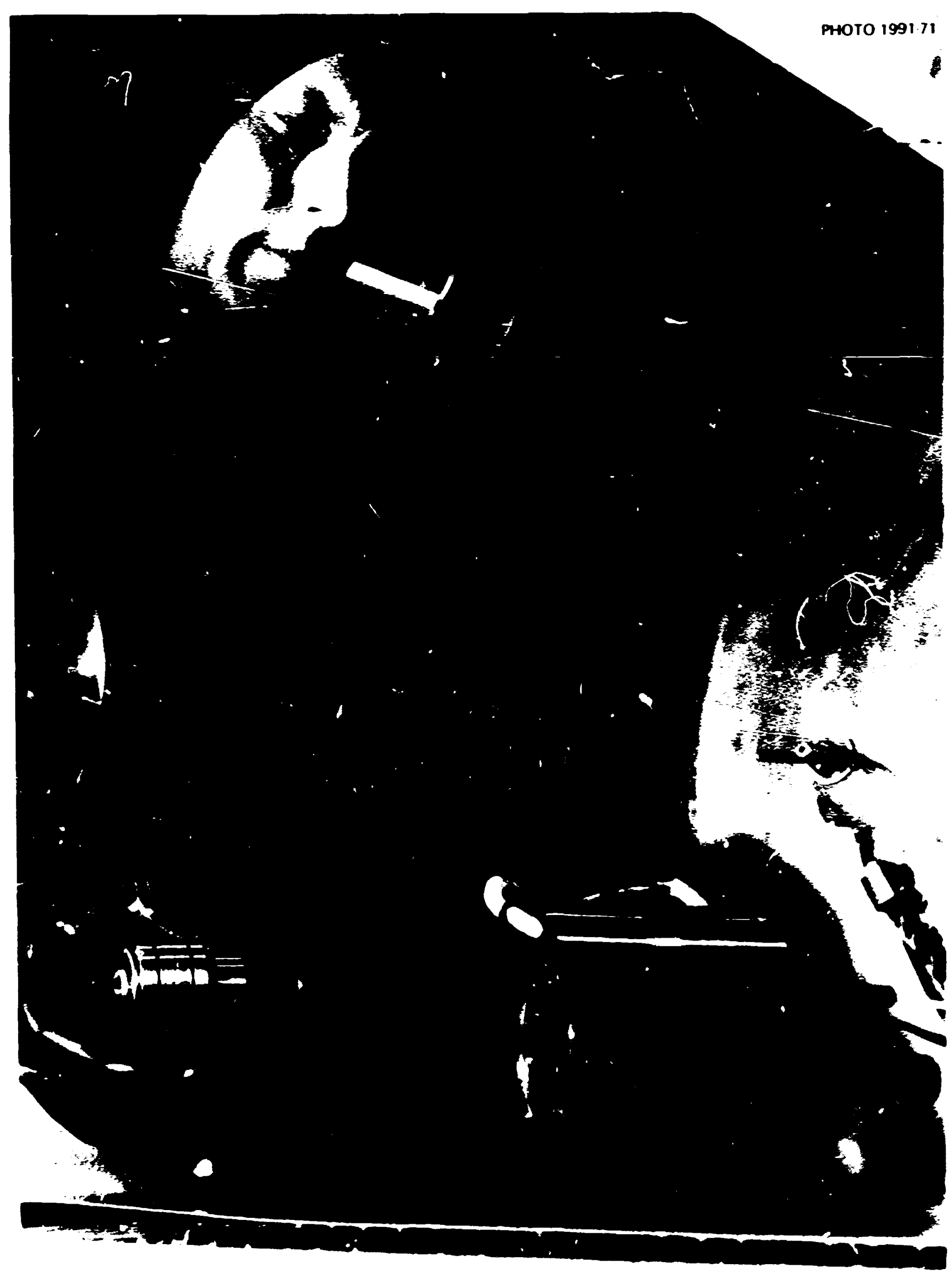

Fie. 31. Roll bonding motybdenum at $250^{\circ} \mathrm{C}$ in inert atmosphere chamber. 


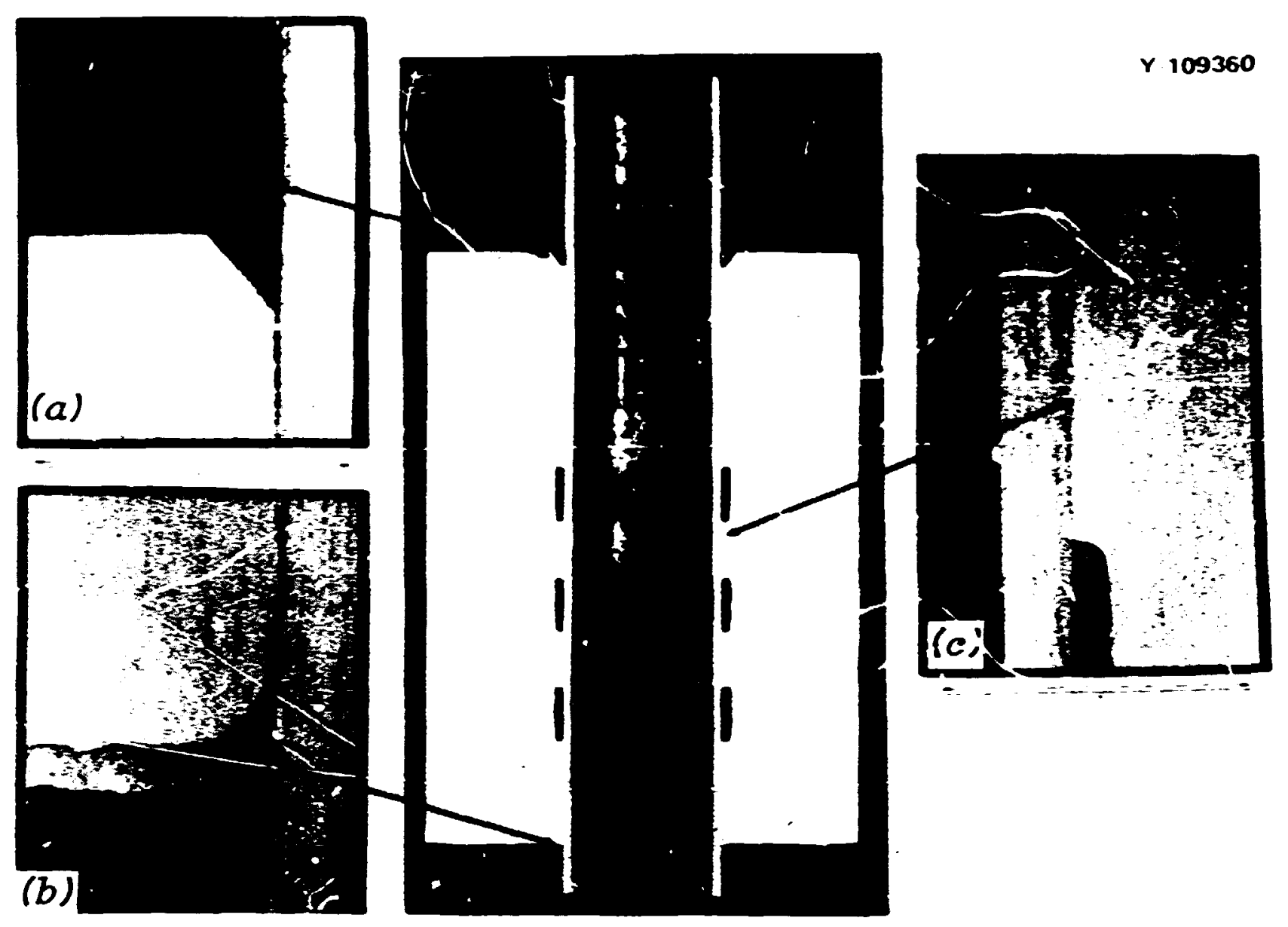

Fiz. 32. Section throngh molybdeavin rollbonded joint (c) seabed by chemical vapor deposition (b) and back-brazizg (a).

bonding that has been effected between the tube and boss by the three methods of sealing. Note that the molybdenum tube has sealed azainst the boss along the land between the grooves, but there is no evidence of material flowing into the groove. This would indicate that the depth of the groove $(0.026 \mathrm{~m}$. in this case) is relatively unimportant in making this type of joint. Some material flows into the tube-bo s crevice in both CVD tungsten coating and back-brazing. However, the brazing filler inetal generally penetrated considerably further than the CVD tungsten coating did.

\section{CONSTRUCTION}

The construction portion of this project can be divided into four stages. These are: (1) construction of a full-size mockup of the test stand, (2; fabrication and prefit of components, (3) joining of components into sujassemblies. and (4) interconnection of subassemblies to complete the test stand. Stage 4, however, has not been completed.

\section{Mockup Construction}

A full-siale mockup of the test stand was constructed of wood and stailıless steel tubing. It was an Invaluabie tool in many different areas, including design, fabrication, and asirmbly. The mockup was initially built from a set of preliminary piping drawings. Fina: piping drawings were preparec after studying the mockup and making various changes to optimize locations of lines and components.

The mockup was also used to ensure that lines were accessible for welding and brazing and to determine the specific locations of all of the weld joints. Problems er zouniered ili constructing the mockup (such as difficulties in making complex tube bends) were worked out in this phase, thus making fabrication of the molybdenum tubes much edsier. The experience gained by the pipe fitter on the mockup also proved valuable when actual test-stand construction was sta:ted. 


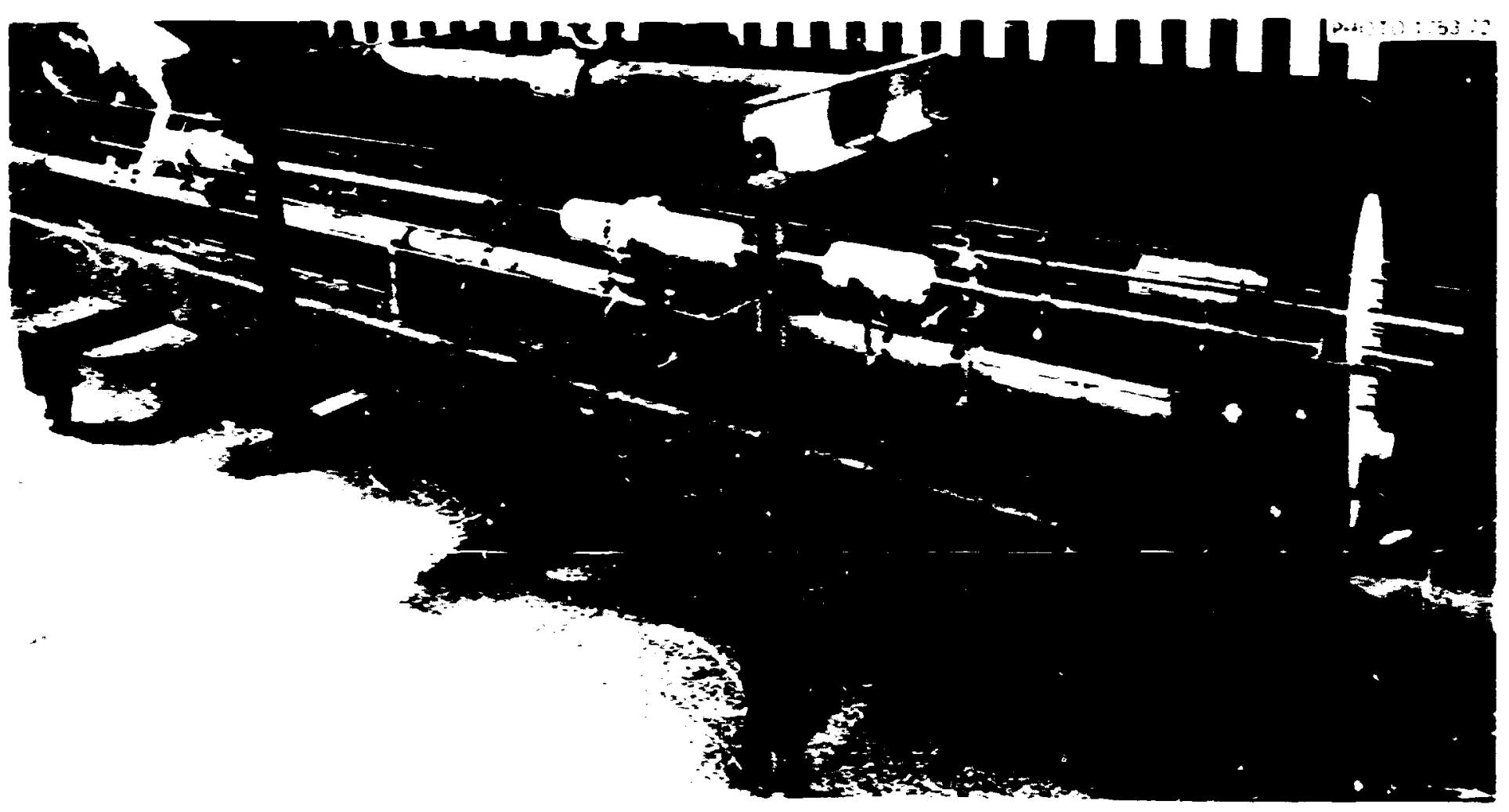

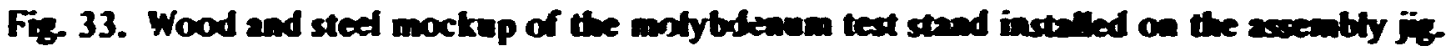

After design of the system was essentially finalized, ar assembly jig was built that was ilso to bi used for transpurting the completed stand to the experiment c.ll for installation. The major design criterion for this jig was that it lad to be very rigid to minimize flexing of the loop during inoving. The resulting structure (as seen in Fig. 33 with the mockup installed) was a long central spine consisting of an 8-in.-wide flange I beam for ayi-1 stiffness, with two 8 in. channels welded on for additional resistance to torsional loads. Cruss members were used to suprort the stainless steel flange from which the loop would be suspended, for attachment of casters, and for attachment of tronnions to be used for pivoting during erection.

A detailed procedure $u$ as written for transportation of the completea test stana from the assembly area in the Metals and Ceramics Division to the experimental cell on the third floor of the Chemical Technology Division building, where the test stand was to be operated. Because of the expected fragility of the completed system and the time delay and added expense if the loop were damaged, a full run-through of the entire transportation procedure was carried out using the mockup. The assembly jig was instrmented with strain gages to measure deflections and with accelerometers to record load inagnitudes. These factors were monitored during the entire move except for a brief period while the test stand was on a truck between buildings. In addition to these quantitative measurements, several pieces of molybdenum tubing, which contained both bare welds and welds protected by brazed sleeves, were attached to the mockup at strategic locations. The mockup and assembly jig are shown in Fig. 34. The practice move was a complete success in: that it was carrief out very smoothly, the loads and deflections recorded were well belon acceptable values, and on reinspection, we found that the welded specimens had not been damaged. 


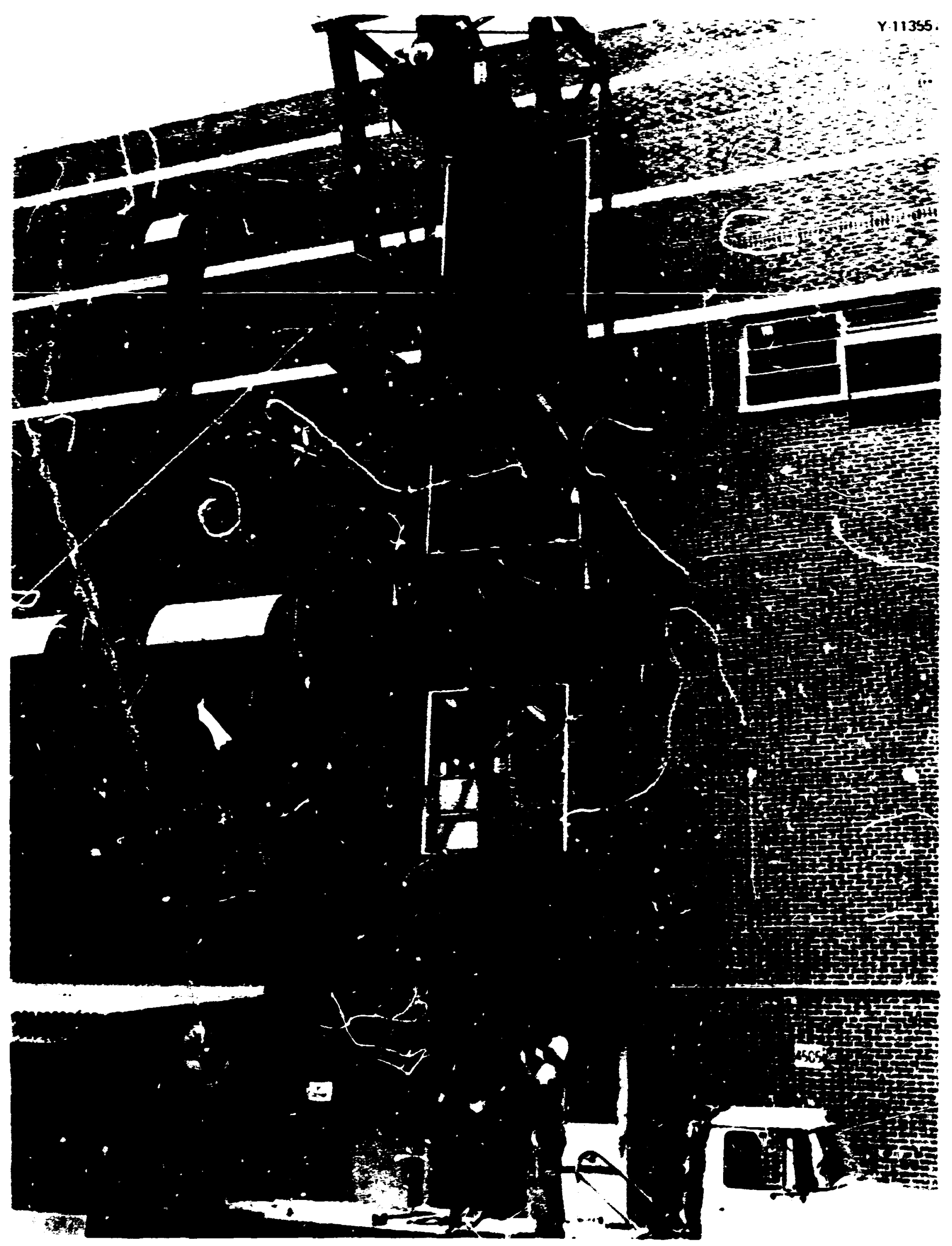

Fig. 34. Mockup and aecembly ig being lifted into the room above the experiment cell. 


\section{Fabrication and Prefit of Components}

The next stage insoliced the substitution of moisbdemm components for the wood and stect

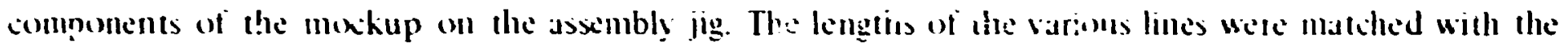
available lengths of nohbdenum tabing. and selection was made to avoid. whenever possible. any unnecessary weld joints.

A!l tubes were bent at room temperature with standard hand or bench-mounted tubing benders.

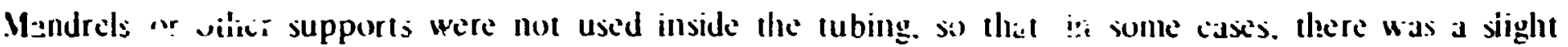
natlenitg in the bend. Flattening vicurred predominamly in some auriy bends (on $6 / 4$ - and $3 / 8$-OD tubing) made with a hand bender with a single fixed die. Wa subsequantly ninimired this condition by switching to a bench-mouned bender which had both a fixec and a sliding dic. Fxampies of some of the bends made on ine test stand are shown in rig. 35.

After bending. the tubes weire cut at the required weld-join ionations using a specialiy designed abrasive cutoft device. It was necessary to cut the lines at positions about 6 in. $\because$. nll the pots under ihe consiraint oi the sice libitations of the vacuum inamber of the electron-beam welder used for making the header-lo-ineader welds. The relatively small jize of this chamber ( $36 \mathrm{in}$. ivide. 23 in. deep. and 24 in. high) limited the total lergth of a vessel half section and its protruding iubes te about 17 in. The eutofi device. which was designed and built at ORNL, features a 4-in.-diam thin abrasive wheel powered by a sillall di motor mounted on a machinist s cross slide for precise movement. A slit V-block was used to support both ends of the eube being cut. With this equipment, we were able to niake cuis in mulybdenum tubing throt required no subsequent preparation prior to joining by welding.

After all of the various lines were bent and installed, aiong with the unjoined pots, on the field-assembly jig. the tubing was removed, degreased with acetone, and stress-relieved in vacuum for $60 \mathrm{~min}$ at $900^{\circ} \mathrm{C}$. We

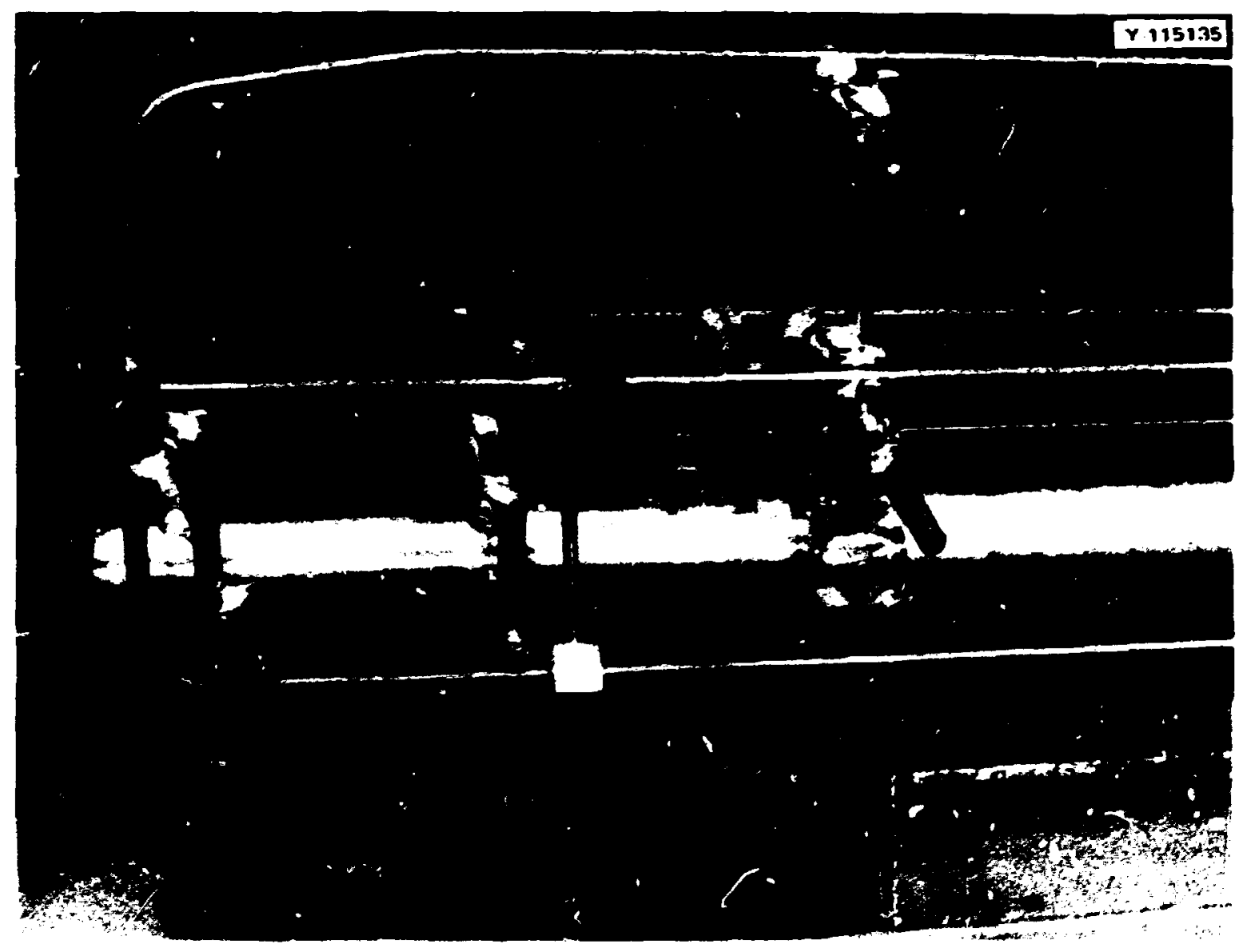

Fig. 35. Bottom section of test stand illustuting bends in $1 / 4$ - and $3 / 8$-in.-diam molybdenum tubing. 
dectded not tu attempt whemeally ilean the entire lengths of tubing using the proicdure desiribed abuve

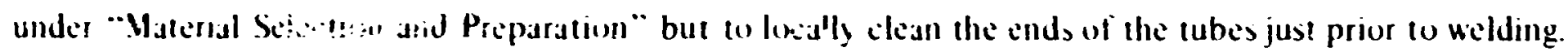

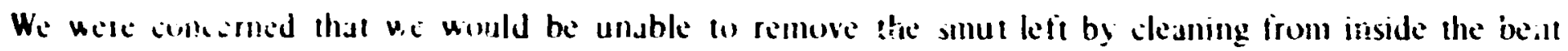

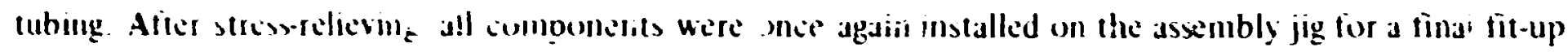
inect prior la sullstruction.

\section{Fabrication of Subassemblies}

Four seitions of the loup were fabricated as siparate subassemblies. These were the bismuth and salt feed puts and tike upper and lower disengaging sections. Although each of the subassemblies was different. the basic steps iaken in their fahrication: were the same. and these are as follows:

1. Join tubes (a) half sectum iheader) with electron-beam weld

2. Attach remaining tubes to hali secition with roll bond

3. Helium leak check half siction

4. Apply tungstin by inemical vapor deposition to inside of half so:tion

: lldium leak :heik

6. Install interral components such as bathle plates

7. Assemble two halt sections and pin with ri:olybdenum ptis

8. Join half sections with electron-beam girth weld

9. Radiographically :nspect

10. iis'ium leak check

i l. install girth band and braze along with back brazes of tube-to-header joints

12. Ficliam leak check the completed subasseinbly

The techniques used in each step of this list were discussed in previcus sections of this raport. The lower disengaging subassembly is shown in Fig. 36 after the header-1o-header weld was made but prior to hrazing The brazed bismuth feed pot is shown in Fig. 37. Both of thesc subassemblies were helium leak-light.

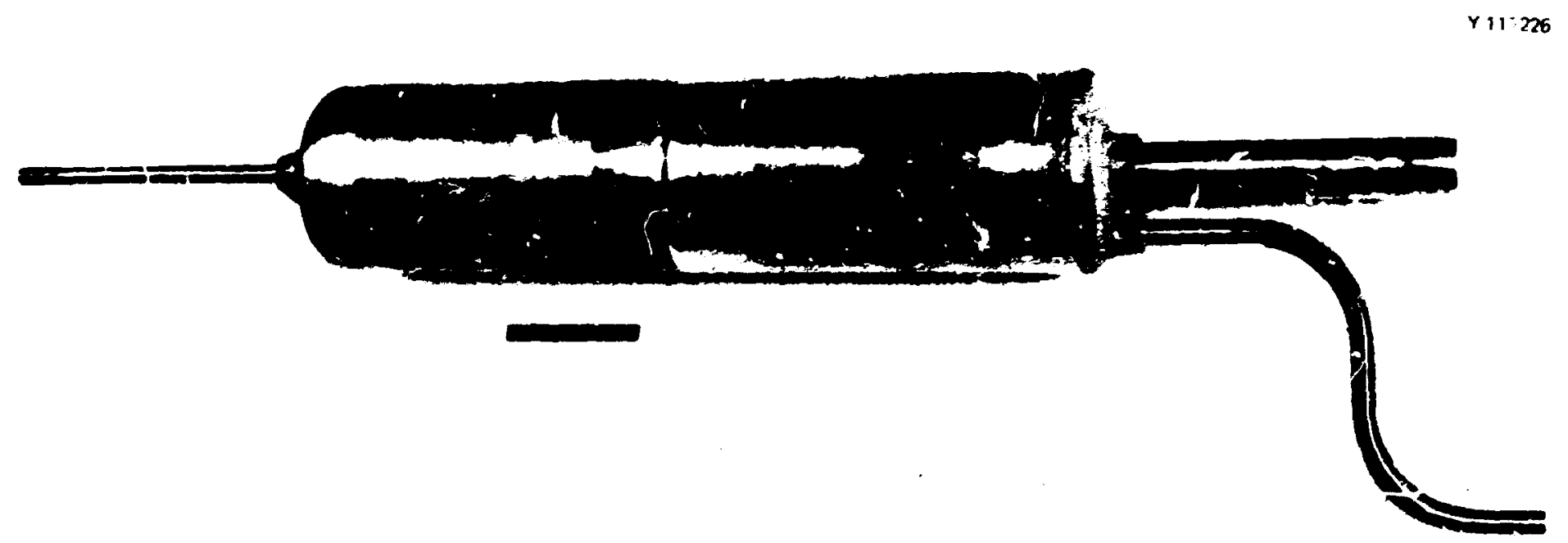

Fig. 36. Lower disengaging section after the cylindrical girth weld was made by the electron-beani process. 


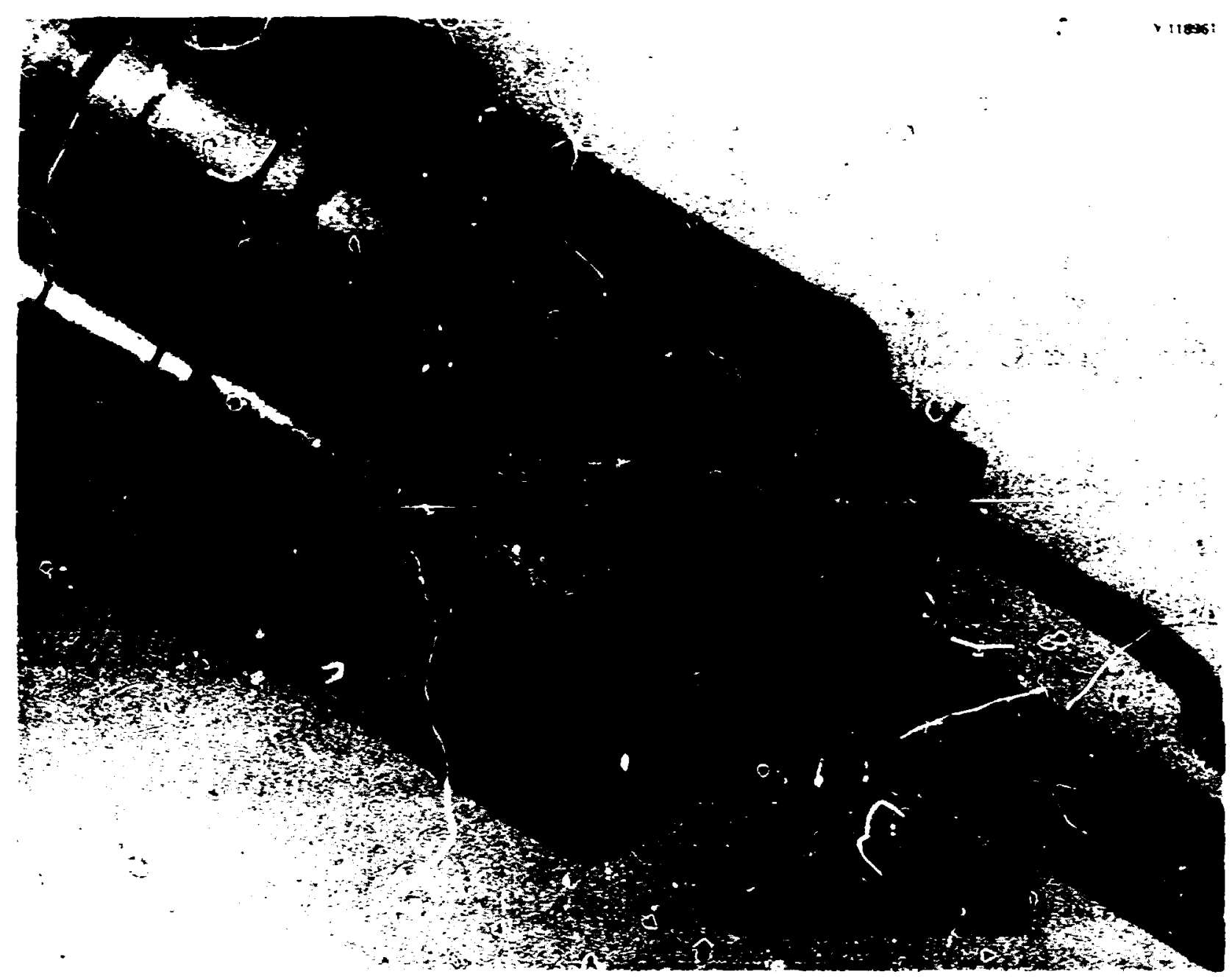

Fig. 37. Upper end of the bienuth fred pot after furnace brazieg of the ginth band and twbeto-beader joints with the iron-base brazing filter metal. Note ihe molybdenum caps brazed over the reservoirs in the boss (arrow).

\section{Interconnection of Subassemblies}

The completed subassimblies will be reinstalled on the assembly jig for a final check of the fit-up of the various tube-to-tube weld joints. Our basic philosophy with regard to final assembly of the test stand Is that wherever possible, all welds and brazes will be made in the protective atmosphere of a welding chambcr. Howe:er, even with a.7 extension that increases the length of ou-chamber to over $12 \mathrm{ft}$, we will be unable to accommodate the entire test st nd, so that some welds will have to be made outside the glove box. However, by careful planning, we have developed an assembly sequince in winich only the final 7 of 43 tube-to-tube we!ds will have to ne mede in the field. The test stand wil! be welded in three major sections, with each section bring alternately transferred to a rigid beam for installation in the welding chamber. After all the joints $(1$ a given section have heen welded and the reinforcing sleeves brazed, the completed sestion will be reinstalled on the assembly jig for final field welding.

\section{ACKNOWLESGMENTS}

The work described $n$ this report was supported by the Molten Salt Riactor Pıogram and exierided from 1969 to the piesent In andition to tite authors, many others made sigiiificant contributions. E. $L$. Nicholson and W. F. Schaffer were responsible for design of the test stand. Cremical vapor deposition techniques were developed by J. I. Federer and roll bonding techniques hy J. L. Griffith. A. C. Sihaffhauser, J. D. i.udson, C. C. Nelson, and J. W. Hendricks were significant contributors io fabrication and joining studies, i.,d J W. Koger, O. B. Cavin, and L. R. Trotter conducted the supporting compatibility tests. 
Appendix A

SPECIFICATIONS FOR PJRCHASE OF MOLYBDENUM TUBING

Specification MET-RM-î-208

TENTATIVE SFECIFICATION FOR SEAMLESS, ARC-CAST MOLYBDENTR: TUBING FOR HIGH-TEMPERATURE SERVICE

SCOPE

1. This specification covers wrought seamless molybdenum tubing produced from vacuum arc castings or equivalent melting practices.

MANUFACTURE

2. Tubes shall be lab-icated from arc-cast molybdenum extruded billets. HEAT TREATMENT

3. Tubes shall be furnished in a stress-relieved condition.

CHEMICAL COMPOSITION

4. The chemical composition of the starting tube shell shall conform to the chemical composition requirements prescribed in Table 1.

Table 1. Chemical Composition

\begin{tabular}{lc}
\hline \multicolumn{1}{c}{ Element } \\
\hline Molybdenum & $99.90 \mathrm{~min}$ \\
Carbon & $<50 \mathrm{ppm} \max$ \\
Aluminum & $20 \mathrm{ppm} \max$ \\
Calcium & $20 \mathrm{ppm} \max$ \\
Cobalt & $20 \mathrm{ppm} \max$ \\
Copper & $10 \mathrm{ppm} \max$ \\
Iron & $100 \mathrm{ppm} \max$ \\
Lead & $20 \mathrm{nnm} \max$ \\
Magnesium & $20 \mathrm{ppm} \max$ \\
Yiangaiese & $20 \mathrm{ppm} \max$ \\
Nickel & $20 \mathrm{ppm} \max$ \\
Siiicon & $80 \mathrm{ppm} \max$ \\
T:ii & $20 \mathrm{ppm} \max$ \\
Oxygen & $<10 \mathrm{ppm} \operatorname{mix}$ \\
Hydrogen & $5 \mathrm{ppm} \max$ \\
Nitrogen & $20 \mathrm{ppm} \max$ \\
--. &
\end{tabular}




\section{CHECK ANALYSIS}

5.(a) A check analysis shall be performed by the Seller on one finished tube from each lot. The concentration of each specified element shall be as prescriied in Table I except carbon shall be $<70$ ppm and oxygen shall be $<50 \mathrm{ppm}$. A lot shall be ret'ined as all finished material of the same nominal wall thicknes: which is produced from the same heat of alloy and subject to the same finishing treatment. The lot shall iaclude cnly that material which is heat treated in the same furnace charge.

(b) The material for check analysis shall be equally divided into two (2) portions, one (1) to be used by the seller for check analysis, and one (1) to be sent to the Company. The metheds of chemical analyses used in determination of elements mentioned in Table 1 shall be approved by the Company prior to use. The results of the chemical analyses shall be reported to the Company and shall corform to the requirements specified in Table 1 .

\section{PERMISSIBLE VARIATION IN DIYENSIONS}

6. (a) Diameter and Wall Thickness

The permissible variation in diameter and wall thickness of tubes shall nct exceed limits prescribed below:

\begin{tabular}{|c|c|c|c|}
\hline $\begin{array}{l}\text { Nominal Outside } \\
\text { Diame'ter in } \\
\text { Inches }\end{array}$ & \multicolumn{2}{|c|}{$\begin{array}{l}\text { Variation in } \\
\text { Outside Diameter } \\
\text { Over and Under } \\
\text { (in.) }\end{array}$} & \multirow{2}{*}{$\begin{array}{l}\text { Variation in } \\
\text { Wali Thickness } \\
\text { Over and Under } \\
(\%) \\
\pm 10\end{array}$} \\
\hline Under 1 & +0.005 & -0.000 & \\
\hline 1 to $11 / 2$ incl. & +0.007 & -0.000 & \pm 10 \\
\hline Over $11 / 2$ to 2 exil. & $+c .008$ & -0.000 & \pm 10 \\
\hline 2 to $21 / 2 \mathrm{excl}$. & +0.010 & .0 .000 & \pm 10 \\
\hline $21 / 2$ to 3 excl. & +0.012 & -0.000 & \pm 10 \\
\hline 3 to 4 incl. & +0.015 & -3.000 & \pm 10 \\
\hline
\end{tabular}

(b) Straightness

The tubing shall be supplied in straight lengths with a maximum deviation of $0.060 \mathrm{in}$. per 3-ft-jength neasure in any plane. 
SURFACE FINISH AND WORKMANSHIP

7.(a) The finished tubes shall be free from oxide or scale and any other foreign material.

(b) The finished tubes shall be free of cracks, seams, laps, gouges, tears, or other defects which exceed five (5) percent of the thickness or 0.005 in., whichever is larger.

(c) Defects may be reroved by grinding, provided the nominal wall thicknesses are not decreased to less than that permitted in Section 6. Ground areas shall have the same surface finish requirements as unground areas of the material. Ground areas shall merge smoothly with the adjacent surface.

CERTIFICATICN AND INSPECTION

8. (a) The Seller shall notify the Company in writing five (5) days in advance of the date inspection shall be conducted so that the Company's inspector ma $:$ be present to witnes.s fiuid-penetrant inspection, to checi cimensions, and to visually inspect the material.

(b) Visual Inspection

Each tube shall be visuaily inspected by the Seller uraer direct daylight, or fluorescent light of at least 100 fcotcandles to ensure conformance with Section 7 .

(c) Penetranci Inspection

The outside surface of tru turing shal? be penetrant inspected in accordance with Company Specification, Tentative Method for LiquidPeretrant Inspection (Designated: MET-NDT-4).

(d) iitrasonic Inspection

The ms.terial shall be ultrasonically inspected in accordance witn Company Specification, Tentative Method for Ultrasonic Inspection of Metal Pipe and Tubing (Jesignated: MET-RM-4) with the following exception: the derth of the notch in the calibration standard, referenced in Section $4(a)$ of the above mentioned specification, shall be $0.005 \mathrm{in}$. or $5 \%$ of the material thickness, whichever is larger. 
(e) The coller shall submit to the Company a certified statement of compliance that all materials conform to this specification and shall attcch certified reports of results of all required tests. Each test report shall be iaentified. The following reports shail be frnished the company at time of shipment or earlier if available and requested by the Company.

1. Chemical analyses (check and ingot),

2. Fluid-penetrant inspectinn, and

3. Ultrasonic inspection.

\section{PACKING FOR DELIVERY}

9. Tubes :shall be capped and boxed to protect against damage and to maintain clearliness of the tubing during handling and shipment. and each container shall be marked with the following information: i. Size and type of material and

2. Heat number.

\section{MARKING}

10.(a) Each end of each tube shall be tagged with the following identification marking:

1. Manufacturer's name'.

2. Specification No. MET-RM-B 208,

3. Heat number,

4. Lot number, and

5. Tube diameter and wail thiskness. 
Specification MET-NDT-3

Tentative Specification for the Ultrasonic Inspection

of Metal Pige and Tubing

Introduction

This standard includes requirements of ASTM E213-68, "Ultrasonic Inspection of Metal Pipe and Tubing for Longitudinal Discontinuities," with modifications and additional requirements. Sections and paragraphs of ASTM E?I3-6E not specifically mentioned in this standard remain as written in tine ASTM Standard. Molified sections are arranged under the same headings and paragranh numbers as employed in ASTM E213-68 with the mcdified portions of the seciions underlined. This specification covers both (a) Iongituiinal and (b) transverse flaw detection techniques.

However, only the lonitudinal test is applied if a specific request for the transverse test is not spacified by the service request. Requirements are mandatory unless specifically excepted by the service request which also shail specify the applicable examination level.

A. Longitudinal Flaw Detection

Scope

1. This method covers a procedure for detecting longitudinal discontinuities in metal pipe and tubing using pulse-reflection ultrasonic contact or immersion techniques. It is intended tc be used for tubular products having outside diameters from approximately $1 / 8$ to 5 in. These techniques have been used for smaller and larger sizes, however, and may be specified upon contractural agreement by the purchaser and the producer.

Calibration Standards

5. (d) The notch dimensions shall be as given below for the specified examination level. The applicable examination level shall be as specified oy the service request.

Calibration of Apparatus

6. (c) A strip chart recording of each successful calibration shall be made and labeled with the appropriate iaentisication (i.e. date, time, notch size, notch location and identification of the calibration standard).

Procedure

7. (h) During the inspection, strip chart recordings of the ultrasonic response for each tube shall be made and labeled with the appropriate identification (i.e. date, time, tube number, numbered end of the tube, tuke iength, the starting and stopping positions on the trace, and identification of the calibration standard). 
Calibration Standard Notch Sizes

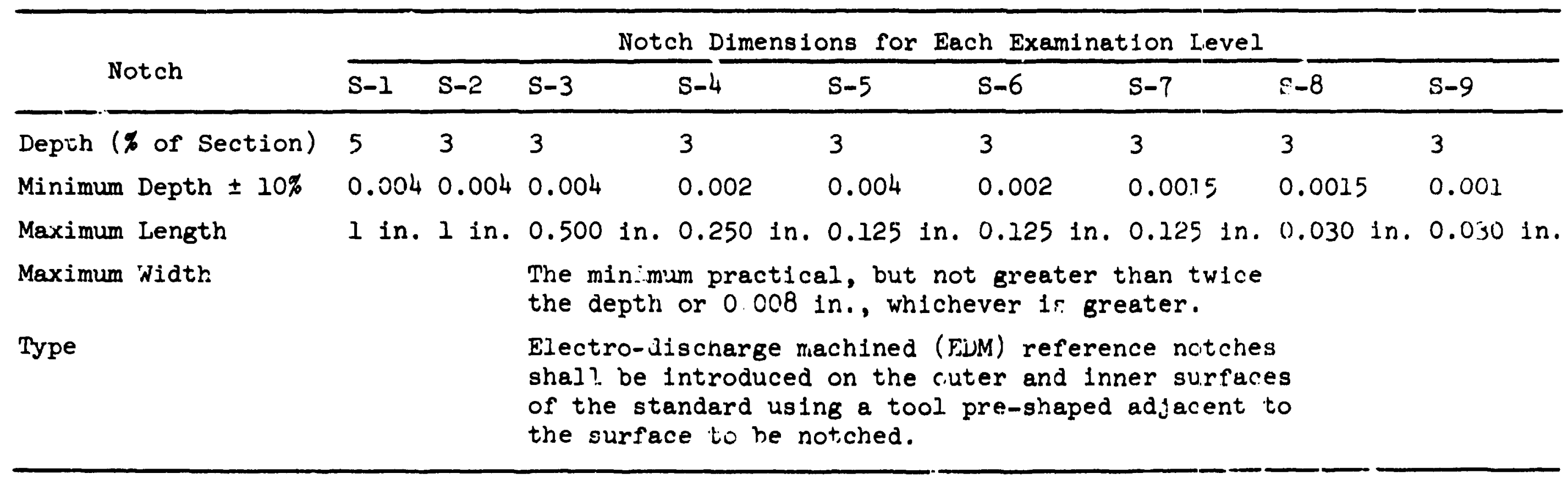


Report

9. (6) The inspector shall supply appropriate calibration and inspection strip chart recordirgs labeled with proper identification.

Personnel Qualification

10. All personnel performing ultrasonic examination operations under this standard shall be qualified in accordance with requirements of the 1968 edition of the ASME Coce Sertion III, Sub-section IX-400.

B. Transverse Flaw Detection

Scope

1. This method covers a procedure detecting t.ransverse discontiruities in metal pipe and tubing using pulse-reflection ultrasonic contact or immersion tashniques. It is interjed to be used for tubular products having outside diameters from approximately $1 / 4$ to 6 in. These techaiques have been used for smaller and larger sizes, however, and may be specified upon contractural agreement by the purchaser and producer.

\section{Calibration Standards}

5. (a) A calibration standari of a convenient length shall be prepared from a length of pipe or tube of the same dianeter

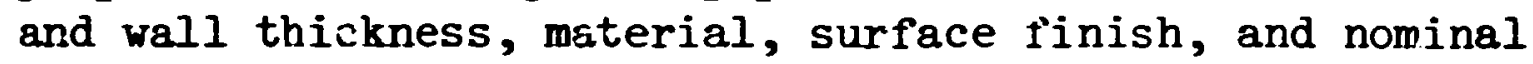
heat treatment as the material to be inspected. The calibration pipe or tube shail be free of discontinuities or other conditions producing "noise" indications which can cause constrictive or destructive interference with the detection of the reference notches. A transverse reference notch shall be introduced on the outer and inner surfaces of the standard. If both reference notches are to be generated on the same end of the standard, they shall be at least 120 deg apart. All upset metai burrs, etc., adjacent to the notches shall be removed.

5. (d) The notch dimensions shall be as given belni for the specified examination level. The applicable examination level shall be as specified by the service request.

Calibration of Apparatus

6. (c) A strip chart recording of each successful calibration shall be mede and labeled with the appropriate identification (i.e. date, time, notch size, notch location and identification of the calibration standard). 
Calibration Standard Notch Sizes

\begin{tabular}{|c|c|c|c|c|c|c|c|c|c|}
\hline \multirow[b]{2}{*}{ Notch } & \multicolumn{9}{|c|}{ Notch Dimensions for Each Examination Level ${ }^{a}$} \\
\hline & $s-1^{b}$ & $s-2^{b}$ & $s-3^{b}$ & $s-4$ & $s-5$ & $s-6$ & $s-?$ & S.-8 & $s-9$ \\
\hline Depth (\% of Section) & 5 & 3 & 3 & 3 & 3 & 3 & 3 & 3 & 3 \\
\hline Minimum Depth $\pm 10 \%$ & 0.004 & 0.004 & 0.004 & 0.002 & 0.004 & 0.002 & 0.0015 & 0.0015 & 0.001 \\
\hline Maximum Length & 1 in. & 1 in. & 0.500 & 0.250 & 0.125 & 0.125 & 0.125 in & $0.030 \mathrm{in}$. & $0.030 \mathrm{in.}$ \\
\hline Maximum Width & & & $\begin{array}{l}\text { The } m i \\
\text { the de }\end{array}$ & $\begin{array}{l}\text { aum prac } \\
\text { or } 0.0\end{array}$ & $\begin{array}{l}\text { al, but } \\
\text { In., wh }\end{array}$ & $\begin{array}{l}t \text { great } \\
\text { ever is }\end{array}$ & $\begin{array}{l}\text { than twi.c } \\
\text { eater. }\end{array}$ & & \\
\hline Type & & & $\begin{array}{l}\text { Electr } \\
\text { shall } \\
\text { of the } \\
\text { the su }\end{array}$ & $\begin{array}{l}\text { lischare } \\
\text { introdu } \\
\text { andard } \\
\text { ce to b }\end{array}$ & $\begin{array}{l}\text { achined } \\
\text { on the } \\
\text { ng a to } \\
\text { otched. }\end{array}$ & $\begin{array}{l}\text { DM) ref } \\
\text { ter and } \\
\text { pre-sha }\end{array}$ & $\begin{array}{l}\text { nce notch } \\
\text { ner surfa } \\
\text { adjacent }\end{array}$ & $\begin{array}{l}\text { s } \\
\text { es } \\
\text { to }\end{array}$ & \\
\hline
\end{tabular}

Note: S-1, S-2, S-3 and S-4 are identical to those required by RDT-F3-8'S of February 1969.

bote. For small diameter tubing tinese notch iength requirements could be impracilable, thus shorter notches should be used. 
Procedure

7. (c) Unless otherwise specified, the material shall be inspected with the ultrasound transmitted in only one longitudinal direction under identical conditions to those used for equipment calibration (Note 4). Upun contractual agreement between the furchaser and the producer, inspection may be required with trie sound being transmitted in both longitudiral directions.

7. (h) During the inspection, strip chart recordings of the ultrasonic response for each tube shall be made and labeied vith the appropriate identification (i.e. date, time, tuke number, numbered end of the tube, tube iength, the starting and stopping positions on the trace, and identificr.tion of the calibration standari).

Report

9. (6) The inspector shall supply appropriate cailuration ana inspection strip chart recordings labeled with proper identification.

Personnel Qualification

10. All personnel performing ultrasonic examination operations under this standard shall be qualified in accordance with requirements of the 1.968 edition of the ASME Code Section III, Sub-section IX-2.00. 
Specification MET-NDT-4

\section{TENTATIVE METHODS FOR LIQUID-PENETRANT INSPECTION}

\section{SCOPE}

1.(a) This specification covers requirements for fluorescent-penetrant and visible dye-penetrant inspection of metals or fabricated metal parts.

(b) If details of procedure not covered in this specification arise during the course of work, these details shall be formulated oy the Selier and submitted to the Company for approval prior to utilization under this specification.

METHODS

2. This inspection method shall te either:

(a) The fluorescent-penetrant method descrived herein, or

(b) The visible dye-penetrant method described herein.

\section{MATERIAL}

3. The brand and composition of penetrants, developers, emulsifiers, and cleansers to be used in inspection must be approved by the Company hefore use.

\section{PREPARATION OF MATERIALS AND PARTS}

4. (a) All materials to be inspected shall be cleaned before and after inspection. The materials must be free of any rust, scale, welding or brazing flux, spatter, grease, paint, oily films, and dirt which might interfere with penetrant inspecticis. Slag and oxide shall be removed from welded joints by means that will not peen nor rough the meta? surface. Wire brushes having chromium-nickel stainless steel bristles or having bristles of the same material being cleaned shall be used.

(b) Airasive blasting shall not, $r a$ used.

(c) All materials or parts shall be free of pickling or cleaning solutions prior to drying before penetrant application.

(d) Any specif'ied visual. inspection shall be perfoimed before pers crant inspection.

(e) Gri.lding or other methods of metal removal shall not mask iefects when penetrant inspected.

\section{DRYINE AFTER CLEANING}

5. All parts shall be dry after cleaning so that no water or solvent remains in or over discontinuities. fny drying shall be accomplished in still air, in iryjin, ovens, forced-air circulation, or equivalent methods approved $b_{y}$ the Company. 


\section{FLUORESCENT POST-EMALSIFIED PENETRANT: PROCEDURE}

\section{Penetrant Applicatior}

Apoly port-emuisified penetrant to the rart ensuring that ail surfaces remain wetted by the penetrant for the minimum time required in Table 1 prior to emulsification. The temperature of the parts and penetrint during penetrant application shall not exceed $100^{\circ} \mathrm{F}$ or be less than $60^{\circ} \mathrm{F}$.

TARLE 1

Process Tjmes for Jost-Emulsified and Solvent-Removable Penetranis

\begin{tabular}{|c|c|c|c|}
\hline Form & $\begin{array}{l}\text { Minimum } \\
\text {-enetration } \\
\text { Time } \\
(\text { min) }\end{array}$ & $\begin{array}{l}\text { Maximum } \\
\text { Emuls if }{ }^{a} \text { iation } \\
\text { Time } \\
\text { (min) }\end{array}$ & $\begin{array}{c}\text { Minimum } \\
\text { Developing } \\
\text { Time } \\
\text { (min) }\end{array}$ \\
\hline Casting? & 10 & 15 & 10 \\
\hline Eytrusions and Forgings & 20 & 1.0 & 15 \\
\hline Welds & 20 & 5 & 10 \\
\hline $\begin{array}{l}\text { All forms witr Machine } \\
\text { Finish } 125 \text { rms or better }\end{array}$ & 20 & 3 & 15 \\
\hline $\begin{array}{l}\text { A } 1] \text { forms Rougher than } \\
125 \mathrm{rms}\end{array}$ & 20 & 10 & 15 \\
\hline $\begin{array}{l}\text { Tubular Products } 0.125-i n \text {. } \\
\text { wall or less and Macirive } \\
\text { Finish } 125 \text { rns or better }\end{array}$ & 20 & 1 & 15 \\
\hline
\end{tabular}

${ }^{a}$ Emulsification tirue shall be demonstrated as the minimum recilired tc remme excess penetrant from the surfaces being inspect,ed, but not exceti the time stated in this column.

Emulsificat,ion

7. (a) Apply the smulsifier either by dipping the part into it or by flowing or sprayi.ig it on the part.

(b) Emulsification ine shall be atmonstrated as t'ie minimum time necessary to remore all excess penetrant and shall not exceed the time as stated in Table 1 of this specification.

\section{Rirsing}

8. (a) After the emulsification period, remove the surface film of penetrant and emuisifier from the part by forceful water spray.

(b) If the surface film of penetrant on the part cannot be completely removed because of insufficient emulsification of the penetrent, the part shall be completely reprocessed through the entire liquid-penetrant inspection cycle. 


\section{Developing}

Repeat dryirg operation as outlined in Section 5. The temperature of air usec for drying shall not exceed $150^{\circ} \mathrm{F}$ for material of less than 1/4-in. thickness and a maximum of $200^{\circ} \mathrm{F}$ for thicker material. A. minimum drying time shall be used so as to just dry the part but not permit evaporaticn of the penetra it. Dry developine powder shstll be applied thinly and uniformly to the entire surface of the port. Excess powder shall be knockea uff by gently shaking or iapping the part or by use of low-pressure clean compressed air. The developin time shall be as specified in Table 1 .

\section{Inspection}

1C.(a) After the development of indication:, insfect the parts with a high-incensity "black light" in a darliened area or booth. The black light for inspection shall be attained by using no less than a 100-w merrury vapcr bulb of the sealed reflector type with a visible-light filter. The maximum distance between the black light and the piece teing inspected shall be 15 in.

(b) The operator shall fallow his eyes to become sccustcmed to the darkness of the inspection booth before inspecting the parts.

\section{VISIBLE DYE-PENETRANTT PROUEDURE}

Penetrant i.pplication

11. (a) The applicatiun of dye penetrant shall not be atteiryted until the precleaning and drying operations required in sections 4 ard 5 hare been completed.

(b) Penetration time begins at the time of immersion or other application of the penetrant. The minimlum penetration time is set forth in Table 1 . All suriaces of tho part shall be wetted for the entire tirie.

(c) Tise tempers.ture $n_{i}$ parts during peretrant application shall not exceed $100^{\circ} \mathrm{F}$ or be less than $60^{\circ} \mathrm{F}$.

12. Penetrant Remover

The penetrant shall be removed by wiping with a clean cloth dampened with solvent, followed by wiping with a clean, dry cloth. Use of solvent-saturated cloths or flushing witl so; vents for penetrant removal is prohibited.

Developing

13. (a) After excess penetrant has been removed ard parts are aried, a thin, uniform coaing of developer shall be applied to the area being inspected. The developer shall be thoroughiy ogita.ted both before using and periodically during application.

(b) The developer shall be applied so that there are no laps or runs that may obscure fine indications. 
(a) If the requirements of (a) or (b) are not. met or if the part displays an excessive pink hue after the developer has been apolied, the part siall then be thorolghly rleaned so as to meet the cleanliness requirements of section $4(\mathrm{a})$. The entire inspection procedure shall then be repeated. 
Appendix B

ELECTRON AEAS WELUNG PARAMETERS

FOR TUBE-TO-HEADER JOINTS

\begin{tabular}{|c|c|c|c|c|c|}
\hline Tube outside dinmeter, in. & 0.250 & 0.375 & 0.500 & 0.875 & 1.125 \\
\hline Joint width, in. & 0.040 & 0.050 & 0.060 & 0.100 & 0.120 \\
\hline Accelerating voltage. kV & 120 & 120 & 110 & 140 & 120 \\
\hline \multicolumn{6}{|l|}{ Bam current, $m A$} \\
\hline Proheat & & & & 5 & 11 \\
\hline Weld & 8 & $s$ & 12 & 10 & 23 \\
\hline \multicolumn{6}{|l|}{ Remplutivis } \\
\hline Prelueat & & & & & \\
\hline Weld & $1 / 2$ & $1 / 2$ & $1 / 2$ & $1 \%$ & $1 \%$ \\
\hline Travel sperd, in/min & 24 & 14 & 19 & 11 & 14 \\
\hline
\end{tabular}

Note: All weld joints were of the corner-finge type as illustrated in Fig. 4. The efectron gun is of the self-accelerating triode desien (Hamilton Standard 5 32! The beam was defocused by $15 \mathrm{~mA}$ in each case, and the beam current was maicillly "downsloped" to prevent crater formation at the end of each weld. 


\section{Appendix C}

\section{PAR AMETERS FOR WELDING OF BUTT JOINTS IN MOLYBDENUM TUBING USING AN ORBITING-ARC WELL HEAD}

Table C-1. Parame.ers for welding 0.250, 0.375-, and 0.500 -in. $0 D$ lubing

All welds were made inside an ar!on-filled glove box with an Asiro-Arc k-875 orbiting-are iveht head. The welding cycte. including the specti of rotatiols of the welding head. was conisolled by a Netiuna! Standard 1/P-150 vild programrnker. App:oxi:ately $5 \mathrm{c}:$ ? of arzzon wis passe 1 through the weld head during the cycke. The electrode wa; 0.062-in.-

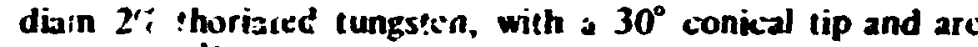
length of $1 / 32$ in. A riv yistersum weld inser! having the geumetry shown in I.j. 2 was used for all welds.

\begin{tabular}{|c|c|c|c|}
\hline Tube outside diameter, in. & 0.250 & 0.375 & 0.500 \\
\hline \multicolumn{4}{|l|}{ Initial } \\
\hline Current, A & 30.0 & 54.0 & 65.0 \\
\hline Time, sec & 6.0 & 12.0 & 14.0 \\
\hline \multicolumn{4}{|l|}{ Weld } \\
\hline Current, A & 56.0 & 75.0 & 92.0 \\
\hline Time, $\sec ^{a}$ & 10.0 & 140 & 17.0 \\
\hline \multicolumn{4}{|l|}{ linish } \\
\hline Current. A & 1.0 & 1.0 & 1.0 \\
\hline Time. $\sec ^{b}$ & 5.0 & 7.0 & 7.0 \\
\hline \multicolumn{4}{|l|}{ Travel speciu, in./min } \\
\hline Initial & 7.8 & 4.9 & 7.0 \\
\hline Weld & 9.4 & 6.4 & 7.9 \\
\hline Finish & 9.4 & 6.4 & 7.9 \\
\hline
\end{tabular}

ancludes 3-sec upslope fror., initial to weld cursent.

hownslope time from welt to finish current.

Table C-2. Parameters for welding 0.875and 1.125 -in. OD tubing

These welds were made insitc an argon-filled glove box ith a modified Rytek E.W-l.5i orbitingarc weld head. The welding cycle was controiled by a Millet ESR 150 weld programme: which had been modified to increase the upslope and to:'nstupe times. The weld head was driven at a constan" sp..d by a separate power supply. The electrode was 0.162-in.-diam 2\% thoriated tungsten, with a $30^{\circ}$ conical tip and an arc kength of $1 / 16$ in.

\begin{tabular}{|c|c|c|}
\hline Tube outside diametcr, in. & 0.875 & 1.125 \\
\hline Vall thickness, in. & 0.050 & 0.060 \\
\hline Upslope time, sec ${ }^{a}$ & 18 & 18 \\
\hline \multicolumn{3}{|l|}{ Weld } \\
\hline Current. A & 125 & 125 \\
\hline Time, sec & 20 & 30 \\
\hline Downslope time. sec ${ }^{b}$ & 18 & 18 \\
\hline Travel speed, in./min & 8.7 & 7.0 \\
\hline
\end{tabular}

a Upsiope from alf:oximately 2 A initial current to weld current.

bownslope from weld current to approximately 2 A finish current. 